

AAA月A

AAMWM MmM

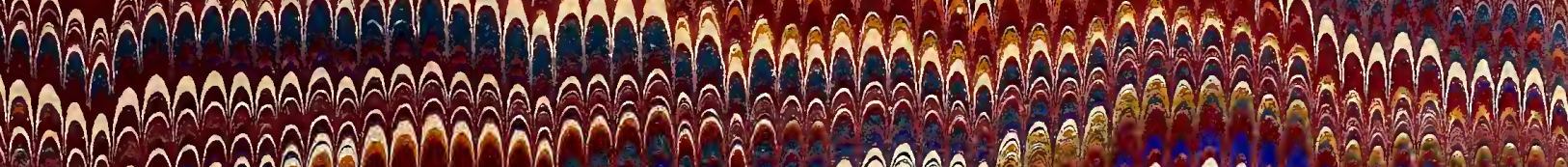

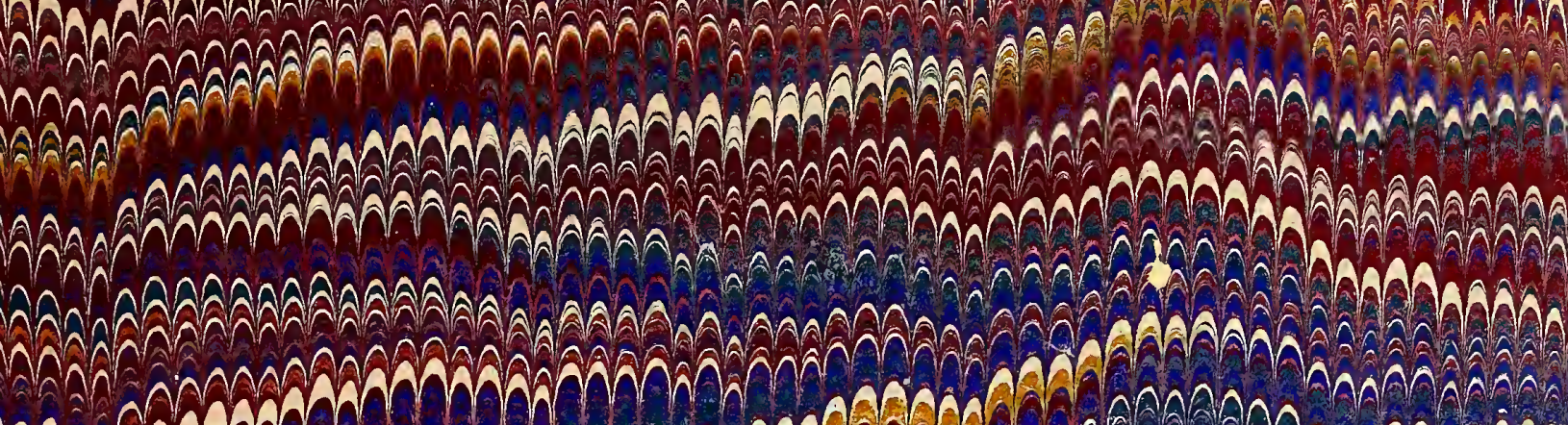

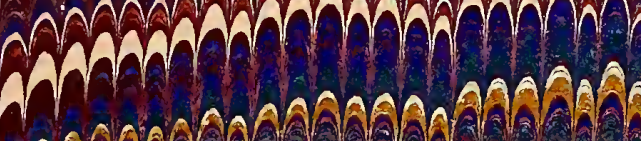

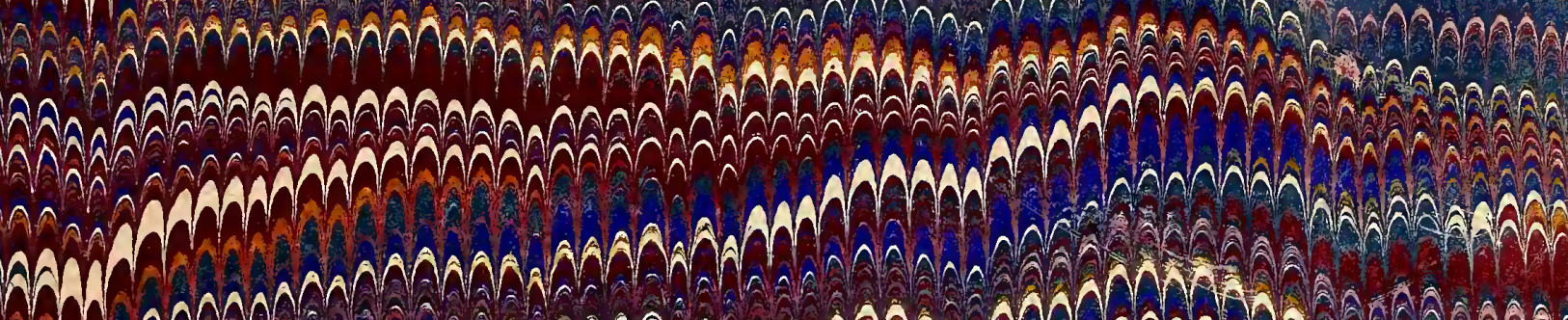
Aam

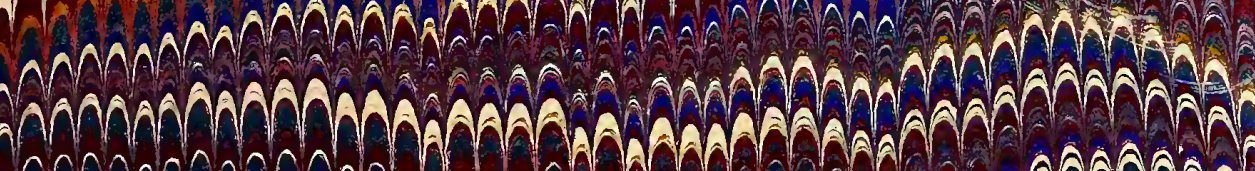

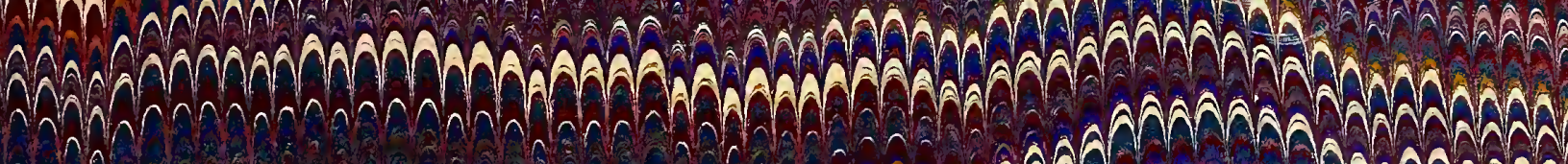
man

AAAMAMTCMm A AAAAAAAAAAAAAOA

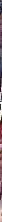

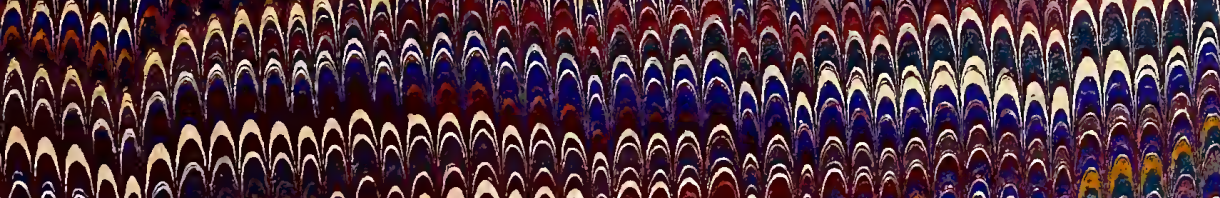
wamabah

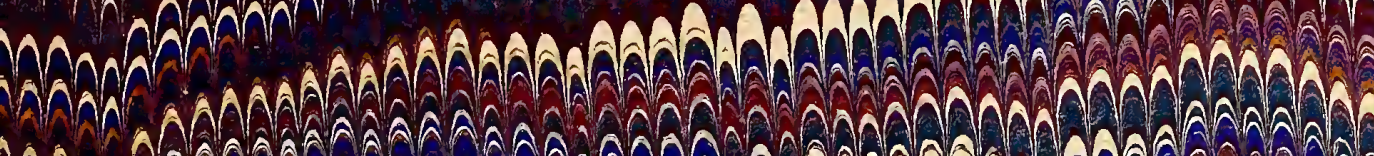

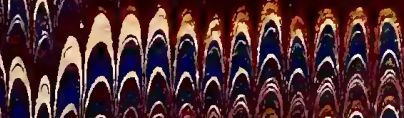



Dividion of Mollus

Sectional Librcay 





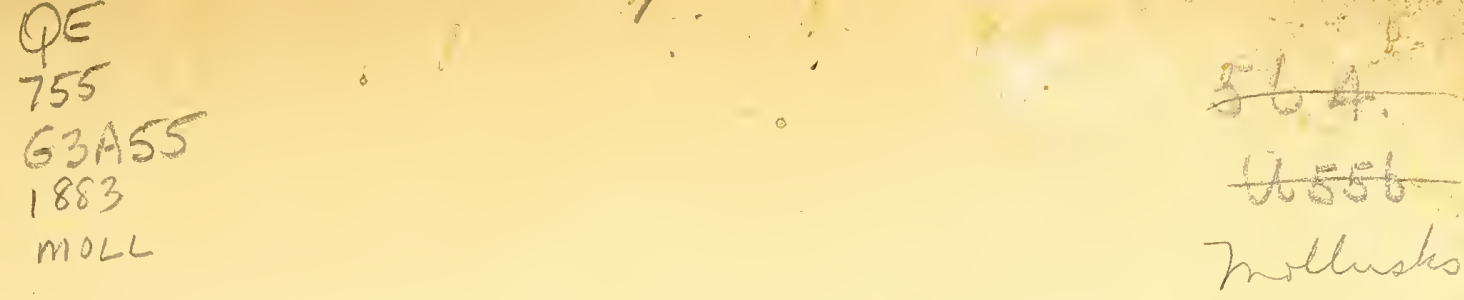

\section{BEITRAG ZUR KENNTNISS}

\section{DES ELSÄSSER TERTIÄRS}

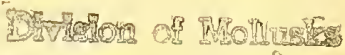
Rectione? Rercat

DIE

\section{ÄLTEREN TERTIÄRSCHICHTEN}

I M ELSASS.

\section{INAUGURALDISSERTATION,}

DER

MATHEMATISCHEN UND NATURWISSENSCHAFTLICHEN FACULTÄT

DER KAISER-WILHELIS-UNIVERSITÄT STRASSBURG

ZUR ERLANGUNG DER DOGTORWÜRDE
PORGELEGT PON
A. $A \mathrm{~N} R \mathrm{EAE}$.

Mit 3 lithographirten Tafeln.

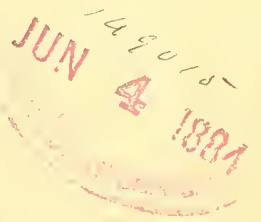

\section{STRASSBURG,}

DRUCK VON R. SCHULTZ \& Cie

(Bergfr-Levrault's Nachfolger).

1883. 

Seinem hochverehrten Lehrer

\section{Herrn Professor Dr. E. W. Benecke}

zu Strassburg i. Els.

in Dankbarkeit gewidmet

vom Verfasser. 



\section{0 R W 0 RT.}

Die Anregung zu der Bearbeitung des Tertiărs im Elsass erhielt ich durch Herrn Professor BenEcke, welcher mich auf dieses Gebiet, das ja lïngere Zeit hindurch brach gelegen hatte, hinwies. Dieser mein hochverehrter Lehrer verfolgte wälırend der ganzen Zeit meine Arbeit mit reger Theilnahme und hat mich bei derselben in jedweder Hinsicht wohlwollend unterstüzt. Das Malerial, welches meiner Arbeit als Grundlage dient, befindet sich, soweit ich es nicht besonders erwähnt habe, in der Strassburger Landessammlung. Dasselbe wurde zum grössten Theil auf meinen zahlreichen Excursionen im Elsass von mir selbst gesammelt. Die Arbeit ist in den Räumen der geologischen Landessammlung ausgeführt worden, welche mir auf das Liebenswürdigste von Herrn Professor GoHen zur Verfügung gestellt wurden; ich bin demselben daher zu allergrösstem Danke verpflichet. Herrn Dr. 0. BöTrGER in Frankfurt a. M., meinem hochgeschätzten, fruheren Lehrer und Freund, muss ich an dieser Stelle vor allem meinen Dank dafur aussprechen, dass er mir bei seiner gründlichen Kenntniss der Land- und Süsswalsserschnecken, sowie des Mainzer Tertiärbeckens, mit seinem werthvollen Rathe beistand. Durch ihn erhielt ich ferner die Reuss'schen Originale zu der Abhandlung über die Foraminiferen des Septarienthones ron Offenbacls. Sowoln diese, wie auch das mir von Herrn Dr. STEINMann freundlichst mitgetheilte Vergleichsmaterial, war mir in hohem Grale bei der Bestimmung der elsässer Foraminiferen nützlich. Ich darf deshalb nicht versäumen, auch letzterem Herren noch meinen besonderen Dank hier alszutragen. III. 
Bei meiner Arbeit war ich, soweil sich dieselbe auf die technisch wichtigen bitumenführenden Oligocảnschichten bezieht, genöthigt, auf die in den Bergwerksakten gesammelten Erfahrungen zu recurriren. Auclı hier wurde mir das bereitwilligste Entgegenkommen gezeigl. Herr Regierungsralh von ALBERT halte nicht allein die Güte, mir die erforderlichen Pläne und Profile zur Verfugung zu stellen, sondern er gestattete mir auch, ihn auf einigen Excursionen in die wichtigsten Petroleumgebiete des Elsasses zu begleiten, wofür ich ihm stels dankbar sein werde.

\section{A. Andreae.}


I.

\section{DER BUGIISWEILER-KALK}

UND

GLEICHALTERIGE BILDUNGEN

AM OBERRHEIN.

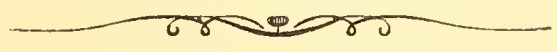





\title{
DER BUCHSIVELLER-KALK
}

\author{
UND
}

\section{GLEIGHALTERIGE BILDUNGEN AM OBERRHELN.}

\section{Wichtigste Litteratur.}

1762. Benninger. Oryctographia agri buxovillani et vicinae.

1814. Calmelet. Description de la mine de lignite vitriolique et alumineux du Mt. Bastberg et de l'usine de vitriol ef d'alun de Bouxviller. Journal des Mines, XXXVII, n²20, pg. 239-256.

1822. Guvier G. Recherches sur les ossements fossiles (Lophiodon v. Buchsweiler).

1835. Duvernoy. Mém. de la Soc. du musce d'histoire nat. de Strasbourg. (Lophiodon und Sus? von Buchsweiler.)

1839-64. Blanville. Ostéographie. (Lophiodon, Palaeotherium, Anoplotherium? und Arctomys von Buchsweiler angeführt.)

1852. Daubrés. Description géologique et minéralogique du Bas-Rhin, pg. 191 - 203. (lst namentlich massgebend für die Lagerungsverhältnisse.)

1870-75. Sandberger F. Dje Land- und Süsswasser-Gonclyylien der Vorwelt, pg. 221-235. (Ist grundlegend für die Fauna von Buchsweiler.)

\section{Geologische Verhältnisse.}

Die Mitteleocän-Schichten, die ältesten tertiären Ablagerungen in unserem Gebiete, spielen im Elsass eine verhältnissmässig untergeordnete Rolle. Dieselben erscheinen niemals in 
grossen zusammenhängenden Massen, obwohl sie durch die ganze Oberrhein-Ebene verbreitet sind. Sie bestehen durchweg aus Süsswasserablagerungen, welche zur Zeit der Bildung des marinen Grobkalkes im Pariser Becken, in kleinen und wie es scheint von einander gesonderten Seen zum Absatze gelangten. Dieselben treten uns als Mergel, pyritreiche Braunkohlen, Süsswasserkalke oder kalkige Sandsteine entgegen und sind durch das Leitfossil Planorbis pseudammonius ScHцотн. sp. gekennzeichnet. Sie überlagern die jurassischen Schichten des Rheinthales und werden ihrerseits wiedermm von oligocäner Molasse oder Diluvium bedeckt.

Das wichtigste Vorkommen der hierher gehörigen Schichten ist dasjenige am Grossen Bastberg bei Buchsweiler im Unter-Elsass (Eisenbahnstation zwischen Hagenau und Zabern). Wir wollen mit der Besclireibung desselben beginnen.

Die Lagerungsverliältnisse des Bastberges sind kurz folgende :

Ueber dem liegenden Dogger und Malm (Zone der Rhynchonella varians $\mathrm{ScH}$. sp. und Zone des Stephanoceras macrocephalum ScH. sp.) zeigt sich zunächst ein Complex von thonigen, mergeligen, braunkohlenführenden Schiclıten, deren mittlere Mäcl1tigkeit etwa $15 \mathrm{~m}$ beträgt. Hierauf rulıt eine $5-20 \mathrm{~m}$ dicke Bank von Süsswasserkalk ${ }^{2}$. Derselbe ist liellgelb, zerklüftet, durch und durch erfüllt von Schneckensteinkernen und hat bei weitem die meisten von Buchsweiler stammenden Fossilien ge-

1. Ein theilweises Profil des Kalkes ist uns dadureh erhalten, dass НаммеR in einem Brief an Covier (Strasbourg, 8. messidor an 13) eine Beschreibung des Steinbruches, welcher jetzt versehüttet ist, gibt. Im Luszug etwa folgendes: Oben 1-2 Fuss Ackerboden, dann 3-5 Fuss sehmutzig-hellgrauer, dichter und harter Kalk mit wenig Schneeken, alsdann 3-5 Fuss fossilreicher, brüchiger Kalk, zu unterst knochenführende Schicht mit verhältnissmässig wenig Schnecken. In Coviel, Recherches sur les oss. foss. 1822, pg. 195. 
liefert. Zuweilen wird der Kalkstein fleckig, oolithisch oder weich und kreideartig. In den obersten Lagen enthält er namentlich viele Exemplare von Planorbis Chertieri Dest. und Nanina Voltzi Desn. sp. Auf den Kalk folgt eine wenig mächtige Mergelschicht, welche die gewaltigen Conglomerate trägt, die im Gipfel des Grossen Bastberges $(329 \mathrm{~m})$ die ganze Gegend überragen.

Der Bergbau, welcher wesentlich zum Zwecke der Alaunund Vitriolbereitung aus der ungemein pyritreichen, erdigen Braunkohle betrieben wurde, ist jetzt fast eingegangen.

Wir sehen uns daher genöthigt, die in früherer Zeit durch denselben erschlossenen Profile, welche in DAubrÉe's Arbeit niedergelegt sind, hier anzuführen.

I. Allgemeines Profil des Tertiärs von Buchsweiler mit mittlerer Mächtigkeitsangabe:

1. Ackerboden .......... 0, 0, . . m.

2. Gelbe Mergel . . . . . . . . 3, 3, m.

3. Süsswasserkalk . . . . . . . 18,00 m.

4. Grüne Mergel mit zerdrückten Planorben und Limneen, sowie Sphaerium (Caliculina) Castrense Noul., welche Art im Kalk fehlt. Er enthält eingeschaltete dünne Kalkbänke und geht nach obenhin in einen weisslichen, fossilfreien Mergel über ......... 12,00 m.

5. Brauner Thon (von den Arbeitern Mulm genannt).......... . . 0, . . . . . .

6. Pyritreiche Braunkohle 0,50 bis ..... 2, 2,00 m.

7. Brauner Thon undurchlässig für Wasser (meist $0,30 \mathrm{~m})$, darunter harte, sandige, weissliche, roth gefleckte Thone......... 1,50 m. 
Die ganze Mächtigkeit, welche zuweilen auf $54 \mathrm{~m}$ steigt, beträgt durchschnittlich an $40 \mathrm{~m}$.

II. Bohrung auf dem Bastberg im November 1844 :

1. Ackerboden ............ 0 0,25 m.

2. Gelbe Mergel. . . . . . . . . . . 3,25 m.

3. Süsswasserkalk . . . . . . . . 4 4,50 m.

4. Weissliche Mergel, darunter der grüne Mergel und schliesslich die braunen Thone, welche sich stets im Hangenden der Braunkohle finden............. . $6,00 \mathrm{~m}$.

5. Brannkohle . . . . . . . . . $1,00 \mathrm{~m}$. $15,00 \mathrm{~m}$.

III. Gleichzeitige Bohrmng etwa $200 \mathrm{~m}$ von der vorigen entfernt:

1. Ackerboden ........... . . 0,15 nı.

2. Gelbe Mergel ........... . . . $1,85 \mathrm{~m}$.

3. Süsswasserkalk . . . . . . . . 16, . . . . . . .

4. Sandiger, weisser Thon ...... 3,15 m.

5. Kalk. . . . . . . . . . . $1,15 \mathrm{~m}$.

6. Thon ........... . 4, . $4,32 \mathrm{~m}$.

7. Kalk. . . . . . . . . . . 0,16 m.

8. Grüne Mergel .......... 13,69 nı.

9. Brauner Thon ........... . . 0, . . . . . . . .

10. Braunkohle ............ . 1, . $1,5 \mathrm{~m}$.

42,83 III.

IV. Bohrung am Weg nach Imbsheim, dieselbe zeigt das Verschwinden der Brannkohle im südlichen Theil der Ablagerung: 
1. Ackerboden ........... . . 0,15 $\mathrm{m}$.

2. Süsswasserkalk. . . . . . . . 16,15 11 .

3. Mergeliger Thon . . . . . . . . . 9,00 $\mathbf{m}$.

4. Süsswasserkalk mit Mergel wechsellagernd. . 10,00 m.

5. Weisser Thon . . . . . . . . . 3,30 m.

6. Rother Thon. ........... 1, . $1,65 \mathrm{~m}$. $40,25 \mathrm{~m}$.

Zur petrographischen Charakteristik der erwähnten Gebirgsarten ist wenig zu sagen; wir folgen auch hier z. Th. den Angaben DAubrée's, zumal da uns nicht von allem genannten Materiale Proben zur Verfügung standen.

Die erdige, chocoladefarbige Braunkohle enthält $10 \%$ Wasser und in den obersten, reichsten Lagen 12-13\% Schwefelkies. Derselbe tritt, obwohl leicht zersetzbar, in der regulären Form des Pyrits auf. Die Braunkohle ist eine sehr unreine und enthält grosse Mengen von Thon, ein günstiger Umstand, der bei der Alaunbereitung in Betracht kommt. Gyps bildet sich als sekundäres Product und efflorescirt aus der Kohle; auch findet er sich auf Klüften in derselben ausgeschieden. Man hat niemals bestimmbare Pflanzenreste in der Braunkohle gefunden.

Die grünen Mergel haben eine gral- bis gelbgrüne Farbe, sind sehr wenig plastisch, kalkig und enthalten in Menge die plattgedrückten, weissen Schalen von Planorbis pseudammonius und Limneen. Im Schlemmrückstand fand sich nichts bemerkenswerthes.

Der Süsswasserkalk ist ein dolomitfreier, ziemlich reiner Kalk, welcher etwas Eisen und Kieselsäure enthält. $\mathrm{Er}$ zeigt keine sehr deutliche Schichtung, ist stark zerklüftet und wird von zahlreichen krystallinischen Kalkspathadern und Drusen durchzogen. Gewöhnlich ist der Kalk dicht und hart von hell- 
grauer oder hellgelber Farbe; er geht aber in einzelnen Bänken in einen weichen, weisseı und kreidigen Kalkstein über. Viele Blöcke des Kalkes haben ein eigenthümliches, fleckiges Aussehen. Die unregelmässig polygonalen, weissen, mulmigen Parthien werden ähnlich wie in einer Breccie durch die harte, graubraune Kalkgrundmasse zusammengehalten. Neben diesem fleckigen Kalk findet sich noch ein mehr oder weniger feiner, schöner, oolithischer Kalk'.

Die Grundmasse zwischen den Oolithkörnern ist in der Regel härter und durch organische Substanz dunkler gefärbt als diese selbst. Wir müssen die Oolithe als eine ursprüngliche Bildung ansehen, denn wir finden dieselben in und um die Conchylieuschalen angehäuft; sie durchsetzen jedoch dieselben niemals. Im Dünnschliff erscheinen die Oolithkörner ausserordentlich gleichmässig feinkörnig und lassen selbst bei Färbung nur eine äussere randliche Zone erkennen, während die Grundmasse vorwiegend aus grosskrystallinischem Kalke besteht. Die Analyse zeigte, dass der Kalk der Oolithkörner zwar demjenigen der Grundmasse qualitativ gleich ist, aber quantitativ in sofern abweicht, als derselbe fast $6 \% \mathrm{mehr}$ an Beimengungen wie Eisenoxyd, Kieselsäure und kohlensaure Magnesia enthält. Die oolithischen Blöcke pflegen die besten Versteinerungen zu enthalten, d. h. solche Versteinerungen, deren Schale noch erhalten ist.

Der Buchsweiler-Kalk umschliesst in einzelnen Bänken zahlreiche Schneckeureste ähnlich wie z. B. der Hydrobienkalk des Mainzer Beckens, nur dass wir es bei Buchsweiler meist mit Steinkernen zu thun haben und dass nicht eine Species durchaus vorwiegt, sondern dass sich melırere Arten den Rang

1. In Guvien, Rech. sur les oss. foss. wird der pisolithische (resp. oolithische) Kalk ebenfalls erwähnt. T. I, pg. 540. 
der grössten Häufigkeit streitig machen. In erster Linie ist hier wohl Euchilus Deschiensianum zu nennen, dann folgt Planorbis pseudammonius und die Paludinen. An der Oberfläche eines grossen Handstïckes lassen sich zuweilen die Reste von 8-10 verschiedenen Arten constatiren.

Was die Menge des Vorkommens betrifft, so hat Daubrée nach Schätzung berechnet, dass ein Cubikmeter des Buchsweiler-Kalkes öfters 8000 bis 10000 Individuen enthält. Trotz dieser grossen Häufigkeit sind die Verhältnisse zum Sammeln keine sehr günstigen, weshalb auch gute Suiten von Buchsweiler Conchylien selten sind. Nur hin und wieder trifft man unter den zahllosen Steinkernen mit Schale erhaltene Exemplare an, oder vielmehr solche Individuen deren ursprüngliche Schale durch späthigen Kalk ersetzt ist, und alsdann hält es noch schwer, dieselben aus dem oft harten und spröden Kalk heraus zu präpariren'.

Wie die beistehende Kartenskizze veranschaulicht, zeigt der Süsswasserkalk in wesentlichen die Gestalt einer Ellipse deren grosse Axe von NO nach SW verläuft, und welche im Süden eine starke Ausbuchtung besitzt. Der früher ziemlich lebhafte Bergbau hat nun gezeigt, dass die Tertiärschichten, ohne selbst von einer grösseren Verwerfung gestört zu sein, allseitig mit einem Winkel von etwa $6-9^{\circ}$ und mehr (bis $16^{\circ}$ ) nach der Mitte dieser Ablagerung zu einfallen. Dieser Umstand, sowie derjenige, dass die benachbarten Juraschichten eine muldenförmige Biegung zeigen, veranlasste DAubrée zu der Annahme, dass der Buchsweiler-Kalk in dieser Weise beckenförmig abgelagert worden sei. Wir dürfen uns jedoch nicht zu

1. Es ist keineswegs anzunehmen, dass die Schneekengehäuse bei der Bildung des Kalksteins ron irgend welcher Bedeutung gewesen seien, derselbe ist jedenfalls chemisch niedergesehlagen. Auch sundern die der Hasse nach überwiegenden Süsswassersehneeken bekanntlich am wenigsten Kalk ab. 
der Anschauung verleiten lassen, dass die jetzige Begrenzung des Kalkes dem ursprünglichen Umfange des Süsswassersees entspräche. Jedenfalls war derselbe viel grösser und reichte wohl bis nach Bitschhofen. Immerhin wird man bei ciner so alten Schicht der Erosion genügend Rechnung tragen müssen. Auch ist im Auge zu behalten, dass die Buchsweiler Tertiärschichten

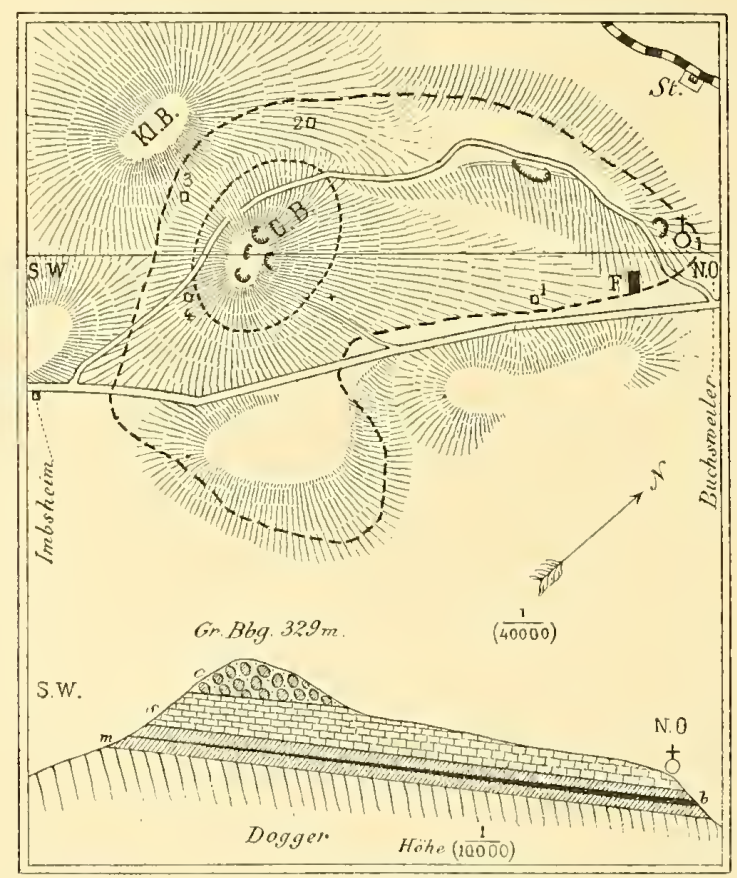

Fig. 1. Kartenskizze des tertiären Süsswasserkalkes vou Buchsweiler z. Th. nach DAubriE.

... - Grenzen des Süsswasserkalkes (s.); ... Grenzen der Conglomerate (c.); m. $=$ Mergel mit Braunkohle; む Kirehe von Buchsweiler; F. Fabrik; 1-4 Schachtöftnungeu.

sich nicht mehr in ihrer ursprünglichen Lagerung befinden, indem sogar die den Kalk überlagernden Conglomerate ein deutliches Einfallen nach NNO zeigen und in denselben abgerollte Stïcke des Süsswasserkalkes vorkommen sollen.

Dem Buchswciler-Kalk glcichalterige Tertiärschichten finden sich zwar im ganzen Oberrheinthale vereinzelt, von Basel 
bis Bruchsal; dieselben sind aber alle selır unbedeutend. Wir beginnen mit den weiteren Vorkommnissen im Unter-Elsass.

In der Gemeinde Dauendorf, 14 Kilometer in östlicher Richtung von Buchsweiler entfernt, wurde in früherer Keit eine pyritreiche Braunkohle neben den dort vorkommenden Bohnerzen gewonnen und man erkannte folgende Lagerungsverhältnisse: Znoberst ein dichter Kalk, reich an Conchylien. Derselbe enthält Hornsteinstücke und Charen-Reste. Darunter folgen grüne Mergel und braune Thone mit einem Braunkohlenflötz. Das Ganze ruht auf den Bohnerzlagern auf. Von Fossilien ist folgendes bekannt: ein oberer, rechter Molar von Lsophiodon tapiroides Cuv., ein Canine, welcher vielleicht derselben Art angehören dürfte, ferner werden Paludinen (wohl Iydrobien) und Cypris-Schalen von Voltz erwähnt.

In dem Orte Dauendorf selbst, beträchtlich höher als die alten Gruben, finden sich wiederum tertiäre Süsswasserschichten; ein in neuster Zeit gegrabener Brunnen lieferte mir folgendes Profil :

1. Lehm . . . . . . . . . . 2, 2, 2 m.

2. Feste, gelbe Steinmergelbänke..... $0,5 \mathrm{~m}$.

3. Helle, gelbe und graue, sandige Nergel, letztere mit Hydrobien . . . . . . . . 6, 6, n.

4. Fette, blauschwarze Mergel ....... 9, 9, m.

5. Helle, schmutzige Mergelkalke ...... $1,0 \mathrm{~m}$. $19,0 \mathrm{~m}$.

Die Mergel (3.) sind reich an Schwefelkies und besitzen einen starken schwefligen Geruch, ihr Schlemmrückstand ist sandig kalkig. Die in den grauen Mergeln enthaltenen Conchylienbruchstücke (Fragmente von Planorbis etc.) sind mit Ausnahme der Hydrobien zu mangelhaft erhalten, um eine sichere Bestimmung zuzulassen. Man kann 2 Arten von Hydrobien 
unterscheiden: Hydrobia Dauendorfensis nov. sp. und Hydrobia cf. Websteri Morr. sp. (vergl. pg. 34, 35, Tf. III, Fig. 1, 2).

Bei Neuburg, etwa 1 Kilometer von dem Dauendorfer Vorkommen entfernt, werden die in früherer Zeit dort abgebauten Bohnerze gleichfalls von Süsswassermergeln mit Braunkohle und dann von einem grauen Kalkstein überlagert. Der unreine, pyritische Kalk ist ungefähr $1 \mathrm{~m}$ mächtig und ganz von Conchylien erfüllt. Ein mir vorliegendes Stïck enthält namentlich Planorbis pseudammonius. Ferner werden noch die Ueberreste einer Scliildkröte von Daubrée erwälınt.

Bei Bitschlofen am Buhlinger-Berg, 4 Kilometer nordöstlich von der früheren Neuburger Bohnerzgrube, zeigen sich ähnliche Lagerungsverhältnisse. Ein von DAubréE gegebenes Profil mag dieselben veranschaulichen.

1. Mergel . . . . . . . . . . 5, 5 m.

2. Süsswasserkalk mit Mergel wechselnd.... $8,00 \mathrm{~m}$.

3. Thone mit Bohnerz ......... 2, 2,60 m.

$15,90 \mathrm{~m}$.

Darunter die liegenden Juraschichten. In den grauen Mergeln trifft man, ausser Limneen, mit Schale erhaltene Exemplare von Planorbis pseudammonius. An diesem Punkte sind jetzt ebenfalls keine Aufschlüsse mehr vorhanden; ich fand jedoch bei dem nahe gelegenen Dorfe Bitschhofen einen Kalkblock ähnlich dem Buchsweiler-Kalk mit Limners Michelini und Planorbis pseudammonius.

DaubréE erwähnt von Mietesheim pyritreiche Mergel mit Braunkohlen-Spuren, welche die dortigen Bohnerzlager bedecken; es ist von denselben, wie bei Bitschhofen, nichts mehr zu sehen. Die blaugrünen Mergel lingegen, welche ich in einem zufälligen Aufschluss südöstlich von diesem Dorfe 
antraf, müssten über denselben liegen, denn sie zeigen die grösste Analogie mit den oligocänen Mergeln von Lampertsloclı.

Die bisher angeführten Vorkommnisse zeigen alle grosse Aehnlichkeit mit einander. Die aus Süsswasserkalk und braunkohlenführenden Mergehn bestehenden Schichten überlagern die Bohnerzthone. Planorbis pscudammonius ist überall lüufig, ausser in den höheren Schichten im Orte Dauendorf, wo die bei Buchsweiler seltenen Hydrobien vorwiegen. Etwas abweichend davon verhalten sich einjge Kalke, welche ich für etwas jünger als den Buchsweiler-Kalk halten möchte, und die sogleich angeführt werden sollen. Dieselben überlagern bei Morschweiler, am Bischenberg und bei Bernhardsweiler direkt die Dogger-Schichten oder kommen in den hangenden Conglomeraten vor. In diesen Kalken tritt Pl. pseudammonius zurück und Hydrobien-Steinkerne sind am häufigsten. Am Bischenberg fand ich ferner ein Bruchstück von Megalomastoma mumia Lnk. sp., die im jüngeren Palaeotherienkalk von Brunnstatt häufig ist.

Auf dem Wege von Morschweiler nach Dauendorf, nicht weit vom erstgenannten Ort, steht auf einer Anhöhe eocäner Süsswasserkalk an. Derselbe wird in kleinen Steinbrïchen gewonnen, da man sein Material den umliegenden Jurakalken zur Beschotterung der Strassen vorzieht. Der hellgelbe Kalk gleicht in seinem Aussehen auffallend dem noch zu er:wähnenden Kalke vom Bischenberg und von Bernhardsweiler im mittleren Elsass. Eimzelne Bänke desselben sind lart und homogen, andere haben im Imeren ein poröses und zerfressenes Aussehen. Dieser Kalk besitzt keine grosse Mächtigkeit, er lagert direkt auf dem Parkinsonoolith (Schichten der Ostraea acuminata Sow.) auf und wird von einer dünnen schmutzig-gelben Mergelschicht bedeckt. Die Fossilien in dem- 
selben sind sparsam und schlecht erhalten. Hydrobien und Limneen-Steinkerne wiegen vor.

Der Bischenberg oder Nationalberg, ein isolirter Vogesenvorberg, erhebt sich zwischen Oberehnheim und Bischofsheim zu einer Höhe von 363 n. Seine Basis besteht vorwiegend aus Hauptoolith, sein Gipfel aus oligocänen Conglomeraten, und zwischen diese beiden Gebilde ist eine Schicht von Süsswasserkalk eingeschaltet. Der Kalk ist nirgends direkt aufgeschlossen; man findet jedoch an der Grenze des Oolith's und der Conglomerate zahlreiche umherliegende Stücke desselben. Abgerollte Fragmente des Süsswasserkalkes fand ich schliesslich auf der Höhe des Berges in den Conglomeraten selbst. Der gleiche Kalk kommt ferner noch auf dem Conglomerathügel hinter dem Ort Bernliardsweiler vor, ungefähr 1,5 Kilometer südlich rom $\mathrm{B}$ ischenberg. Das Aussehen des Kalksteins ist ziemlich wechselnd, er ist fleckig, hellgelb oder hellgrau, öfters sandig, zuweilen dicht, zuweilen zerfressen und cavernös. Ich beobachtete nachstehende Fossilien:

Planortis pseudammonius ScHLTH. sp. Diese Art fand ich nur auf der südwestlichen Seite des Bischenberges, und zwar in schönen grossen $(3,5 \mathrm{~mm}$.) mit Schale erhaltenen Exemplaren. Anf der Nordseite, wo die anderen Arten am häufigsten sind, scheint sie zu fehlen.

Planortis Chertieri Desh., namentlich bei Bernhardsweiler.

Limnea olivula Rovis sp. Diese Art ist am Bischenberg häufiger als bei Buchsweiler.

Limnea of. Michclini Desh.

Megalomastoma cf. mumia Lмк. sp. Ein Steinkern nebst dazugehörigem Abdruck im hellgelben Kalk vom Bischenberg. Derselbe stimmt nach Grösse, Form und Sculptur ganz mit der obigen Art; es fehlen an demselben jedoch die untersten 
Windungen und die Mündung. Aus dem BuchsweilerKalk ist nie etwas derart bekannt geworden.

Ausserdem finden sich nicht selten Hydrobien-Steinkerne und Cypris-Abdrücke.

An die besprochenen elsässischen Fundstellen von eocänem Süsswasserkalk schliessen sich diejenigen der benachbarten Länder, Badens und der Schweiz, naturgemäss an. Die Pfalz und Rheinhessen, kurz das ganze Mainzer Becken hat keine analogen Tertiärbildungen aufzuweisen. In Lothringen ${ }^{1}$ und Württemberg (Bohnerze?) scheinen gleichfalls Tertiärschichten des Eocän's und Oligocän's zu fehlen.

In Baden ist nur ein einziges Vorkommen von Schichten bekannt, welches mit dem Buchsweiler-Kalk zu parallelisiren ist. Der schon mehrfach ${ }^{2}$ besprochene Sandkalk, welchen man in umherliegenden Brocken bei Ubstadt und vereinzelt auch bei Malsch unweit Langenbrücken gefunden hat, gehört hierher. Der plattige, gelbe Kalksandstein enthält ziemlich schlecht erhaltene Fossilien (Steinkerne). Es ist das Verdienst Sandberger's folgende Arten darunter erkannt zu haben:

1. Paludina Orbignyana DEsH.,

2. Euchitus Deschiensianum Desh. sp.,

3. Planorbis Chertieri DesH.,

4. Plan. psendammonius ScH. sp.,

5. Pomatias Sandbergeri NouL.,

6. Melanopsis sp. vielleicht Castrensis NouL.

1. Die nahe an der lothring'schen Grenze vorkommenden Thone und Quarziteonglomerate (Speicher etc.) werden neuerdings vielleicht mit Recht als tertiăr angesprochen (mitteloligoeảne Küstenbildungen). Durch die Güte des Herrn Dr. vaN Werveke konnte ich derartige Thone auf Foraminiferen untersuchen und fand dieselben durchaus steril. In Würltemberg dürften einige Bohnerze zum Eoeän gehören.

2. Nenes Jahrb. für Min. ete. 1859 (G. Defrner und 0. FraAs). Ferner W. Beneche und E. Cohen, Geognost. Besch. der Umg. v. Heidelber'g 1881, pg. 498.

III. 
Ausserdem Fischschuppen, Krokodilzähne und SchildkrötenReste.

Am Schlusse bleibt uns noch eine vereinzelte Fundstelle zu nennen übrig. Dieselbe liegt im Canton Solothurn zwischen Hobel und Kempen, nicht weit von Basel. Es soll von dem Vorkommen jetzt nichts mehr zn sehen sein. Der dortige Kalk hat nur Reste von $\mathrm{Pl}$. pseudammonius in grosser Zahl geliefert, welcher mir nebst der var. Leymeriei Desh. aus der Greppis'schen Sammlung vorliegt. Soviel man es nach einem kleinen Stück beurtheilen kann, zeigt der Kalk von $\mathrm{Hobel}$ petrographisch grosse Uebereinstimmung mit dem von $\mathrm{Buclisweiler,} \mathrm{auch}$ ist oolithische Structur an demselben wahrzunehmen.

\section{Palaeontologische Verhältnisse.}

\section{A. Säugethiere.}

Was die Fauna von Buchsweiler betrifft, so haben wir zunächst eine Reihe von Säugethieren zu nennen, welche, wenn es sich um die Bestimmung des Alters einer Tertiärschicht handelt, ja in erster Linie in Betracht kommen. Die LophiodonArten sind die charakteristischesten und häufigsten Säugethiere der Buchsweiler Fauna, welche zahlreiche Reste, allerdings meist nur Kieferbruchstücke und Zähne, geliefert haben. Die Lophiodonten von $\mathrm{Buchsweiler}$ sind schon seit langer Zeit bekannt und haben dadurch eine gewisse Berühmtheit erlangt, dass Cuvier in seinen Recherches sur les ossements fossiles, Reste derselben abbildete, beschrieb und 2 Species auf dieselben begründete. Buainvizre salı sich später veranlasst, die beiden Buchsweiler 
Arten wieder mit einander und mit dem Loph. Isselense Cuv. zu vereinigen, ohne jedoch einen genügenden Grund dafür anzugeben. Diese Vereinigung ist unzulässig; auch wurde sie von späteren Autoren, welche über Lopliodon schrieben, wie MAACK $^{1}$ und RüTIMEYer ${ }^{2}$ nicht acceptirt. Wir wollen an anderer Stelle, bei Besprechung der beiden Buchsweiler Arten, die wich- tigsten Unterscheidungsmerkmale hervorheben.

Als eine sehr alte Gruppe der perissodactylen Ungulaten stehen die Lophiodonten den durchschnittlich jüngeren Palaeotherien im Eocän gegenüber. Sie charakterisiren namentlich die älteren Bohnerze, so in der Schweiz bei Eg e rkingen, in Mittelfranken bei Heidenheim und finden sich in verschiedenen Mitteleocänbildungen Frankreichs: A r'genton (Indre), Issel (Aude) etc. Aus dem Oligocän ist mit Sicherheit kein Lopliodon bekannt und im Miocän folgen die Tapire, welche wohl direkte Nacl-kommen von Lophiodon sind. Die Lophiodonten zeigen die einfachsten Zähne unter den Ungulaten und der primitive, gradlobige Typus ihrer Molaren bildet den Ausgangspunlit für die complizirteren Zähne anderer Unpaarhufer. Während so die Molaren Anklänge an diejenigen der Tapire und der Palaeotherien erkennen lassen, sind namentlich die Caninen abweichend gebildet und zeigen wie bei anderen altfossilen Ungulaten carnivoren Charakter. Ferner ist noch ein primitiver Zug zu erwälnen, welcher schon oft hervorgehoben worden ist, nämlich, dass bei Loptiodon die Praemolaren in höherem Grade von den Molaren differenzirt sind als bei dem viel jüngeren Tapir. Am Schädel von Lopliodon sind die verhältnissmässig langen Nasenbeine, sowie die grossen einander genäherten Schläfengruben bemerkens-

1. G. A. MAAck, Palaeontologische Untersuchungen über noch unbekannte Lophiodonfossilien von Heidenheim am Hahnenkamme in Mittelfranken. Jeeipzig 1865.

2. Rutrmeyer, Veber eocäne Sängethiere aus dem Gebiet dos schweizerischen Jura 1862. 
werth. Die artenreiche Lophiodon-Familie besitzt in Europa eine ziemlich weite Verbreitung und wird im Eocän von Nord-Amerika namentlich durch die nahe verwandte Gruppe Hyrachyus (LeIdy) vertreten, welche dort eine grössere Bedeutung als Lophiodon selbst erlangt. Hyrachyus koinmt in Europa nur sparsam vor (Phosphorite von Quercy) und steht im Ganzen dem Tapir näher, dasselbe wird von GAUDRY als Zwischenform zwischen Lophiodon und diesem angesehen ${ }^{1}$.

Die beiden Arten von Buchsweiler sind:

\section{Lophiodon tapiroiales Cuv.}

"Grand Lophiod. de Buchswiller". Abgebildet in Cuv. R. sur les 0 . foss., t. II, pl. VI, 2, 4; pl. VII; 1, 3, 5. Ferner wurde die stark verkleinerte Abbildung eines zerdrückten, vorn abgebrochenen Schädels von Duvernoy in den MLém. de la Soc. d'hist. nat. de Strasbourg 1835 T. II. gegeben².

Diese Art erreichte nicht ganz die Grösse eines Pferdes, gehört also immerlin zu den grossen Lophiodon-Arten, wenn sie

1. A. Gaudny, Les enchaînements du Monde animal dans les temps géologiques. Mammifères tertiaires. Paris 1878, pg. 64.

2. Duvennoy, Notice sur un crane de Loph. et in fragment de mâchoire d'une très-petile espèce de Pachyderme présumée du genre Sus. pg. 9. - In den Mém. d. l. Soc. d'hist. nat. d. Strsbg. T. V. 1862 (Résumé p. 15) gibt Prof. Schimper eine kurze Notiz über Säugethiere ron Buchsweiler. Er erklärt darin Duvennoy's Lophiodon für ein Rhinoceros (Aceratherium) incisivus, olne wèiteren Grund für die ldentifikation anzugeben. Das betreffende Schädelfragment befindet sich noeh in der Strassburger Landessammlung und ich nahm von neuem Gelegenleit, die darin vorhandenen Zahnreste sorgfältig zu untersuchen. Von dem vorletzten Mularen ist die innere Hälfte gut erhalten und stimmt rollständig mit $L$. tapiroides überein. Es ist namentlieh hervorzuheben, dass das Thal zwischen den 2 Querjochen eben so breit und flach ist wie bei der letztgenannten Species. Umriss und Grösse des letzten Molaren, dessen Krone zerstört ist, stimmen gleichtalls mit L. tapiroides. Von den tiefer eindringenden Sehmelzfalten der Rhinoceroszähne ist nichts zu sehen. Wir müssen daher den Durensoy'sehen Schädel zu Lop. lapiroides stellen. 
auch von dem $L$. rhinocerodes Rüтsм. aus den Bohnerzen noch an Grösse übertroffen wird. Als Unterschied von L. Isselense, welchem die obige Art nahe steht, führe ich aus der schon erwähnten Arbeit von MAAcK folgendes an (pag. 30): "Bei L. Isselense Cuv. sind beide Querjoche der unteren Molarzähne ebenso wie bei L. Parisicnse Gerv. fast gar nicht mit einander verbunden, wälırend bei $L$. tapiroides ein Anschluss der Zwischenkante in lıalber Höhe des vorderen Joches stattfindet. Das Querthal der oberen Backenzähne von L. Issclense ist eng, und der Haupthügel der Aussenwand bildet eine etwas geknickte Falte mit stumpfer Mittelkante; bei $L$. tapiroides dagegen ist die Bucht zwischen den Querjochen weit und seicht, der vordere Hügel der Aussenwand hoch und einen ziemlich regelmässigen Kegel darstellend." Dies mag hier genügen; die Unterschiede von $L$. Buxovitlanum sollen bei dieser Art besprochen werden. Taf. III. fig. 6 ist in 1/1 n. gr. ein letzter rechter Molar des Oberkiefers von Lophiodon tapiroides aus den Mergeln von Dauendorf stammend abgebildet. Der Zahn zeigt eine vorzügliche Erhaltung und ist auf der Kante und inneren Spitze der beiden Querjoche kaum etwas abgekaut, was darauf hindeutet, dass derselbe keinem alten Individuum angehörte. Bezeichnend ist für den letzten oberen Molaren die starke Convergenz, welche die $\Lambda$ ussenwand mit der Innenwand nach hinten zeigt, und die schiefe Richtung, welche die erstere zu den Querjochen eimnimmt. Die starke Warze am Vorderrande der Aussenwand, sowie der kräftige, namentlich vorn entwickelte Basalwulst sind für Lophiodon charakteristisch. Von den 5 Schmelzpyramiden ist der mittlere Hügel der Aussenwand am höchsten, dann folgen sogleich die beiden Kegel, welche von den inneren Enden der Querjoche gebildet werden. Die vordere und namentlich die hintere Warze der Aussenwand sind weit schwächer entwickelt. Die Dimensionen dieses Zahnes sind: 


$$
\begin{aligned}
& \text { Grösste Breite }=36 \mathrm{~mm} . \\
& \text { Grösste Länge }=45 \mathrm{~mm} . \\
& \text { Grösster Durchmesser }=51 \mathrm{~mm} .
\end{aligned}
$$

Der grösste Durchmesser der letzten Molaren von L. rhinocerodes beträgt hingegen $64-67 \mathrm{~mm}$. L. tapiroides findet sich ausser bei Buchsweiler noch in den Bohnerzen von Egerkingen, wo dasselbe mit sieben anderen Lophiodon-Arten zusammen vorkounmt'.

\section{Lophioalon Buxovillanum Cuv.}

Abgebildet in Cuv., Rech., t. II, pl. VI, 3, 5; pl. VII, $2,4$. "Loph. secondaire de Buchsw." Diese Art erreiclite ungefähr die Grösse des indischen Tapirs. Schon Cuvier hob hervor, dass die Loben der Unterkiefermolaren bei dieser Art schief nach vorn geneigt und ausserdem stark nach vorn umgebogen sind, wodurch sie sich im Habitus den Palaeotherien nähern. Der letzte Unterkiefermolar ist selır lang und dreilobig. Von den Oberkieferzähnen gibt RüтıмeYer in dem schon erwähnten Werke folgende Beschreibung: Der ganze Habitus der Zähne ist sehr verschieden von $L$. tapiroides. Sie haben ein compaktes, scharf gezeiclmetes Gepräge. Die Aussenwand ist relativ kurz und niedrig, kaum höher als die Querjoche. Letztere sind hoch, massiv, kurz und stark, nach hinten concav und steigen am inneren Ende in hohe Spitzen auf. Der Basalwulst ist schwach. Die Dimensionen der Zähne sind etwa $1 / 3$ kleiner als bei der vorigen Species. Ein rechtes Oberkieferstück, mit grösstentheils zerstörten Zahnkronen, welches mir vorliegt, zeigt

1. Rttrmeyer, Eoc. Säugeth. etc. L. tapiroides abgebildet Tf. II, 13-26; IV, 44; Lop. Buxovillanum auf Tf. III, Fig. 37-39. 
Spuren der 3 ziemlich grossen Molaren und der 3 kleinen Praemolaren, auch ist ein Theil der Eckzahnalveole erhalten, so dass kein Raum als Diastem übrig blieb. L. Buxovillanum findet sich ausserdem in den Bohnerzen von Egerkingen und nach den Angaben von Norduans bei Kapitanowká im Chersonschen Gouvernement nicht weit von Odessa. Falls die Zähne von Lophiodon medium Cuv., wie RüTrMEYer vermuthet und $M_{\Lambda A C \kappa}$ annimmt, Milchzähne von $L$. Buxovillanum sind, so wären noch andere Fundorte und unter anderen auch Argenton hinzuzufügen.

\section{Lophiodon sp. cf. tapiroides Cuv.}

Can. inf. dex. Taf. IV, Fig. 10, 11, 12, 13.

Von Dauendorf liegt mir ein Eckzahn vor, welcher der rechten Unterkieferhälfte angehört haben muss. Die wenigen bisher von Blainville, Rütimeyer und MaAck abgebildeten Lopliodon-Caninen zeigen grosse Aehnlichkeit mit diesem Zahn, ermöglichen aber nicht die Bestimmung der Species. Man ist bei den Eckzähnen in sofern schlimm daran, weil ihre Veränderlichkeit sowohl in Bezug auf das Geschlecht, sowie auf ein oder die andere Art der gleichen Gattung (z. B. bei Rhinoceros) eine viel grössere ist als bei den Molaren. Wenn dieser Zahn von Lophiodon tapiroides herrührt, was am walıscheinlichsten ist, so dürfte derselbe cinem jungen oder weiblichen Individuum angehört haben (letzteres ist wegen der vollständigen Ausbildung und der Abnutzung an der Spitze am wahrscheinlichsten). Nach dem Verhältniss zu urtheilen, welches bei anderen LophiodonArten (z. B. L. rhinocerodes) zwischen der Grösse des letzten Molaren und Caninen besteht, würde der Dauendorfer Molar einen grösseren Eckzahn erwarten lassen. RüтıмехеR rechnet 
jedoch eine untere Eckzahnkrone zu L. tapiroides, welche nur $15 \mathrm{~mm}$ im Durchmesser zeigt, während unser Zalm an der Kronenbasis $18 \mathrm{~mm}$ und $15 \mathrm{~mm}$ misst. Wegen der sehr schöıen Erhaltung und wegen des Fundortes glaubte ich den Zahn abbilden zu sollen ${ }^{1}$. Die mässig comprimirte Wurzel des Caninen ist beinahe doppelt so lang als die Krone. Letztere besitzt auf der inneren Seite vorn und hinten je eine scharfe Schmelzkante. Die Krone, welche innen etwas concav, aussen convex ist, wird von einem schwachen Basalwulst eingefasst und zeigt, von der-inneren Seite betrachtet, eine stärkere Krïmmung als die Wurzel. Die. Spitze ist auffallender Weise voll aussen ein wenig abgenutzt, eine Usur, die nur durcl den oberen dritten Incisiven berrirkt worden sein kann, der bei Lophiodon ähnlich wie beim Tapir sehr kräftig war. Der ganze Zahn hat einen carnivoren Habitus.

\section{Propalueotherinm Isselanum GERv.}

Ein Unterlieferbruchstück mit schlecht erlıaltenen Zähnen, welches vou Buchsweiler stammt, wird von Buasnville als zu Palaeotherium Isselanum gehörig betrachtet. Dasselbe findet sich erwälnt in der Ostéographie IV. Y. p. 174 u. p. 161, und ist abgebildet auf pl. VIII. Ich kenne das Original nicht und darf mir, zumal bei dem schlechten Erhaltungszustand, kein Urtheil nach der Abbildung erlauben ${ }^{2}$.

1. Der betreflende Canine war als Anthracotherium bestimmt und als solcher auch in der Litteratur aufgeführt worden. DaubréE, Desc. d. B. R., pg. 201.

2. Ob das von Decbos in einem Vortrage in Mülhausen erwähnte Vorkommen von Propalacotlerium bei Buchsweiler sich auf die Angabe BLAnvilce's stützt, ist inir unbekannt. Cf. Bull. de la Soc. indust. de Mullouse. 1870. 


\section{Propalaeotherium Argentonicum Cuv. sp.}

Molaren des Oberkiefers'. Tf. Ill, Fig. $18 a, b ; 19$.

Zwei isolirte, obere, linke Molaren eines Propalaeotherium, aus dem Buchsweiler-Kalk stammend, liegen mir vor. Es scheint mir der letzte und vorletzte Backenzahn ein und desselben Individuums zu sein; ersterer ist wohl erhalten, bei dem anderen ist leider die Aussenwand abgebrochen. Der auf Tf. III, Fig. $18 a$ abgebildete Zahn zeigt die typischen Formen des Propalaeotherienzahnes. Die starke Convergenz der Aussenwand mit der Innenwand nach hinten kennzeichnet ihn als letzten Molaren. Die Aussenwand zeigt die charakteristische Festonnirung. Sie zerfällt zunächst durch eine mittlere sehr scharf ausgeprägte Kante in 2 ungefähr fünfseitige, oben in den äusseren Schmelzkegeln scharf zugespitzte Felder. Diese Felder werden unten und aussen von Wülsten umrahmt und besitzen in der Mitte, je eine von der Kegelspitze nach dem Basalwulst herablaufende Verdickung. Am vorderen 'Theil der Aussenwand zeigt sich die stark erhobene Warze ganz wie bei Lophiodon. Die Ausbildung der Querjoche, welche sich schräg an die Aussenwand ansetzen, ist jedoch von Lophiodon recht verschieden. Das vordere Querjoch nimmt seinen Ursprung zwischen der Warze und dem vorderen Schmelzkegel der Aussenwand; dasselbe bildet eine ziemlich hohe und scharfe nach vorn concave Kante, bis es in der Mitte der Vorderseite sich zu einem Kegel erhebt. Auf diesen Kegel folgt eine tiefe Einsenkung,

1. Die beiden erwähnten Zähne liegen wohl sehon lange in der Strassburger Sammlung, sie waren als Anchilherium Aurelianense bestimmt und trugen den Fundort Buchsweiler. Farbe und Erhaltung lassen nieht daran zweifeln, dass die Fundortsangabe lichtig ist. Um so auffallender erscheint es, dass ScHMPER Anch. Aurelionense yon Lobsann erwähnt. Dic Art ist, so viel ich weiss, daselbst nie vorgekommen. Mém. d. l. Soc. d'kist. nat. de Strasbg. T. V. 1862. 
und dann schwillt das erste Querjoch nochmals an, um den sehr kräftigen und isolirten, vorderen Schmelzkegel der Innenseite zu bilden. Verfolgen wir, von dem hinteren Kegel der Innenseite ausgehend, das zweite Querjoch, so bemerken wir, dass dasselbe in einer scharfen Kante, welche sehr schnell an Höhe abuimmt, nach vorne verläuft. In der Mitte erhebt es sich nochmals ein wenig zu einer kleinen medianen Schmelzspitze. Der Contakt des hinteren Querjoches mit der Aussenwand liegt an deren Basis zwischen dem medianen Wulst und dem hinteren Kegel derselben. Der mediane Wulst der Aussenwand entspricht offenbar morphologisch der Warze vor dem ersten Schmelzkegel. Der Basalwulst ist überall, mit Ausnahme der Innenseite, sehr kräftig. Von oben gesehen sind, mit Weglassung der vorderen Warze, namentlich 5 Schmelzkegel am Zahn bemerkbar, indem der mittlere Kegel des hinteren Querjoches ganz zurücktritt. Die Disposition dieser 5 Kegel, von welchen 3 vorne und 2 hinten liegen, erimuert ganz an den Zahn vou Anthracotherium, bei welchem auch Homologa für die mittlere Schmelzleiste und die vordere Warze zu finden sind.

Die Dimensionen des Zahnes betragen:

$$
\begin{aligned}
& \text { Grösste Länge }=20 \mathrm{~mm} . \\
& \text { Grösste Breite }=25 \mathrm{~mm} . \\
& \text { Grösster Durchmesser }=27 \mathrm{~mm} \text {. } \\
& \text { Länge der Aussenwand }=22 \mathrm{~mm} \text {. } \\
& \text { Unterkieferzähne'. Tf. III, Fig. } 20 .
\end{aligned}
$$

Unterkieferzähne eines Propalaeotherium, welche in einem zertrümmerten Kiefer stecken und wohl zu derselben Art gehören, fanden sich ebenfalls bei Buchsweiler. Der letzte Molar ist $28 \mathrm{~mm}$ lang, während der des Propalaeotherium Isselanum nach

1. Das betreffende Kieferstück mit Zähnen wurde mir freundlicher Weise von Herrn DEECEE in Strassburg aus seiner Sammlung überlassen. 
Rütimerer nur $24 \mathrm{~mm}$ misst. Derselbe hat 3 starke Querjoche, von welchen das hinterste am niedrigsten ist. Ausserdem entsteht durch die Umbiegung des vorderen Querjoches ganz vorn am Zahn noch ein niedriges, unvollständiges Joch. Der auf der Innenseite gebildete Hügel des vorderen Querjoches ist etwas abgenutzt und erscheint breit. Dieser Zalın, welcher mehrfache Sprünge zeigt, liess sich aus dem harten Gestein nicht so vollständig herauslösen, um sich zum Abbilden zu eignen. Der vorletzte Molar misst $20 \mathrm{nmm}$, der gleiche, im Uebrigen sehr ähnliche Zahn von $P$. Isselanum, nur $15 \mathrm{~mm}$. Derselbe ist vierwurzelig und zeigt auf der Krone alle Eigenthümlichkeiten des Propalaeotherium-Zahnes. Die beiden Querjoche sind hinten vollständig gradlinig und stehen nur wenig schräg. Dieselben sind an der Aussenseite spitzwinkelig umgebogen. Das zweite Querjoch entsendet an der Umbiegungsstelle eine hohe diagonale Kante (Verbindungskamm), welche nach dem inneren Hügel des ersten Querjoches verläuft. Letzterer erscheint viel breiter als der innere Hügel des hinteren Querjoches und ist an der Spitze im frischen Zustand doppelt. Die Umbiegung des vorderen Querjoches, welche dem Verbindungskamm entspricht, bildet am vorderen Zahnende ein kleines rudimentäres Querjoch. Der Basalwulst ist, mit Ausuahme der Innenseite, überall vorhanden, er ist kräftig und erhebt sich auf der Hinterseite zu einer starken Spitze, welche bei dem abgebildeten Zahn sehr abgenutzt ist. Diese Spitze, ein Homologon des dritten Talons am letzten Backenzahn, ist gerade für die Unterkiefermolaren der Propalaeotherien sehr charakteristisch. Der dritte Molar ist dem zweiten sehr ähnlich, misst jedoch nur $18 \mathrm{~mm}$. Dann folgen noch 2 zerstörte Praemolaren, deren Länge, soweit sie sich ermitteln lässt, folgende ist : $\mathrm{p}^{1}=15,5 \mathrm{~mm}^{1} ; \mathrm{p}^{2}=14 \mathrm{~mm}$. Der 
zweite Molar des rechten Unterkiefers ist Tf. III, Fig. 20 abgebildet.

Die Unterkieferzähne nehmen nach RütrmeYeR eine vermittelnde Stellung zwischen Lophiodon und Plagiolophus ein; letztere verbinden ihrerseits wieder die Propalaeotherien mit den ächten Palaeotherien. Gaudry fasst die Propalaeotherien mit der nahe verwandten Gruppe Pachynolophus zusammen.

Von den 3 bisher bekannten Propalaeotherium-Arten: dem P. parulum Rïtrim. aus den Bohnerzen von Gösgen (Ob. Eoc. bis Unt. Oligoc.?), P. Issclanum Cuv. sp. von Issel [Dép. de l'Aude] (Mt. Eoc.) und aus den Bohnerzen von Egerkingen (Mt. Eoc. bis Ob. Eoc.?). sowie den1 I'. Argcntonicum Gerv. von Argenton [Dép. de l'Indre] (Mt. Eoc.), kann nur die letztgenannte grösste Art bei der Speciesbestimmung der Buchsweiler Reste in Betracht kommen. Der bei Gaudry (Enchaînem., p. 161, Fig. 213) abgebildete linke Oberkieferzahn, welchen ich wegen seiner ziemlich quadratischen Form für den zweitletzten Molaren halte, stimmt mit dem betreffenden Zahn von Buchsweiler gut iiberein und ist nur eine Spur grösser. Gervais ${ }^{1}$ bildet keine Reste von Prop. Argentonicum ab und verweist auf die Unterkieferzähne, die Cuvien in seinen Oss. foss., p. 498, t. IV als "Palaeotherium d'Orléans trouvé à Argenton " erwähnt. Blainvilue bildet in der Ostéographie einige Zähne nebst einem Tibia-Kopf, einem Astragalus, Calcaneus und einem Cuneiforme von Propalaeotherium Argentonicum auf Pl. 8 bei den Palaeotherien ab. Er bezeichnet alle diese Reste auf pg. 189 als "Palaeothcrium? mcdium". Es muss noch dahingestellt bleiben, ob die Extremitätenknochen in der That zu den betreffenden Zähnen gehören. Der Astragalus ist im Ganzen lophiodonartig,

1. P. Gervas, Paléontologie et Zoologie franģaise. Animanx vétébrés. Paris 1859, lg. 116. 
worauf schon GERvaIs aufmerksam machte. Die abgebildeten Zähne sind ziemlich stark abgenutzt; es sind die 2 letzten Molaren des Unterkiefers und, wie es scheint, die entsprechenden Zähne aus dem Oberkiefer. Diese Zähne stimmen gut mit denjenigen von Buchsweiler überein; leider ist jedoch die Abkauung bei den Zähnen von Argenton zu weit vorgeschritten und die Abbildung zu klein und nicht scharf genug, um geringere Details vergleichen zu können.

Ich möchte um so mehr auf das Vorkommen von Propalaeotherium bei $\mathrm{Buchsweiler} \mathrm{hinweisen,} \mathrm{da} \mathrm{wir} \mathrm{noch} \mathrm{so} \mathrm{wenig}$ von dieser interessanten Gruppe wissen. Von dem Gliederbau wissen wir fast nichts, und das wenige was uns von der Bezahnung bekannt ist, erweckt mit Recht unsere Wissbegierde. Nach Kowadevsкx's Ansicht sind die Propalaeotherien berufen, später noch eine grössere Rolle in der Palaeontologie zu spielen, indem ihre Zähne einen vermittelnden Typus zwischen den Lophiodonten und Palaeotherien innehalten und zugleich an die fünflobigen Molaren der jüngeren Paarhufer erinnerı.

Dieser vermittelnde Typus findet sich auch in der That in sehr alten Schichten mit der Lopliodon-Fauna zusammen. Die einzigen Fundpunkte, wo derselbe mit ächten Palaeotherien zusammen auftritt, sind die Bohnerze. Bei Egerkingen Propal. Isselanum mit 2 Palaeotherien; bei Ob. Gösgen Prop. parvulum mit 5 Palaeotherien. Prop. Argentonicum fehlt meines Wissens in den Bohnerzen und findet sich nur bei Argenton und Buchsweiler.

\section{? Anoplotherium sp.}

Zwei Molaren in einem Kieferbruchstück von einer kleinen Art sind in Buainvilite's Ostéographie auf PI. VI, Bd. IV 
abgebildet. Ich möchte einstweilen noch das Vorkommen eines Anoplotherium bei Buchsweiler bezweifeln.

\section{? Arctomys sp.}

Ein Unterkieferbruchstück, welches von Buchsweiler stammen soll, ist in Blainville's Ostéogr. IV. EE. P1. 11. (publication posthume) abgebildet. Die Beschreibung fehlt, aber ein flichtiger Hinweis darauf findet sich T. IV. CC., pag. 187.

\section{Cebochoems anceps GERV.}

Tf. IV, Fig. 14, 15.

Derselbe wird von Schimper in einer kurzen Notiz von $\mathrm{Buchsw}$ eiler erwähnt ${ }^{1}$. Die Angabe stützt sich vielleicht unter anderem auf das kleine Backenzähnchen, welches mir vorliegt und welches zu dieser merkwürdigen Gattung gehört. Dasselbe entstammt einem linken Unterkiefer und dürfte der zweitletzte Molar sein. Das Zähnchen misst beinahe $7 \mathrm{~mm}$ in der Länge und $5,5 \mathrm{~mm}$ in der grössten Breite. Es besitzt 2 lange Wurzeln, während die Oberkieferzähne von $C c b$. anceps merkwürdiger Weise 4 Wurzeln haben und dadurch von den dreiwurzeligen Molaren der Affen und Hufthiere abweichen. Die Schmelzkrone zeigt 4 mïssig abgekaute Kegel von Bunodontem-Habitus. Da ich keine Abbildung eines Unterkiefers von Ceb. anceps finden lonnte, so muss ich mich in der Speciesbestimmung auf Scirimper verlassen. Ein Unterkiefer von Ceboch. minor findet sich bei GaUdRx (Enchaînem., pg. 231, Fig. 305) abgebildet, er stammt

1. Mém. de la soc. dhist, nat. de strasbg., T. V, pg. 15 (Résumé). Auf die gleiche Notiz wurde schon bei $\boldsymbol{L}$. Buxovillanum verwiesen. 
aus den Phosphoriten von Quercy. Das von Duvernor mit grosser Bestimmtheit zu den Suiden ${ }^{1}$ gestellte Unterkieferstück mit den beiden letzten Molaren wird, wie dies auch Schimper erklärt hat, wohl zu Ccbochocrus gehören. Ich kenne das Original nicht aus Autopsie, da es sich nicht mehr in der Strassburger Sammlung befindet. Ceb. anceps fand sich ausserdem in den Ligniten von Pérreal bei Apt, von welcher Lokalität GrrvaIs ${ }^{2}$ einen Oberkiefer abgebildet hat. Die Gattung Cebochoerus, zu den Bunotherien gehörig, ist auf das Eocän und Unteroligocän beschränkt; über den Skelettbau ist nichts weiter bekannt.

Schildkröten. Ein kleines Panzerbruchstück ciner grossen Art liegt mir aus dem Buchsweiler Süsswasserkalk vor ${ }^{3}$. Schildkrötenreste sind ferner aus dem Eocän des Rheinthales von Neuburg (Unt.-Els.) und von Ubstadt in Baden bekannt.

Kleine Reptilzähne von linsenförmigem Querschnitt mit scharfen Seitenkanten und zuweilen gefältelter Spitze findet man ab und zu bei Buchsweiler. Sie dürften verschiedenen Thieren angehören: so erimert Fig. 21a, Tf. III durch seine Fältelung an Lacertilier; Fig. 216 ähnelt mehr gewissen Krokodilzähnen. Krokodilzähne haben sich auch bei Ubstadt gefunden, von wo ferner noch Fischschuppen erwähnt werden.

1. Mém. de la Soc. du musée d'hist, nat. de Strasbg., pg. 9. Die von Duvernoy gegebene etwas kleine Abbildurg ist bei Blanville reproduzirt und erwăhnt T. 4, pg. 186. Der letzte Unt.-Kiefer-HoLar ist mit einem hinteren Talon versehen wie bei Ceb. minor.

2. Gervas, Paléontol. française. Anim. vertébrés, 1859, Pl. 35, Fig. 3, pg. 198.

3. In den Mém. de la soc. d'hist. nat. de strasbg. erwähnt Schumper T. II, pg. 15 "un fragment de carapace de tortue provenant du calcaire de Buchsweiler". 


\title{
B. Mollusken.
}

\section{Paludina (Vivipara) IIammeri Defrance 1825.}

\author{
Tf. I, Fig. $13 a, b, c$.
}

(Sandberger, Land. Sw. Conch. 1875, pg. 224, Tf. XIII, Fig. 6-6b. Defrance, Dict. d. scien. nat., XXXVII, pg. 306, etc.)

Diese Paludina ist die grösste bei Buchsweiler vorkommende Art; sie erreicht zuweilen eine Höhe von beinahe $40 \mathrm{~mm}$ und eine entsprechende Breite von $30 \mathrm{~mm}$. Sie ist ungemein häufig im Süsswasserkalk, selte» in den darunter liegenden grünen Mergeln. Das dickschalige Gehäuse ist schwach genabelt, besitzt eine eiförmige, oben zugespitzte Mündung, nicht sehr tiefe Nähte und 6 mässig gewölbte Umgänge, deren letzter fast eben so hoch ist wie die vorhergehenden zusammen. Die aus zahlreichen, ziemlich gleichmässigen Längskielen bestehende Sculptur tritt nur auf den obersten Windungen und auf dem letzten Umgang, kurz vor der Mündung, deutlich hervor. Am schärfsten ist dieselbe jedoch auf der Unterseite, rings um den Nabel, ausgeprägt. Ausserdem sind feine ungleichmässige Anwachsstreifen vorhanden, welche die Längskiele durchlkreuzen und nur bei älteren Individuen, auf dem letzten Theil der untersten Windung, kräftiger werden. Die Art ist nur von $\mathrm{Buchs-}$ weiler bekannt, von welchem Fundorte mir auch ein junges, linksgewundenes Stück, als interessanter teratologischer Fall, vorliegt. 
Paludina (Vivipara) Orbignyana Deshayes 1864-66.

\author{
Tf. I, Fig. $12 a, b, e$.
}

(Deshayes, G. P., Desc.d.Anim. s. vert. du bass. de Paris, 1866, II, pg. 48I, pl. 32, Fig. 20, 21, pl. 33, Fig. 1, 2. - Sandberger, Land. Sw. C., pg. 224, Tf. XiI, Fig. $7-7$ a.)

Diese Art steht der vorigen recht nahe, so dass ich mich hier am besten darauf beschränke, die wichtigsten Unterscheidungsmerkmale anzuführen. Das gleichfalls sehr dickschalige Gehäuse von $P$. Orbignyana ist höher, spitzer kegelförmig, die letzte Windung ist relativ niedriger, die Ungänge sind flacher und die Mündung ist ein wenig runder, als bei P. Hammeri. Die Sculptur zeigt sich in gleicher Weise wie bei der vorhergehenden Species, nur ist dieselbe viel schwächer, so dass die Schale fast glatt aussieht. In der Grösse bleibt P. Orbignyana gegen $P$. Hammeri zurück; sie erreicht jedoch immerhin bis zu $35 \mathrm{~mm}$ Höhe und $24 \mathrm{~mm}$ Breite. Die Art ist im Süsswasserkalk von Buchsweiler nicht gerade häufig, während sie bei Ubstadt in zahlreichen Steinkernen vorkommt, und SANDberger von dort sogar ein linksgewundenes Exemplar erwähnt. In Frankreich findet sie sich bei Longpont im oberen Grobkalk, ferner in einigen eocänen Süsswąsserkalken am Südrande des Pariser Beckens und im bassin de l'Agoût.

Euchilus Deschiensianum Deshayes sp. 1864-66.

Tf. I, Fig. $11 a-e$.

(Deshayes [l. c.], pg. 492, pl. 33, Fig. 19-21.-Sandberger [l. c.], pg. 225, Tf. XIII, Fig. $8-8 c$.)

Diese häufigste Versteinerung bei Buchsweiler gehört zu der ausgestorbenen Gattung Euchilus, welche in den recenten 
Gattungen Blanfordia (Australien) und Emmericia (Dalmatien) ilır nächstes Analogon hat. Sie ist ziemlich variabel, so dass ihr kegelförmiges Gehäuse bald spitzer, bald stumpfer erscheint. Die grössten Stücke erreichen etwas über $10 \mathrm{~mm}$ Länge und $6 \mathrm{~mm}$ Breite; kleinere, ausgewachsene Exemplare messen hingegen nur $7 \mathrm{~mm}$ (l.) und $4 \mathrm{~mm}$ (b.). Die Schale ist dick und glatt. Es sind 5-6 Umgänge vorhanden. Der Nabel ist schmal und der Mundrand stark wulstig verdickt. In der Jugend werden von Euchilus öfters Ansätze zur Mündung gebildet, welche beim Weiterwaclısen als Wülste zurückbleiben und namentlich an den Steinkernen als charakteristische Furchen auffallen (Fig. 11 d). Ein Deckel ist bisher bei Buchsweiler noch nicht beobachtet worden, man kennt dieselben jedoch von St. Parres. E. Deschiensianum ist ziemlich verbreitet und findet sich, ausser im Süsswasserkalk unserer Lokalität, vereinzelt bei Ubstadt, ferner bei Longpont, St. Parres und Epermailles.

\section{Hydrobia Dauendorfensis n. sp.}

Tf. III, Fig. 2.

In den grauen, vitriolreichen Mergeln von Dauendorf im Unter-Elsass fand sich nicht gerade häufig eine kleine Hydrobie, welche ich mit keiner bekannten Species zu identifiziren vermag. Das porcellanweisse, glänzende, feingestreifte Gehäuse hat 6 Umgänge, ziemlich tiefe Nähte und einen deutlichen Nabelritz; es ist etwa $3 \mathrm{~mm}$ lang und $1,5 \mathrm{~mm}$. breit. Die Mündung ist oval, steht ziemlich grade, und ist in der oberen Ecke stark zugerundet. Der Mundsaum ist niclit umgeschlagen. Die nächststehende lebende Form, welche unserer Art fast bis zur Identität gleicht, ist, wie ich mich in der Sammlung des 
Herrn Dr. BötTGer überzeugen konnte, Hydrobia Simsoniana Beddon von Brighton bei Hobart-town (Tasmanien). Die D a u e n orfer Art ist etwas spitzer und die Umgänge sind etwas runder als bei der recenten Form. Eine jungfossile Art Hydrobia nitida M. F. von Barren-Island in der Bass-Strasse steht dieser Art gleichfalls nahe. Von unseren fossilen Formen lässt sich noch am ersten die gedrungenere Hydrobia bavarica SAND. aus dem Mittelmiocän von Leipheim mit Hydrobia Dauendorfensis vergleichen.

\section{Hydrobia juv.? ef. Websteri MorRIs.}

Tf. III, Fig. 1.

(Sandberger [l. c.], pg. 187. - Deshayes [l. c.], 11, pg. 500, pl. 34, Fig. 32-34. - Morris, Quart. Journ. of the geol. soc., X, pg. 161, Tf. II, Fig. 22.)

Eine andere Hydrobie aus den Dauendorfer Mergeln, welche an Hydrobia Websteri MorR. aus dem englischen und französischen Unter-Eocän erinnert, liegt mir in mehreren Stücken vor. Das glänzende, feingestreifte Gehäuse hat eine spitzkegelförmige Gestalt, flache Nähte und einen deutlichen Nabelritz. Der rechte Mündungsrand bildet in seiner unteren Partie eine gerundete Ecke. Das grösste Exemplar misst $3,2 \mathrm{~mm}$ in der Länge, $1,5 \mathrm{~mm}$ in der Breite und zeigt dabei 7 Umgänge. Ich habe die vorliegenden Exemplare, welche wohl zur Gruppe der Hydrobia Websteri gehören und vielleicht als neue Form aufzufassen sind, nicht mit Sicherheit bestimmen können; einerseits, da ich $H$. Websteri nur aus der Abbildung kenne, andererseits, da Zweifel darüber bestehen können, ob die D a u endorfer Stücke vollständig ausgewachsen sind.

Steinkerne von Hydrobien, die wegen mangelhaften Er- 
haltungszustandes keine nähere Bestinımung zulassen, aber offenbar verschiedemen Arten angehören, finden sich in den Süsswasserkalken von $\mathrm{Buchsweiler}$, vom $\mathrm{Bischenberg}$ und von Morschweiler im Unter-Elsass. Dieselben sind an den beiden letztgenannten Orten sogar häufig. Taf. I, 10 stammt von Buchsweiler, Fig. 9 kommt am Bischenberg und anderen Fundpunkten vor.

Planorbis pseudammonius SchLотннеim sp. 1820.

Tf. II, Fig. 9-13.

(Schlothнim, Petrefactenkunde, I, pg. 101. - SAndberger [l. c.], pg. 226, Tf. XIII, Fig. 10-12; etc.)

Derselbe ist einer der geologisch wichtigsten Planorben, zumal da er sich leicht durch seine grosse Zahl von Windungen und seine Form von den bei uns vorkommenden jüngeren Formen unterscheidet. Das Gehäuse ist oben ziemlich flach und nur in der Mitte ein wenig eingesenkt, an den Seiten gerundet und auf der Unterseite stärker vertieft. Er erreicht zuweilen einen Durchmesser von beinahe $40 \mathrm{~mm}$, während die gewöhnliche Grösse nur $25 \mathrm{~mm}$ beträgt. Es sind 7 mit feinen Anwachsstreifen versehene Umgänge vorhanden. Planorbis pseudammonius ist ein Leitfossil für mitteleocäne Süsswasserschichten (nach SANDberger für Süsswasserbildungen vom Alter des Grobkalkes). Er ist ungemein häufig an vielen Stellen in Frankreich; am Oberrhein findet er sich im Unter-Elsass: bei Buchsweiler im Kalk und in den grünen Mergeln, bei Bitschhofen, Dauendorf, Neuburg und am Bischenberg bei Oberehnheim, in Baden bei Ubstadt, im Canton Solothurn bei Hobel. Form. excavata n. f. (Tf.II, Fig. 10). Als solche kann man die weitläufig aufgewundenen, dicken, auf 
der Unterseite stark ausgehöhlten Exemplare bezeichnen. Obwoll diese Form im Extrem recht verschieden aussieht, so sind doch alle Uebergänge zum flacheren Typus vorhanden".

Var. angigyra n. v. (If. II, Fig. 12). Diese Varietät bildet das entgegengesetzte Extrem der vorigen Form, weicht aber in noch höherem Grade von dem Typus ab. Es sind kleine, dünne und selır eng aufgewundene Stücke, welche auf der Unterseite nur wenig vertieft sind. In Bezug auf die enge Aufrollung erinnert v. angigyra an dell $P$. pseudorotundatus Maтнв́non ${ }^{2}$, ist aber schon dadurch leicht zu unterscheiden, dass bei ihr die Windungen breiter als hoch sind. Die Steinkerne sind schon in der Jugend von der typischen Form des P. pseudammonius unterschieden. Es mag sein, dass man diese Varietät nach späteren besseren Funden einmal zum Rang einer eigenen Art erheben wird. Einstweilen ziehe ich vor, dies noch nicht zu thun, da mir nur Steinkerne vorliegen, und es schwer sein dürfte, dieselben immer sicher vom Typus zu trennen.

Var. Leymeriei Desh. (Tf. II, Fig. 13). Diese von Deshayes als Art, von Sandeerger als Varietät angesehene Form umfasst, im Gegensatz zu den typisclien glatten, die mit Spiralsculptur versehenen Exemplare. Die Spiralstreifen sind meistens recht deutlich und bilden, indem sie sich mit den Anwachsstreifen kreuzen, eine zierliche Gitterung. Die Streifung kann in

1. Das was Noulet als P. Castrensis bezeichnet (Mem. sur les coq. foss. des lerrains d'eau douce du S.-O. de la France, 1868, pg. 73), und was SANobengen als eine Varietät von $P$. pseudammonius auffasst, deckt sich nicht mit der obengenannten Form. Ausscrdem stimmen die verschiedenen Beschreibungen von P. Castrensis durchaus nicht überein. Weil ich nichts derart aus dcm rheinischen Eocän kenne, wurde die Form füglich weggelassen.

2. Pt.pseudorotundalus Matil., 1843, wulde von Sandberger, L. Sw. C., pg. 220 und 226, mit $P t$. pseudammonius Sсн. sp. vereinigt. Neuerdings wurde derselbe von MAтHÉRon wiederum als selbständige Species abgebildet. Recherches paléontologiques dans le Midi de la France. Marseille 1879. XV. Part., PI. 0-1, Fig. 12. 
verschieden starkem Masse ausgebildet sein, auch obliterirt sie bei sehr grossen Exemplaren auf der letzten Windung. Die Sculptur ist nicht an eine bestimmte Gestalt gebunden und findet sich sowohl bei der f. excavata als beim Typus. Au Steinkernen ist natürlich keine Unterscheidung möglich. Diese Sculpturvarietät ist sehr verbreitet, ich kenne dieselbe aus unserem Gebiete von Buchsweiler, vom Bischenberg und von Hobel.

Planorbis (Segmentina) Chertieri Deshayes 1864-66.

Tf. II, Fig. $14 a, b, c$.

(Deshayes [l. c.], II, pg. 753, pl. 46, Fig. 5-8. - Sandberger [l. c.], pg. 226, Tf. XIII, Fig. 9.)

Denselben sammelte ich in zahlreicheu, schönen Exemplaren in einem ziemlich hoch gelegenen Aufschluss NO vom Bastberggipfel in weichen kreidigen Kalkstücken. Im harten Kalke des tiefer gelegenen Steinbruches ist er beträchtlich seltener. Das Gehäuse ist oben gewölbt, in der Mitte nur ein wenig eingesenkt, unten abgeflacht und weit genabelt. Von einem Kiel ist nichts zu sehen. Die Abdrücke zeigen sehr feine, unregelmässige Anwachslinien. Der Durchmesser beträgt bis zu $13 \mathrm{~mm}$, die Höhe meist $3 \mathrm{~mm}$ und der letzte Umgang nimmt über $1 / 3$ des Gesammtdurchmessers ein. Unter den vielen Exemplaren, welche ich gesehen habe, fielen mir einige kleine, abrveichende Steinkerne aus dem harten Kalk auf. Dieselben sind dünner als gewöhnlich und sind an den Seiten etwas spitzer zugerundet. Ich glaube dennoch, dass sie zu derselben Art gehören, möchte aber darauf aufmerksam machen. P. Chertieri ist im französischen Eocän ziemlich verbreitet, in unserem Gebiet trifft man ihn ausser bei Buchsweiler, bei Ubstadt, wo er sehr 
selten ist; etwas häufiger findet er sich bei Bernhardsweiler, und von Morschweiler besitze ich fragliche Reste.

\section{Limnea olivula Rours 1868.}

Tf. II, Fig. $8 a-d$.

(Sandberger [1. c.], pg. 228, Tf. XIII, Fig. 14; etc.)

Eine kleine, etwa $10 \mathrm{~mm}$ lange, leicht kenntliche Art. Das bauchige, oben kurz zugespitzte Gehäuse hat 5 Umgänge, wovon die Höhe des letzten mehr als $1 / 2$ der totalen Länge ausmacht. Die Nähte sind tief, die sehr dünne Schale besass deutliche Anwachsstreifen, war öfters uuregelmässig eingeschnürt und am unteren Theil der kurzeiförmigen Mündung etwas umgeschlagen. $L$. olivula ist bei Buchsweiler ziemlich selten; das bauchige Exemplar (Tf. II. Fig. a) stammt von diesem Fundpunkte; es kommen aber grade hier auch schlankere Formen vor, die bei mangelhafter Erhaltung nicht sicher bestimmbar sind. Häufiger ist die Art am Bischenberg, woselbst sie sich am nördlichen Abhang nicht weit von "Les Récollets" findet.

\section{Limner Michelini DESH. 1864-66.}

Tf. I, Fig. $7 a-d$.

(Deshayes [l. c.], II, pg. 718, pl. 45, Fig. 9, 10. - Sandberger [I. c.], pg. 227, Tf. XIII, Fig. 13.)

Sobald man es mit ausgewachsenen, grossen Individuen $\mathrm{zu}$ thun hat, ist diese Limneen-Art mit keiner anderen $\mathrm{zu}$ verwechseln. Sie zeichnet sich aus durch ihre grosse Zahl von flachen Windungen $(7-8)$ und durch ihren relativ kurzen, 
runden, mehr aufgeblasenen letzten Umgang. Die Grösse, welche sie erreicht, beträgt bisweilen $30 \mathrm{~mm}$. Anders verhält es sich, wenn man die Steinkerne jüngerer Individuen betrachtet, die Variabilität ist hier eine ungemein grosse, so dass man oft über ihre Zugehörigkeit zu dieser Species im Zweifel sein kann. In Anbetracht, dass die Variabilität der lebenden Limneen eine so ausserordentlich grosse ist, und dass wir es in $\mathrm{Buchsweiler}$ gewöhnlich nur mit Steinkernen zu thun haben, hielt ich es für rathsam, keine Arten aus der Formenmannigfaltigkeit auszuscheiden. Auch lassen sich bei den Steinkernen Uebergangsreihen zwischen verschiedenen Formen beobachten. L. Michelini findet sich ausser in Frankreich bei Longpont, St. Parres, Castres etc., bei Buchsweiler ziemlich häufig, auch dürften Steinkerne vom Bischenberg hierher gehören.

\section{Limmea sp. ined.}

Tf. I, Fig. 8 a, $b, c$.

Die abgebildeten Fragmente gehören nicht zum Formenkreis der vorigen Species. Sie sind durch ihre schlanke Gestalt, ihre lange, schmale Mündung und ihre oft wellig vertiefte oder gegitterte Schale unterschieden. Das mir vorliegende Material ist zu ungenügend, um eine genauere Fixirung dieser Art zu erlauben. Buchsweiler.

\section{Succinea (Brachyspira) palliolum Rous 1868.}

Tf. II, Fig. $19 a-c$.

(Sandberger [l. c.], pg. 232, Tf. XIII, Fig. 23; etc.)

Diese seltene nur von Buchsweiler bekannte Art ist ausgezeichnet durch ihre breite, flache Gestalt und ihre äusserst 
kurze Spitze, welche nur $1 / 6$ der ganzen Länge ausmacht. Das grösste meiner Exemplare hat fast 3 Umgänge und misst in der Länge $11 \mathrm{~mm}$, in der Breite 6 und in der Dicke $4,3 \mathrm{mnn}$. Die Mündung ist breit eiförmig und oben zugespitzt. Die dünne Schale zeigt Anwachsstreifen und wird im Alter nach SuccineenArt öfters etwas runzelig gewellt.

\section{Promacellina Sandberger.}

Die von Buchsweiler stammende Parmaeellina vitrinaeformis SANDB. wurde von Bronn zu den Vitrinen gestellt. SANDBERger erkannte diese Bestimmung; wegen der Dickschaligkeit des Gehäuses, als irrig und indem er den obigen Gattungsnamen schuf, wies er derselben einstweilen einen Platz im System zwischen "Peltella und Testacella" an".

Nach einigen schönen Exemplaren, welche ich neuerdings gesammelt habe, soll es versucht werden, diese fossile Nacktschnecke soweit wie möglich zu charakterisiren.

Das sehr dickschalige, äusserst fein gestreifte Gehäuse gleicht in seiner Form, namentlich von oben gesehen, ganz den Daudebardien. Jugendwindungen und späteres Anwachsgewinde sind auf der Schale nicht zu unterscheiden wie bei $P$. calyeulata SBr. Auf der Unterseite weicht Parmaeellina von Daudebardia ab, die sehr grosse gerundete Mündung ist von einem verdickten Rande umgeben, welcher sich in dex oberen Ecke deutlich zahnartig erhebt. Die Dickschaligkeit hat Parmaeellina mit Testacella gemeinsam. Die Steinkerne lassen auf dem unteren Theil des letzten Umgangs streifige Höckerchen und

1. Das Genus Testacella Gov. gehört jetzt zur Familie der Testacellidae, das Gen. Peltella Webr. und V. Bes. (= Parmacella Guv.) zur Familie der Bulimulidae. und schliesslich Peltella Adaws (= Mfariaella GrAy.) zur Familie der Vitrinen; wir dürften uns hier schwer zurecht finden. 
Grübchen erkennen, welche auf die rauhe und körnige Beschaffen- • heit der immeren Schale hindeuten. Parmacellina scheint mir zur Familie der Testacellidae zu gehören und würde ihren Platz im System zwischen den Gattungen Daudebardia Hartm. und Testacella Cuv. einnehmen.

Parmacellina vitrinceformis SANDBERger 1870-75.

Tf. II, Fig. $20 a-d$. (Sandberger [1. c.], pg. 232, Tf. XIII, Fig. 24.)

Bisher noch die einzige Art der Gattung, ist bei Buchsweiler ziemlich selten. Das kleine, dickschalige Gehäuse wird bis zu $8 \mathrm{~mm}$ lang und $5 \mathrm{~mm}$ breit, hat $1^{\frac{1}{2}}$. Umgänge und eine elliptische unten etwas eckige Gestalt. Die innere Schalenschicht ist meist durch organische Substanz braun gefärbt, welche Farbe auch äusserlich etwas durchscheint. Die übrigen Merkmale finden sich in der Gattungs-Diagnose.

\section{Oleacina (Boltenia) teres Rovis sp. 1868.}

Tf. I, Fig. $4 a-f$.

(Sandberger [1. c.]; pg. 232, Tf. Xill, Fig. 26; etc.)

Eine im Buchsweiler-Kalk seltene und noch nicht vollständig gekannte Art, welche sich in der Form der kleineren Boltenia Sandbergeri Tном. sp. aus dem Miocän von Hoch heim am meisten nähert. Das Gehäuse ist lang und schmal, die Spitze noch unbekannt, die Mündung oben eng und spitz, unten erweitert und gerundet. Die Spindel ist nicht völlig rund, sondern vorne schwach kantig und verläuft ziemlich grade. Die Nähte sind doppelt und unterhalb derselben treten die ungleichen 
Anwachslinien, welche die Sculptur bilden, am schärfsten hervor, so dass auch hier an der Naht das für die Oleacinen so charakteristische, faltig zusammengefasste Aussehen zu Stande kommt. Da die Spitze bei den mir vorliegenden 7 Stücken fehlt, so lässt sich keine Angabe über die Höhe des Gehäuses machen. Die Breite des grössten Exemplares beträgt an der Mündung $6 \mathrm{~mm}$, die Mündungslänge $8,5 \mathrm{~mm}$ und der vorletzte Umgang misst über $1 / 3$ des letzten Umgangs. $B$. teres ist von keinem anderen Fundpunkte bekannt. Saxdberger erwähnt (L. Sw. C. d. Vorw., p. 327) aus dem Brunnstatter Kalk eine grosse schlanke Oleacina (resp. Boltenia), welche er mit $B$. teres vergleicht und glaubt, dass es Merian's Limnea polita sp. ined. sei. Die ziemlich guten Exemplare, welche mir von Brunnstatt vorliegen, gehören in der That einer schlanken Limnea an (cf. pg. 79).

Oleacina (Glandina) Condieri Desh. sp. 1864-1866.

Tf. I, Fig. $2 a-e$.

(Deshayes [I. c.], II, pg. 836, pl. 53, Fig. 4-6. - Sandberger [l. c.], pg. 233, Tf. XIII, Fig. 25; etc.)

Die Glandinen gehören trotz ihrer weiten Verbreitung in der Regel zu den sehr seltenen Erscheinungen; anders verhält sich dies in der Buchsweiler Fauna, wo Glandina Cordieri sogar als ziemlich häufig gelten kann. Im Calcaire de St. Ouen und in den Sables moyens kommt dieselbe Art hingegen sehr selten vor. Das dünnschalige, eichelförmige Gehäuse ist oben in eine kurze Spitze ausgezogen und hat 6 Umgänge. Dasselbe misst in der Länge meist $37 \mathrm{~mm}$, wälnrend die grösste Breite 16-18 mm beträgt. Die Mündungslänge ist $23 \mathrm{~mm}$ und die Höhe des letzten Umgangs beläuft sich auf $3 / 4$ der gesammten 
Höhe. Das Embryoualende ist stumpf, zitzenförmig und glatt, während die ïbrigen Windungen eine charakteristische Sculptur aufweisen. Die sehr deutlichen unregelmässigen Anwachslinien werden von feinen, dicht stehenden, öfters aufgelösten, welligen Längslinien durchsetzt. An den Durchschnittspunkten bilden sich kleine Knötchen, so dass die ganze Oberfläche unter der Loupe ein körniges, gitterartiges Aussehen gewinnt ${ }^{1}$. Die Spindel ist mässig breit, sanft gerundet und schräg abgeschnitten. Die Mündung ist schmal-eiförmig, oben sehr zugespitzt, der rechte Mundrand ist kaum gewölbt und erscheint etwas angedrückt.

Var. elongata n. var. Tf. I, Fig. 6 . Als solche möchte ich eine Form von dem Typus abtrennen, welche mir in 3 Exemplaren, aber in keinem ganz untadeligen Stück vorliegt. Diese Form ist grösser und schlanker als der Typus. Die Breite beträgt $18 \mathrm{~mm}$, die restaurirte Höhe würde circa $4,5 \mathrm{~mm}$ ausmachen. In der Sculptur ist keine Abweichung vorhanden.

$G$. Cordieri ist nahe verwandt mit einer in Mittel-Amerika lebenden Species G. rosea Fúr, wie dies schon Deshayes elkannt und SANDBERGER bestätigt hat.

\section{Oleacina (Glandina) Rhenana n. sp.}

Tf. I, Fig. $1 a, b, c$.

Gl. Rhenana ist durch ihre weit schlankere, mehr kegelförmige Gestalt von G. Cordieri gut unterschieden. Die Maassverhältnisse sind folgende: Die Länge beträgt $38 \mathrm{~mm}$, die grösste

1. Sowohl die schematische Abbildung der Sculptur bei Deshayes (Desc. des Animaux sans vert. découverts dans le bass. de Paris, T. II, PI. 53, Fig. 3), als auch bei SAndberger (I. Sw. C., Taf. XIII, Fig. 256), welche recht verschieden von einander sind, geben den Sachverhalt nicht ganz richtig wieder. 
Breite 14,5 $\mathrm{mm}$, die Mündungslänge $22 \mathrm{~mm}$, die Höhe des letzten Umgangs $26 \mathrm{~mm}$. Die Anzahl der Windungen beläuft sich auf $6 \frac{1}{2}$. Die Form des Gehäuses ist sehr spitz-eiförmig und das Embryonalende ist nicht zitzenförmig wie bei Glandina Cordieri, sondern stumpf-convex. Das Embryonalende ist glatt, die übrigen Umgänge zeigen unregelmässige, gebogene Anwachsstreifen und eine gitterförmige schwach körnige Sculptur wie bei G. Cordieri, welcher sie auch in Bezug auf die Spindelfalte gleicht. Die doppelten Nähte sind sehr wenig vertieft. G. Rhenana ist bei Buchsweiler sehr selten.

\section{Oleacina (Glandina) Deecleei n. sp.}

Tf. I, Fig. 3, $a, b$.

Die Gestalt des Gehäuses dieser kleinen Glandine ist schmal spindelförmig, die Spitze ist kegelförmig gerundet, die untere Partie erscheint schmal elliptisch. Die Länge beträgt 14,5 mm, die grösste Breite 5,5 mm, die Mündungslänge $8 \mathrm{~mm}$ und die Höhe der letzten Windung 9,5 $\mathrm{mm}$. Es sind $5 \mathrm{Um}-$ gänge vorhanden, welche durch feine gebogene Anwachsstreifen verziert sind; diese Anwachsstreifen treten unter der schwach vertieften, doppelten Naht am stärksten hervor. Ueberaus feine, dichtstehende Querlinien durchkreuzen die Anwachsstreifen. Die Spindel ist kurz, ziemlich dick und kaum gebogen. G. Deeekei, welche bei Buchsweiler nicht häufig ist, zeichnet sich durch ihre geringe Grösse und schmale Figur vor den anderen Arten dieses Fundpunktes aus. In der Gestalt gleicht sie einigermassen der miocänell G. rugulosa SAND., welche jedoch grösser und viel stärker sculpturirt ist. 
Cionella (Zua) formicina Rouss sp. 1868.

Tf. I, Fig. $5 a, b, c$.

(Sandberger [l. c.], pg. 230, Tf. XIII, Fig. 18; etc.)

Dieser älteste Vertreter des Genus Cionella, den wir wohl der Section Zua (Leach) einreihen dürfen, nähert sich in Form und Grösse unserer recenten Zua lubrica MüLt. sp. (in der Grösse der var. exigua MENKE). Die häufige kleine Schnecke ist meist 4,5 $\mathrm{mm}$ lang, gegen $2 \mathrm{~mm}$ breit und hat 7 Ungänge, welche durch ziemlich flache Nähte getrennt sind und wovon die Höhe der letzten Windung etwa der Breite gleichlrommt. Die glatte Schale ist dünn und an der zahnlosen, kurzen Mündung verdickt, was sich an Steinkernen als schwache Einschnürung am Mundrande bemerkbar macht. In der Länge und Dicke variiren die Exemplare ein wenig, sind aber stets leicht kenntlich. Die Form der Mündung ist runder, und die Nähte sind weniger tief als bei unserer recenten Zua lubrica. Die Art ist nur von Buchsweiler bekannt.

\section{Azeca Böttgeri n. sp.}

Tf. I, Fig. $6 a-d$.

Schon bei oberflächlicher Betrachtung des grossen CionellenMaterials, welches ich vereinigt hatte, fand es sich, dass manche Individuen durch ihre äussere Form abwichen. Die nähere Untersuchung ergab, dass dieselben dem letzten Umgang und der bezahnten Mündung nach zu Azeca gehören. Das Gehäuse dieser ältesten Azeca ist $5 \mathrm{~mm}$ lang, 2,5 $\mathrm{mm}$ breit, hat $7 \mathrm{Um}$ gänge, sehr flache Nähte und eine gerundet elliptische Gestalt. Die Spitze ist convex-conisch. Der letzte Umgang nimmt etwas 
mehr als $1 / 3$ der ganzen Höhe ein und ist sehr wenig gewölbt. Die Mündung ist schief, schmal, besitzt einen verdickten Rand und 2 grosse, lamellenartige, constante Zähne. Ein grosser Zahn steht an der oberen Partie der inneren Mundseite (Mündungswand); ihm gegenüber etwas tiefer auf dem äusseren oder rechten Mundsaum befindet sich die zweite starke Zahnlamelle. Azeca Böttgeri ist weniger spitz, mehr cylindrisch gerundet, etwas grösser und hat noch flachere Nähte als Cionella formicina; auch sind bei der letzteren die Umgänge in einer steileren Spirale aufgewunden, was dadurch hervortritt, dass die Nähte derselben schiefer stehen als bei $A$. Böttgeri. Areca-Arten waren bisher nur aus den jüngeren Tertiärschichten bekannt. Die Gattung reicht bis in die Jetztzeit und ist allsschliesslich europäisch. A. (Azecastrum) tridens PuLt. (= A. Mentieana Pfeiff.), wohl die nächste lebende Verwandte, findet sich an einigen Punkten Deutschlands als Seltenheit. Dieselbe ist grösser, spitzer und besitzt mehr Zähne als unsere Art. Von den fossilen Arten dürfte $A$. loxostoma KL. aus dem Unt. Miocälı von Mörsingen und Leissacker bei Regensburg der A. Böttgeri noch am nächsten stehen. Ich kenne die Art nur von Buchsweiler, woselbst sie häufig ist.

\section{Pupa Buxovillana n. sp.}

Tf. II, Fig. $1 a, b, c$.

Abdrücke und ein Steinkern einer kleinen, bienenkorbartigen Pupa aus der Gruppe der P. raricosta Stav. von Tu choric (Unt. Mioc.) und der P. lineolata BrN, von H o ch h e im (Unt. Mioc.) liegen mir aus dem Buchsweiler-Kalk vor. Der Steinkern ist rechtsgewunden, zeigt 6 Ungänge, ist $2 \mathrm{~mm}$ breit und $3 \mathrm{~mm}$ lang. Die Umgänge sind bauchig, durch ziemlich 
48

tiefe Nähte getrennt und tragen eine zierliche Sculptur, welche aus etwas gebogenen, weit von einander abstehenden, scharfen Querrippen besteht. Auf einen Umgang kommen 20-22 Rippen und auf den 2 obersten Windungen scheinen dieselben vollständig zu obliteriren. Wahrscheinlich war ein Nabelritz vorhanden und war die Mündung zahnlos; sicheres lässt sich bis jetzt noch nicht darüber sagen, da möglicher Weise ein Stück von der letzten Windung fehlt. Die gleichalterige $P$. Novigentiensis SAND. ist in der Form ähnlich, soll jedoch eine glatte Schale haben.

Clansilia (Canalicia) densicostulata SAND. 1870-75.

Tf. II, Fig. $3 a-\lambda$.

(Sandberger [1. c.], pag. 231, Tf. XiII, Fig. 20.)

Das Gehäuse ist links gewunden, schlank, cylindrisch, dicht und scharf gestreift und besitzt eine stumpfe, cylindrische Spitze. Die Steinkerne und Abdrücke lassen die 3 gewöhnlichen Lamellen auf der Seite der Spindel und der Mündungswand erkennen; von einer Mondfalte ist jedoch nichts angedeutet. BötTGer ist der Ansicht, dass diese Clausilie wahrscheinlich zur Gattung Canalicia gehört'1. Ein ganz untadeliges Stück dieser seltenen Buchsweiler Art ist bisher noch nicht gefunden worden.

\section{Palaeostoc nov. gell.}

Auf Grund unvollkommener Bruchstücke wurde die Buchsweiler Art dieses Genus $P$. Fontenayi von Rouis zu Pupa und von SANDBerger zu Torquilla gebracht. Weit besseres

1. Cf. Palaeontographica X, p. 310, 18003 (Gatt. Canalicia); ferner BötтGË, Clausilienstudien, 1877 , pg. 110. 
Material zeigte uns jetzt, dass wir es mit einem neuen Genus zu thun haben.

Palaeostoa nimmt im System Stellung zwischen dem Genus Megaspira LeA und Triptyehia SANDBERGER (= Milne-Edwardsia Bourg) $)^{2}$. Das rechts gewundene Gehäuse ist spitz kegelförmig, unten fast cylindrisch. Die Spindelfalten sind durchlaufend. Es ist eine kräftige, lange Basallamelle vorhanden und eine grosse Anzahl langer, fadenförmiger Gaumenfalten. Dieselben sind ungleich stark und zwar derart angeordnet, dass je mehrere schwache zwischen 2 stärkeren Gaumenfalten liegen. Der Mundsaum ist ein wenig umgeschlagen, was an das Genus Clausitia erinnert. Zu unserem Genus gehört, ausser der Buchsweiler Art, jedenfalls noch die $P$. perdentata F. EDw. aus dem Bembridge-Kalk von Sconce (Unt. Oligoc.), welche SANDberger ebenfalls als Torquilla anführt und auf ihre nahe Verwandtschaft zu P. Fontenayi hinweist. Ich konnte die englische Art nicht näher untersuchen, da ich sie nur aus der Abbildung keme.

\section{Palaeostoa Fontenayi Rous sp.}

Tf. II, Fig. $2 a-f$.

Syn. Pupa Fontenayi Rovrs 1868. - Torquilla Fontenayi Sand., 1870-75 (I. c. pg. 231, Tf. XIII, Fig. 22). - Clausilia crenata SAND., 1870-75 (l. c. pg. 231, Tf. XIII, Fig. 19).

In allem liegen mir 38 Reste von dieser ziemlich seltenen Species vor, darunter befinden sich solche, bei welchen die Schale und andere, bei welchen alle Windungen erhalten sind, so dass wir uns eine gute Vorstellung von der interessanten Art machen können. Das Gehäuse ist lang-conisch, hat $12 \mathrm{Um}$ gänge und wird etwa $22 \mathrm{~mm}$ lang, $6 \mathrm{~mm}$ breit. Die letzte

1. Cf. Nachrichtsblatt der Deutschen Malakozoologischen Ges., XIV. Jahrg., Nr. 3, März 1882 .

III. 
Windung beträgt nicht ganz $1 / 3$ der totalen Höhe. Die Schale ist ziemlich dick, auf den letzten Windungen fast glatt und nur mit äusserst feinen Anwachsstreifen versehen. Die Windungen der Spitze hingegen sind, namentlich unterhalb der nicht sehr tiefen Naht, grob gefälteIt. Die Steinkerne und Abdrücke von der Spitze gleichen nach Form, Grösse und Sculptur der Abbildung SANDBergers auf Tf. XIII, Fig. 19; das dort abgebildete rechtsgewundene Fragment wurde Clausitia crenata genannt; ich glaube diese Art mit der Palaeostoa vereinigen $\mathrm{zu}$ müssen. Die Mündung enthält 3 Spindelfalten und eine starke nicht sehr lange Basallamelle (lam. superior). Die Zahl der fadenförmigen Gaumenfalten, welche etwa $3 \mathrm{~mm}$ tief in der Mündung anfangen und sich durch den ganzen letzten Umgang fortsetzen, ist variabel. In der Regel sind 6-7 stärkere und dazwischen melır als das doppelte an feineren Lamellen vorhanden. Bei ausgewachsenen Individuen ist der Mundsaum ein wenig umgeschlagen. Buchsweiler.

\section{Nanina Voltwi Desh. sp.}

Tf. II, Fig. $17 a-c$.

(Sandberger [l. c.], pg. 230, Tf. XIII, Fig. 17. 1875; etc.)

Von dieser häufigen kleinen Nanina, welche SANDBERger mit der recenten Nanina minutiuscula MaRT. (Sect. Macrochlamys) von Amboin a vergleicht, liegen mehr als 100 Reste vor. Das Gehäuse zeigt im grössten Durchmesser meist $10 \mathrm{~mm}$, in der Höhe 4,5 mm - $6 \mathrm{~mm}$ und hat 5-6 Ungänge. Dasselbe ist oben flach gerundet, unterseits weit und durchgehend genabelt. Die Nähte sind oben deutlich aber flach, unten tief. Der Mundsaum besass scharfe Ränder. Die Schale ist dünn, gläızend und zeigt mit Ausnahme der beiden Embryonalwindungen feine Anwachsstreifen. Die Variabilität bezieht sich auf die Höhe und 
die mehr spitze oder gerundete Form der Oberseite. Diese Art ist bei $\mathrm{Buchsw}$ eiler namentlich in den weissen kreidigen und den fein oolithischen Kalkstïcken häufig.

\section{Nanina occlusa F. EDw. sp.}

Tf. II, Fig. $16 a-e$.

(Sandberger [l. c.], pg. 228, Tf. XIII, Fig. 15. - Ebwards, Eoc. mollusca, pg. 64, Tf. X, Fig. 10.)

Das Gehäuse hat 5-6 Umgänge, ist gegen $10 \mathrm{~mm}$ hoch und gegen $15 \mathrm{~mm}$ breit. Die Form ist niedergedrückt, oben und unten gewölbt und an den Seiten kantig gerundet. Die Nähte sind flach, der verdeckte Nabel erscheint an Steinkernen fein stichförmig. Der Mundrand ist unten ein klein wenig umgebogen, ein Umstand, der uns nicht daran hindern darf, diese ihrem ganzen Habitus nach zu den Naninen gehörige Species mit dieser Gruppe zu vereinigen. Die sehr dünne Schale zeigt Anwachslinien, welche oft bündelförmig zusammengefasst sind. N. occlusa, welche vom Untereocän bis in das Oligocän (Isle of Wight) reicht, ist bei $\mathrm{Buchsweiler}$ ziemlich häufig und unterliegt an diesem Orte auch einer gewissen Variabilität. Dieselbe findet darin ihren Ausdruck, dass die Gehäuse etwas kleiner, höher und runder erscheinen, sowie dass sie etwas tiefere Nähte zeigen. Man kann solche extreme Formen als f. conica bezeichnen, Tf. II, Fig. 16 . Einzelne Exemplare von $N$. occlusa sollen sogar noch ein braunes Längsband erkennen lassen; ich habe dasselbe bei Buchsweiler nie beobachtet.

Sandberger rechnete $N$. occlusa noch zu den Heliceen, machte aber auf ihre nahe Verwandtschaft zu $N$. Moussoni PFr. (Habitat?) aufmerksam, und dürfte daher die Art vielleicht zur Section Xesta gehören. 


\section{Patula oligogyra 11. sp.}

Tf. II, Fig. $18 a-e$.

Es ist die älteste bisher bekannte Species der Gruppe, deren Vorkommen im Eocän noch unbekannt war. Das kleine, flache Gehäuse hat einen grössten Durchmesser von $4 \mathrm{~mm}$ und besitzt $4^{1 / 2}$ Umgänge, welche ziemlich langsam an Breite zunehmen. Die untere, weit genabelte Schalenhälfte ist tellerförmig, die obere ist flach gewölbt. Beide Schalenhälften sind durch einen Kiel geschieden und zeigen ziemlich tiefe Nähte. Die charakteristische Sculptur besteht aus scharfen, etwas gebogenen Querrippen, welche die ganze Schale, mit Ausnahme des Embryonalgewindes bedecken. Auf der Unterseite schalten sich noch zwischen die Querrippen unter dem Kiel hie und da kurze, schwächere Rippen ein. Bei einem Abdruck konnte ich ausserdem Spuren von Längslinien unter dem Kiel wahrnehmen. Die Art scheint bei Buchsweiler sehr selten zu sein; ich kenne nur 2 Steinkerne nebst den Abdrücken, ausserdem noch einen isolirten Abdruck und schliesslich Spuren eines vierten Individuums. Keine von den $\mathrm{Hoch}$ he ime r Patula-Arten, welche ich mit derselben verglichen habe, steht unserer Art nahe; auch von den lebenden Species gleicht ihr die alpine Pat. solaria MNke. nur wenig.

Helix laxecostulata SAND. 1870-75.

Tf. II, Fig. $15 a-d$.

(SANDBERger [l. c.], pg. 229, Tf. XIII, Fig. 16.)

Das kleine nicht sehr stark gewölbte Gehäuse misst bei den grössten Exemplaren $10 \mathrm{~mm}$ im Durchmesser und $6 \mathrm{~mm}$ 
in der Höhe; dasselbe hat 4-5 Umgänge, welche durch tiefe Nähte getrennt sind. Es ist oben flacher als unten und besitzt einen tiefen, aber theilweise verdeckten, Nabel. Die Schale ist vor der Mündung ziemlich stark eingeschnürt und letztere erscheint ringsum gelippt. Die im Abdruck am schönsten erhaltene Sculptur besteht aus unregelmässigen, theilweise aufgelösten Querrippen, zwischen die sich eigenthümliche Papillen einschieben, welche ich in der That für Haarpapillen halte. Dieselben gleichen einem kleinen, erhöhten Punkt, welcher von einer vertieften Rinne umgeben ist. Im Abdruck pflegen die Papillen und bei erhaltener Schale die Querrippen deutlicher hervorzutreten. Diese Helix wurde von VouTz als hispida-antiqua bezeichnet. Von Sandberger wird sie mit der recenten $H_{x}$. pyrrhozona Phint. aus China verglichen. Diese zur Section Camaena gehörige Art konnte ich durch die Güte des Herrn Professor Götse in der Strassburger Sammlung vergleichen und glaube kaum, dass $H_{x}$. laxecostulata hierher gehört. Eher dürfte dieselbe mit der Section Gonostoma HeLD = Anchistoma Koв., so z. B. mit der Caracolina Corcyrensis PARTSCH von Cephalonia verwandt sein. Inmerhin dürfte es kaum möglich sein, diese alte fossile Art in eine bestimmte Section der lebenden Helices einzuordnen. Die nur bei Buchsweiler vorkommende Art ist nicht gerade häufig.

\section{Pomatias Sanabergeri NouL. 1868.}

Tf. II, Fig. $6 a, b$.

(Noulet, Mém. sur les coq. foss. d. Ter. d'eau douce du S.-O. de la Fr., II. ed., pg. 94. - Sandberger [I. c.], pg. 235, Tf. XIII, Fig. 29.)

Das Gehäuse ist verhältnissmässig breit, kegelförmig, $10 \mathrm{~mm}$ lang, 5,5 $\mathrm{mm}$ breit und hat 7-8 Umgänge, welche mit gebogenen dicht stehenden Querrippen verziert sind. Die Querrippen sind 
nicht alle gleich kräftig entwickelt und zuweilen alternurt eine stärkere mit einer schwächeren Rippe, was jedoch durchaus nicht immer der Fall ist. Auf der Unterseite ist ein deutlicher Nabelritz vorhanden. Die Mündungsränder sind umgeschlagen und bilden eine nahezu kreisförmige Mündung. Diese älteste Pomatias-Art ist bei Buchsweiler ziemlich häufig, sie findet sich auch bei Ubstadt und in Süd-Franlireich, woselbst sie bis in das Unteroligocän hinauf reichen soll. Der kurzen, breiten Form nach steht $P$. Sandbergeri dem lebenden $P$. striolatus Porro von Genua am nächsten.

Megalomastoma turgidum Rours sp. 1868.

Tf. II, Fig. $5 a, b, c$. (Sandberger [I. c.], pg. 235, Tf. XIII, Fig. 28; etc.)

Vielleicht der Vorfahre der grösseren untermiocänen IMegal. pupa BrN. von Hochheim ist bei Buchsweiler äusserst selten. Das Gehäuse ist $12 \mathrm{~mm}$ lang, und halb so breit. Von den 6 Umgängen ist der zweitletzte am stärksten aufgeblasen. Die Schale ist nicht sehr dick und fast glatt. Die Nähte sind tief, der Nabel ist schmal und die runde Mündung hatte einen wenig ausgebreiteten Rand, welcher wenigstens theilweise bei einem Exemplar vorhanden ist.

Strophostoma striatum Desh.

Tf. II, Fig. $4 a, b, c$. (Sandberger [l. c.], pg. 234, Tf. XIII, Fig. 25; etc.)

Verdient in sofern besondere Beachtung als DesHares auf diese Buchsweiler Species hin, sowie auf St. laevigatum, zuerst 
seine neue Gattung Strophostoma begründete ${ }^{1}$. Die ausgezeichnet schöne und seltene Art liegt mir in 6 Exemplaren vor. Das Gehäuse ist mit einem scharfen Kiel versehen, welcher sich erst kurz vor der viereckig-gerundeten Mündung verliert, an der Stelle, wo dieselbe sich nach oben zu drehen beginnt. Der grösste Durchmesser beträgt $23 \mathrm{~mm}$, die Höhe $8-9 \mathrm{~mm}$ und es sind 5 Umgänge vorhanden. Die Oberseite hat sehr flache Nähte. Die Unterseite ist weit und tief genabelt. Die Sculptur der Schale besteht aus dicht stehenden, unregelmässigen, öfters verzweigten Querrippen, welche unten etwas stärker hervortreten als oben und an einigen sonst gut erhaltenen Exemplaren fast ganz abgerieben sind. Ein Stück lässt rostbraune, aufgelöste Bänder auf der Oberseite erkennen, welche wohl Spuren der ursprünglichen Färbung sind. Nur bei Buchsweiler.

\section{Carychiopsis quadridens n. sp.}

Tf. II, Fig. $7 a, b$.

Diese Species unterscheidet sich von den beiden anderen Carychiopsis-Arten, C. Dohrni Desh. sp. von Jonchery (UnterEoc.) und C. costulata SANdBerger von Hochheim und Tuchoric (Unter-Mioc.) dadurch, dass dieselbe glatt ist und nur feine, aber deutliche Anwachsstreifen zeigt, was sie den typischen Carychien nähert. Die Mündung und die Anzahl der Zähne habelı mich jedoch bewogen, dieselbe bei Carychiopsis unterzubringen. Die kleinen Steinkerne messen $1,6 \mathrm{~mm}$ in der Länge, 0,9 $\mathrm{mm}$ in der Breite und haben 5 Umgänge. Die Gestalt ist eiförmig zugespitzt, die Nähte sind tief. Die ziemlich schmale, wenig schiefe Mündung ist durch 4 Zähne eingeengt, von welchen 2 auf der 
56

Spindelseite resp. Mündungswand und 2 auf der Gaumenseite stehen. Von den Zähnen auf dem äusseren Mundrand ist der obere etwas stärker als der untere. Auf der Spindelseite lingegen ist der untere, ziemlich senkrecht stehende Zahn grösser als der obere. Alle präparirten Exemplare zeigten völlige Constanz der Zähne. C. quadridens ist bei Buchsweiler nicht sehr selten, wird aber wegen ihrer Kleinheit leicht übersehen.

\section{Calyculina Castrense Nout. sp. 1857.}

(Sanderger [l. c.], pg. 321, Tf. XIII, Fig. $1-1 a$ etc.)

Die einzige bei Buchsweiler vorkommende Art, welche ich nicht besitze. Sie findet sich nur in den grünen Mergeln und fehlt gänzlich im Kalk. Es ist eine kleine, nalıezu kreisrunde Art mit enggestellten, concentrischen Anwachsrippen. Nach Noulet ist dieselbe $6 \mathrm{~mm}$ lang und $2,5 \mathrm{~mm}$ dick. Sandberger bildet in den Ld. Sw. C., Tf. XIII, Fig. 1, $1 a$ die beiden Klappen ab. Dieselben sind reclit verschieden von einander, und es ist leider nicht dabei bemerkt, ob sie dem gleichen Individuum angehören. Calyculina Castrense ist ausserdem von $\mathrm{Castres,}$ von Augmontel und von Labruguière bekannt. 
Nachdem wir so die einzelnen Arten aufgeführt und kurz charakterisirt haben, wollen wir versuchen, zum Schluss durch einen allgemeinen Ueberblick ein Bild von der gesammten Schneckenfauna zu entwerfen.

Aus dem oberrheinischen Mitteleocän sind im ganzen 28 sicher bestimmte Arten bekannt, von welchen 7 durchaus neu sind. Von diesen 28 Arten finden sich 27 bei Buchsweiler und 16 derselben sind ausschliesslich dieser Lokalität eigenthümlich. Die Arten vertheilen sich auf 21 Genera und sind alle reine Süsswasser- oder Landbewohner, so dass sich keine Spur eines brackischen Elementes in der Fauna bemerkbar macht. Von den genannten Gattungen sind 5, nämlich Parmacellina, Palaeostoa, Strophostoma, Carychiopsis und Euchilus, in der Jetztwelt erloschen. Der zoogeographische Habitus der anderen Genera und Species ist auf der Schlusstabelle nach Möglichkeit zur Anschauung gebracht. Wir finden, dass derselbe ein sehr gemischter, nicht einmal durchaus tropischer ist. Es begegnen unș verwandte lebende Formen in den verschiedensten Welttheilen, eine Thatsache, die uns bei einer so alten Fauna als derjenigen von Buchsweiler nicht befremdet. Auffallend ist das starke Ueberwiegen der Gastropoden gegenüber den Zweischalern, welche nur in einer einzigen Art, Calyculina Castrense Nous. sp. in den grünen Mergeln vertreten sind, während von dieser sogar jede Spur im Kalkstein fehlt. Es ist mehr als die doppelte Zahl von Landbewohnern gegenüber den Wasserbewohnern vorhanden; jedoch treten die letzteren durch ihren Individuenreichthum in den Vordergrund. Die Wasserschnecken lebten wohl alle in den stehenden Gewässern des Sees. Von den Landbewohnern liebten die meisten feuchte Standorte und hielten sich dicht an der Erde unter 
Moos, Steinen oder im Uferschilf auf, wie Succinea, Parmacellina, Cionella, Azeca, Glandina, Nanina und Carychiopsis. Der jurassische Kalkboden, welcher die Unterlage und Umgebung des Sees bei Buchsweiler bildete, bot den zahlreichen Conchylien die günstigsten Bedingungen zu ihrem Gedeihen; so finden wir denn auch kalkliebende Genera, wie z. B. Pomatias, welche hier zum ersten Male und zwar in Menge auftritt. Die verhältnissmässig beschränkte Artenzahl gegenüber anderen Faunen, wie derjenigen des Süsswasserkalkes von Hochheim z. B., mag darin ihren Grund haben, dass wir es bei Buchsweiler mit einem sehr beschränkten Gebiete zu thun haben und der jedenfalls kleine See wohl nur von unbedeutenden Flüsschen oder Bächen aus der Nachbarschaft gespeist wurde. Die grosse Individuenzahl hingegen spricht dafür, dass einerseits die umwohnenden Conchylien günstige Lebensbedingungen fanden, und dass andererseits längere Zeit hindurch die gleichen Bedingungen andauerten.

Noch ein auffälliges Moment in dem Habitus der Fauna, welches Erwähnung verdient, ist, wenn man so sagen darf, der carnivore Charakter derselben. Raubschnecken treten sonst in den Land- und Süsswasserfaunen immer sehr zurück, während dies bei Buchsweiler nicht gerade der Fall ist. Die Oleacinen, deren lebende Vertreter als Raubschnecken bekannt sind, bilden bei Buchsweiler die artenreichste Gattung, indem sich drei Glandinen und eine Boltenia dort finden. Für Parmacellina müssen wir eine ähnliche Lebensweise annehmen wie für ihre nächsten recenten Verwandten Testacella und Daudebardia; dieselben sind beide lichtscheue, fleischfressende Thiere, die sich von kleinen Würmern und anderen Schnecken ernähren. Diese relativ hohe Zahl von Carnivoren deutet wiederum auf ein reiches Leben an niederen Thieren hin, welchessich an den Ufern des Sees entfaltete.

Versuchen wir es am Schlusse, auf Grund der allerdings 
noch so lückenhaften, geologischen Thatsachell, uns eine Anschauung von den Bodenverhältnissen zu bilden, welche das soeben behandelte Gebiet zur Mitteleocänzeit darbot.

Nachdem der obere Dogger zum Absatz gelangt war, befand sich das südwestliche Deutschland offenbar in einer Hebungsperiode und das Meer zog sich vom Elsass aus wie es scheint nach Süden zurück. Es tritt alsdanu eine grosse Lücke in den geologischen Daten unseres Landes ein; vom oberen Jura und namentlich von der Kreide fehlt jede Spur. Wir können sogar fast mit Sicherheit behaupten, dass zur Kreidezeit überhaupt keine Sedimentbildung im Elsass stattfand, denı wären vorhandene Kreideschichteu durch Erosion entferut worden, so würde man vermuthlich ihren Resten in den tertiären Conglomeraten begegnen, was niemals der Fall ist.

Nach dieser grossen Lücke folgen über den marinen Doggerschichten zuıächst Süsswasserablagerungen, welche ihren organischen Einschlüssen nach als Mitteleocän zu bezeichnen sind und die man ungefähr mit dem Pariser Grobkalk parallelisiren kann. Eine einheitliche Wasserbedeckung, d. h. ein einziger grosser Süisswassersee, war nicht vorhanden. Vielmehr machen es die faunistischen und petrographischen Verschiedenheiten, sowie der Habitus der einzelnen Ablagerungen wahrscheinlich, dass ein ausgedehntes Festland mit mehreren kleineren Seen und Flussläufen existirte. Das zahlreiche Auftreten von Landschnecken, sowie die Verbreitung der Landsäugethiere sind ebenfalls dieser Anuahme günstig. Vogesen und Schwarzwald bestanden keinenfalls in ilurer heutigen Form; auch konnte von einem Rheinthale, wie unserem jetzigen, nicht die Rede sein, indem die g'rossen Verwerfungsspalten, welche dasselbe einfassen und welche im Wesentlichen die Form des späteren Oligocänmeeres bedingteı, wohl noch nicht oder nur theilweise vorhanden waren. Im Elsass selbst und in den umliegenden Länderı hatte zu jener Zeit 
lokal schon die Bolmerzbildung begonnen, welche noch lange Zeit hindurch fortdauerte, jedenfalls bis zum Schlusse des Obereocäns. Wir haben somit Bohnerze, die älter und solche die jünger sind als der Buchsweiler-Kalk; ferner scheint es auch noch Bohnerze zu geben, welche mehreren Etagen des Eocäns zusammen entsprechen.

Wir haben es im allgemeinen im mittleren Europa mit einer Continentalepoche zu thun. Fast ganz Deutschland, die nördliche Schweiz und ein grosser Theil Frankreichs waren Festland und dieses Festland wurde in Norden und Nordosten von dem anglogallischen und der Bucht des Pariser Grobkalkmeeres, im Süden und Südosten von dem alpinen Nummulitenmeere umspültt. Im südlichen und südöstlichen Frankreich herrschen ähnliche Bedingungen wie im Südwesten von Deutschland, und wahrscheinlich sind weitverbreitete Arten, wie z. B. der Pl. pseudammonius, von dort her zu uns eingewandert. Auch die Lophiodonten, deren Haupttummelplatz ja Frankreich war, komnten sich auf diese Weise weithin nach Osten ausbreiten, wo man ihre Reste noch nördlich von dem Schwarzen Meere gefunden hat.

Zur Mitteleocänzeit war der wichtigste und zugleich wohl auch der älteste der rheinischen Seen derjenige von Buchsweiler. Er war anfangs flach und umwaldet, zur Zeit als die pyritischen, grünen Mergel und die Braunkohle sich bildeten; nur wenige Sumpfschmecken bewohnten denselben. Mit der Zeit vertiefte sich der See und aus seinen klaren, kalkhaltigen Gewässern schlug sich ein Gestein nieder, welches uns Spuren eines reichen Lebens bewahrt hat. Propalaeotherium und Lophiodon, von welchen das letztere wohl eine ähnliche Lebensweise wie der Tapir führte, überwiegen unter den Säugethieren. Auch findet sich eine von jenen eigenthümlichen Formen, die

1. Ueber die Vertheilung des Meeres und Festlandes zur Mitleleoeănzeit, vergl. HÉBErT's interessanten und wichtigen Aufsatz. Bull. soc. géol. Fr. (2.) T. XII, PI. XVI. 
als Bindeglieder zwischen der Familie der Schweine und der Affen stehen, wie dies schon der glücklich gewählte Name Cebochoerus ausdrückt. Schildkröten und Krokodile deuten auf den tropischen Charakter der Reptilienfauna hin. Der zahlreichen Teich- und Sumpfschnecken, sowie der eingeschwemmten Landconchylien wurde schon des Näheren gedacht.

Etwas jünger sind wohl die Süsswasserkalke, welche wir vom $B$ ischenberg, von Bernhardsweiler und von Morschweiler kenwen gelernt haben ${ }^{1}$. Dieselben tragen keinen so rein limnischen Charakter mehr. Hydrobien wiegen vor, Paludinen fehlen, und von Landschnecken fand ich nur ein Fragment, das zur Gruppe der Meg. mumia Lmк. sp. gehört; eine Gruppe, die im obersten Eocän von Mülhausen reichlich vertreten ist. Es scheint, dass das helvetische Meer zu jener Zeit sich von Süden her dem Sundgau näherte; vielleicht sogar zeitweise einbrach und, eine flache Bucht bildend, die Mergel (mit Gyps und Steinsalz?) im Liegenden des Brunnstatter Kalkes absetzte. Mit der Zeit gewinnt jedoch das Süsswasser die Oberhand. Wahrscheinlich ist, dass ein grösserer Fluss von Norden oder Nordwesten her in die Sundgauer Bucht einmündete (Blättersandstein von Spechbach). Es bildet sich der Melanienkalk von Brunnstatt, Klein-Kembs etc. Seine Fauna ist keine rein limnische (Melania, Melanopsis, Valvata, Nematura, Neritina); sie deutet auf den Absatz an einer Flussmündung hill und kann die Nähe des Meeres (Alexic) nicht ganz verleugnen.

So wären wir bei der zweiten Tertiärstufe angelangt, welche für den Elsass von Bedeutung ist, und es soll im nächsten Kapitel versucht werden, die wichtigsten geologischen Verhältnisse derselben, soweit sie bekannt sind, in aller Kürze darzulegen.

1. Ob die Hydrobien-führenden Schichten von Dauendorf (Brunnen im 0rt), welche beträchtlich höher liegen als die alten Gruben (mit Lophiodon), denselben beizuordnen sind, muss ich leider noch unentschieden lassen. 


\section{Tabellarische Uebersicht der Buchsweiler Conchylien-Fauna.}

* bezeichnet Geuera, welche aus älteren Schichten bisher nicht bekannt sind; h $\mathbf{h}=$ sehr häufg; $\mathrm{h}=\mathrm{häufg}$; $\mathrm{zh}=$ ziemlich häufg; $\mathrm{s} \mathrm{s} \doteq$ sehr seiten; - bezeichnet das Fehlen; + Vorkommen ohne Häufigkeitsaugabe.

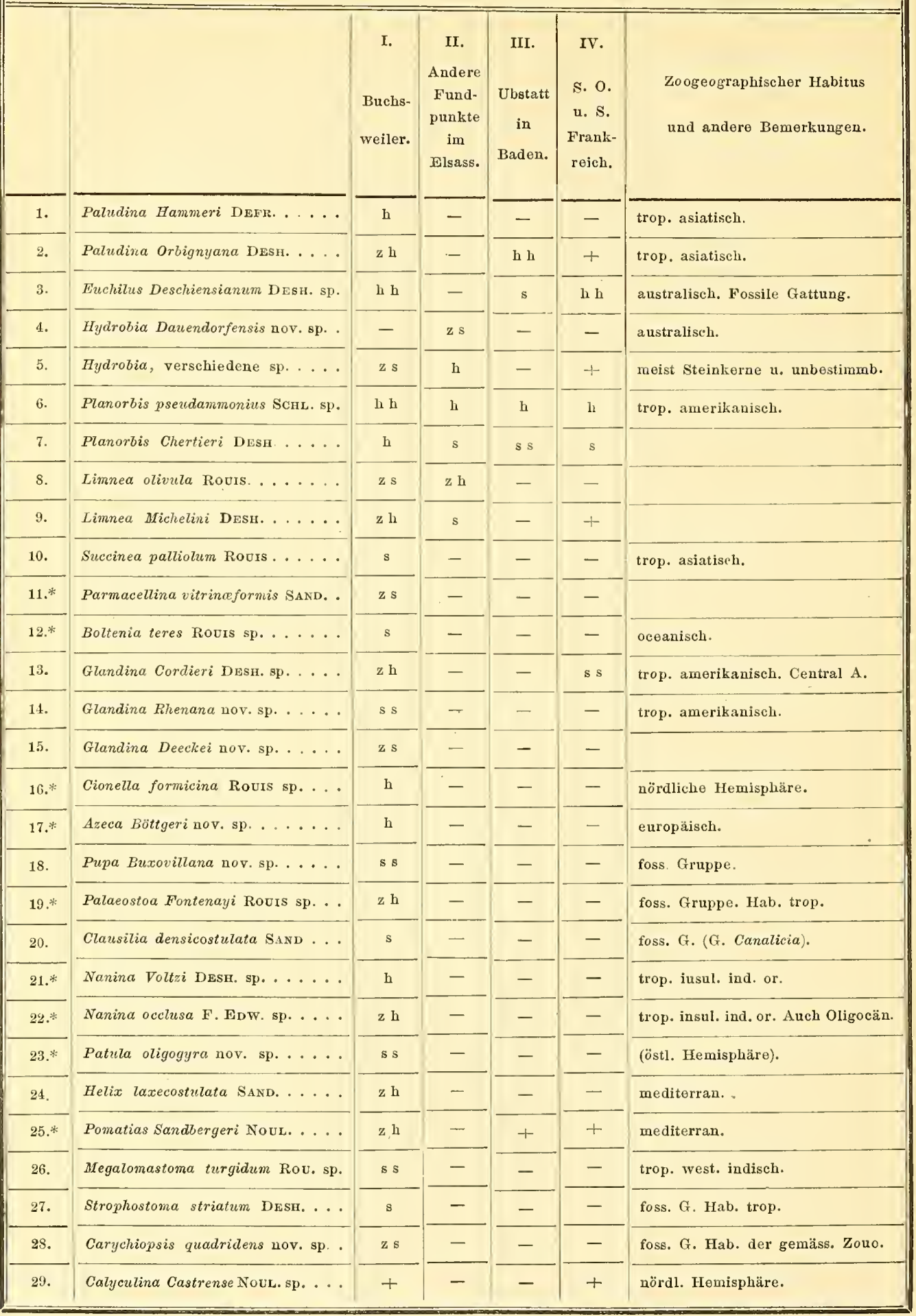


II.

DER MELANIENKALK

ODER

BRUNNSTATTER-KALK. 



\title{
DER MELANIENKALK
}

\author{
ODER \\ BRUNNSTATTER-KALK.
}

In Bezug auf die geologischen Verhältnisse der hierher gehörigen Schichten ist die unten erwähnte Arbeit von KöchıINSchldmberger und Delbos durchaus grundlegend. Die einzelnen Daten, welche sich auf diese Schichten beziehen, sind mit grosser Sorgfalt darin gesammelt und zusammengestellt. Wir können uns daher im Wesentlichen darauf beschränken, das dort angegebene, soweit es wichtig erscheint, nebst einigem neu hinzugekommenen kurz anzuführen. Was die palaeontologischen Verhältnisse angeht, so sind dieselben allerdings einer gründlichen Revision bedürftig, dieselbe konnte jedoch nicht ganz nach Wunsch vorgenommen werden, aus Mangel an einem hinreichenden Material, zumal da mir die Museen von Basel und Mülhausen zu einer eingehenden wissenschaftlichen Untersuchung nicht zugänglich waren. 


\section{Wichtigste Litteratur.}

1848. Merian, P. Ueber die im Susswasserkalke der Umgebung von Mülhausen aufgefundenen Schalthiere. Verhandlungen der naturforschenden Gesellschaft zu Basel, VlII, pg. 33-35.

1857. Meyer, H. v. Palaeotherium medium von Mülhausen. Leonhards Jahrbuch. Briefl. Mittheilung, pg. 555.

1859. HeER, 0. Flora tertiaria Helvetiae, III, pg. 311.

1867. Delbos, J., et Köchlin-Schlumberger, J. Description géol. et minéral. du département du Haut-Rhin, T. II, pg. 14-38.

1870. Greppin, J. B. Le Jura Bernois et Districts adjacents. In den Matériaux pour la Carte géol. de la Suisse, VllI. livr. Berne, p. 159.

1870-75. Sandberger, Fr. Die Land- und Süsswasserconchylien der Vorwelt, pg. 322-327.

1877. ZÜNDEL, G. A., et MIEG, M. Notice sur quelques sondages aux environs de Mulhouse et en Alsace. Bull. de la Société industrielle de Mulh., XLVII, pg. 631.

Zum obersten Eocän gehörige Schichten sind im Rheinthale wesentlich auf den Ober - Elsass beschränkt. Es findet sich ein weiteres Vorkommen bei Klein-Kembs, in OberBaden, einem nahe am Rhein gelegenen Orte, und ausserdem noch ein kleiner, vereinzelter Kalkfetzen bei Morvillars in dem jetzigen Département du Haut-Rhin. Weiter abwärts im Rheinthale, sowie im Mainzer Becken fellen analoge Bildungen durchaus. Die Hauptmasse der besprochenen Schichten bildet im Sundgau und zwar südlich von Mülhausen eine zusammenhängende Ablagerung, deren Grenzen etwa durch folgende Orte gegeben sind: Mülhausen im Norden, Nieder-Spechbach und Altkirch im Westen, Schwoben und Sierenz im Süden, Klein-Kembs im Osten. Auf diesem Gebiete treten die Schichten jedoch keineswegs überall zu Tage. Sie werden 
auf den beì weitem grössten Theil der Oberfläche von jüngeren Tertiärschichten (Blättersandstein ${ }^{1}$, Fischschiefer, Cyrenenmergel ${ }^{1}$ und Gyps), von mächtigem Diluvium (Löss) und Alluvium bedeckt. Ill und Rhein haben ihre Thäler in das wellige Kalkplateau eingegraben und an der Stelle, wo der Rhein sein breites

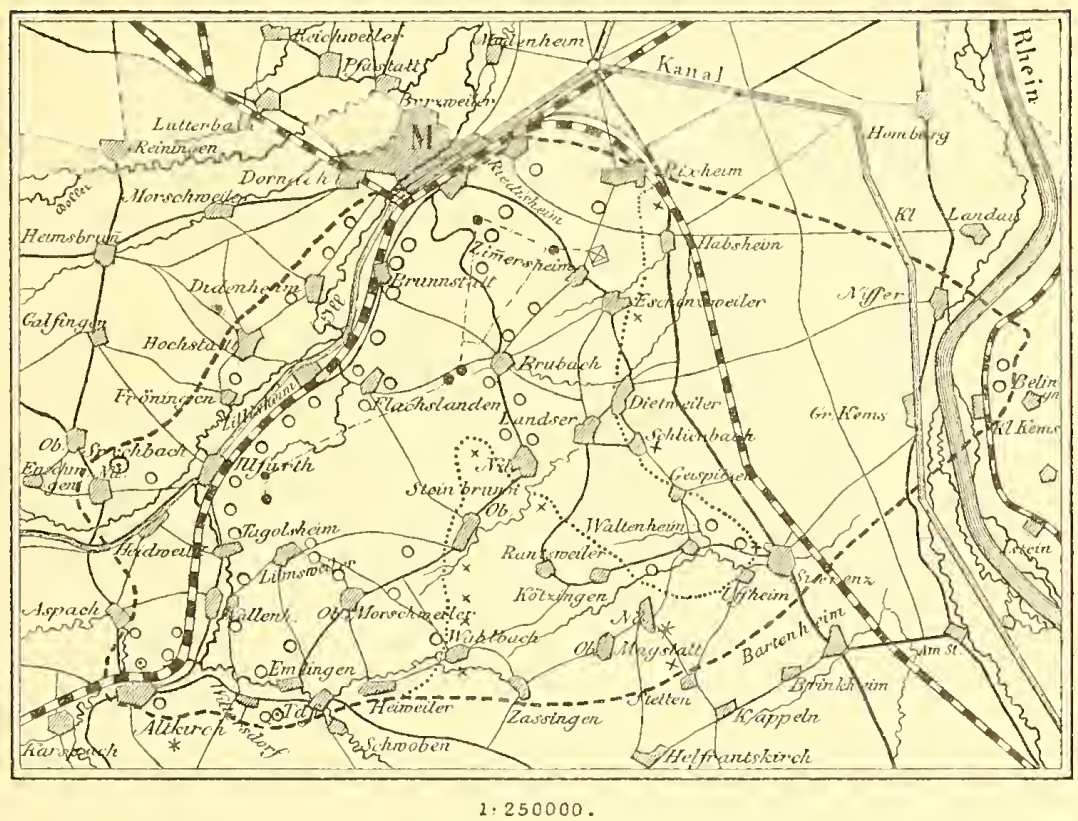

Kartenskizze zur Veranschaulichung der Lagerungsverhältnisse des Melanienkalkes im Sundgau, z. Th. uach der geol. Karte von Köchlin-Schlumberger. O Vorkommen von Melanienkalk als dichter Kalkstein oder feine kalkige Molasse wie hei Lümschweiler, Kötzingen etc.; $\odot$ sandige Aushildung des Melanienkalkes (Spechhach); - - - Umgränzung des Gehietes; $\times$ Blättersandstein (grès à feuilles); * Melettaschichten; ...... Umgränzung; $₫$ Gyps von Zimmersheim; C Cyrenenmergel (marne à cyrènes); _- - . Verbiudungslinie.

Strombett schuf, ist der Kalk wohl vollständig erodirt worden, so dass jetzt kein Zusammenhang zwischen dem Kalk von

1. Die Ausdrücke Blättersandstein (grès à feuilles) und Cyrenenmergel (marnes à cyrènes) sind nicht mit den im Mainzer Becken ubblichen Bezeichnungen fưr gewisse Hiocän- und Oberoligocản-Schichten zu identifiziren. 
Klein-Kembs und demjenigen der elsässer Seite mehr anzunehmen ist. Ausserdem ist es wahrscheinlich, dass die Kalkdecke früher im Westen über Altkirch hinaus bis in die Gegend voll Delle reichte, wo sich noch der letzte Ueberrest bei Morvillars findet. An den beiden am weitesten von einander entfernten Punkten, im Osten und Westen, bei Klein-Kembs und bei Morvillars ruht der Melanienkalk auf dem Jura auf; doch schalten sich an dem erstgenannten Punkte noch Bohnerzthone an der Basis dazwischen ein.

Das Profil von Klein-Kembs mag nach den Angaben Greppins kurz angeführt werden (pag. 161):

1. Ackerboden und Lehm.

2. Grüne Mergel und grauer Kalk.

3. Bräunlicher bituminöser Kalk mit Melania Laurae etc., 20 bis $30 \mathrm{~m}$.

4. Mergel und graue Kalke mit Paludina viviparoides (?)', $7 \mathrm{~m}$.

5. Rothe, bröcklige Thone, $3 \mathrm{~m}$.

6. Rothe, fette Bohnerzthone überlagern den Jura, $4 \mathrm{~m}$.

Anders verlält siclı die Lagerung in der Mitte des Sundgaues, wo verschiedene Bohrungen in der Gegend von Mülhausen gezeigt haben, dass sich im Liegenden des Melanienkalkes noch zum Tertiär gehörige Mergel befinden. In der oben erwähnten Arbeit von Zündes und MIeg sind einige dieser Bohrungen auf einer Tafel graphisch zusammengestellt. Wir geben in Fig. 3 eine Copie der beiden für den Melanienkalk wichtigsten Bohrprofile. A. stellt das Profil des "Puits Heidet" dar, welcher auf der Höhe des Mülhauser Rebberges $98 \mathrm{~m}$ tief niedergebracht wurde. Man fand $8 \mathrm{~m}$ Löss, $67 \mathrm{~m}$

1. Gf. pg. $7 \%$. 
Süsswasserkalk und dann $18 \mathrm{~m}$ blaue Mergel. Nicht weit davon, im zoologischen Garten (B.), erreichte man $66 \mathrm{~m}$ Tiefe. Zuoberst fand man Löss, über dessen Mächtigkeit keine Notiz vorliegt, dann bis zu $62 \mathrm{~m}$ Tiefe Süsswasserkalk mit einem kleimen erdigen Braunkohlenflötz Dei $44 \mathrm{~m}$ und drang schliesslich noch $4 \mathrm{~m}$ tief in die blanen Mergel ein.

Aus diesen Beispielen geht zur Genüge die bedeutende Mächtigkeit hervor, welche der Melanienkalk südlich von Mülhausen erreicht. Was die liegenden Mergel betrifft, so wissen wir nur wenig über dieselben; sie sollen ganz fossilfrei sein und dürfen keinenfalls mit den anderwärts im Elsass verbreiteten oligocänen (tongrischen) Mergeln verwechselt werden. Im Norden schneidet der Melanienkalk auffallend scharf gegen die oligocänen Bildungen ab und selbst Bohrungen über

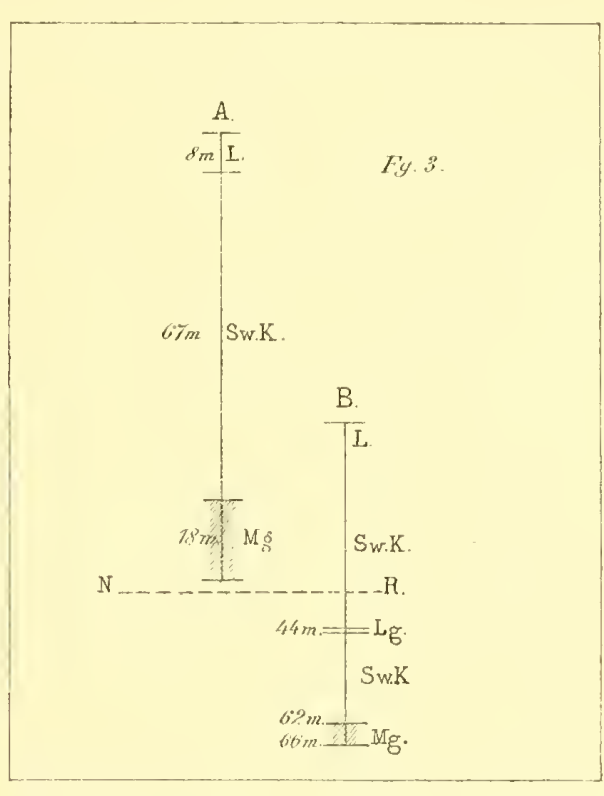

(Nach Ztindel und Mieg) A. Puits Heidet; B. Puits du jardin zoologique; L. = Diluvium; $\mathrm{Sw} . \mathrm{K}$. = obereocäner Kalk; Mg. = cocänc Mergel; Lg. = Braunkohlonfötz: N. R. Niveau des Réunions-Piatzes in Mulhausen.

$200 \mathrm{~m}$ haben denselben nicht in der Tiefe angetroffen. Bei Dornach fand man jedoch unter dem Oligocän, petrographisch abweichende, dunkle Mergel, welche Steinsalz und Gyps führten. Es ist wahrscheinlich, dass diese Mergel den Melanienkalk unterteufen; auch MIEq ist geneigt, dieselben als Eocän anzusehen. Wenn man hingegen diese Mergel mit dem Gyps von Zimmersheim, 
Bamlach etc. vereinigen wollte, so wäre die Annahme einer Verwerfung nöthig.

Die Lagerung des Melanienkalkes ist im ganzen Gebiete eine nahezu ungestörte, horizontale und man nimmt nur zuweilen ein schwaches Einfallen wahr. Im allgemeinen scheint die Regel zu gelten, dass das Einfallen nach den Rändern der Ablagerung zu stattfindet, abgesehen von lokalen Faltungen (z. B. bei Brunnstatt) und kleineren Verwerfungen (z. B. bei Diedenheim).

Der petrographische Charakter der Schichten ist im Ganzen ein einförmiger. Das Hauptgestein besteht aus einem in mehr oder weniger dicken Bänken auftretenden, dichten, ziemlich dolomitischen Kalk. Dieser Kalkstein besitzt einen muscheligen Brucl und zeigt meist eine hellgraue, seltener dunkle, graubraune Farbe. Dieser typische Melanienkalk ist am schönsten und mächtigsten im nördlichen Theil des Gebietes, so z. B. bei Brunnstatt entwickelt. Aehnlich wie bei Buchsweiler trifft man auch Kalkbänke an, welche aus einem fleckigen, breccienartigen Kalke bestehen. Eine solche Kalkschicht ist z. B. in einem Steinbruche bei Geispitzen zu beobachten ${ }^{1}$. Neben dem compacten Kalk kommen ferner liörnige Varietäten vor, so der Kalk vom Lümschweiler, welche wiederum ihrerseits in feinkörnige Kalkmolassen übergehen. Diese finden sich unter anderem in nicht sehr mächtigen Bänken bei Klein-Kembs und bei Kötzingen. Im westlichen Theil bei Altkirch sieht man Kalkbänke und Mergel mit Bänken von gelbem Kalksandstein wechsellagern. Bei Nieder-Spechbacl schliesslich

1. Der Steinbruch auf dem Weg von Sierenz nach Geispitzen zeigt folgende Lagerungsverhältinisse : Oben Löss, dann graublaue, öfters schiefrige Mergel, mehrfach wechselnd mit gelbem Kalksandstein. Die Mergel enthalten zuweilen verkohlte Pflanzenspuren. Darunter folgt fleckiger Kalk, schliesslich grauer, compacter Kalkstein. Die zahlreichen Klüfte sind mit dicken Krusten von Kalkspath überzogen. Ein schwaches, südwestliches Einfallen ist wahruunehmen. 
ïberwiegt, wenigstens in den tieferen Schichten, die sandige Facies vollständig. Zwischen die Kalkbänke sind oft Mergelschichten (namentlich bei Kötzingen) eingeschaltet, und zuweilen trifft man auch dünne Flötze von erdiger Braunkohle an. Das bekannteste derartige Braunkohlenvorkommen ist das von Illfurt, welches zu Anfang dieses Jahrhunderts Veranlassung zu mehrfachen Nachforschungen nach Braunkohlenlagern gab. Man fand jedoch nur ganz umbedeutende, wenige Centimeter dicke Flötzchen von geringer Erstreckung.

Als besondere Eigenthümlichkeiten sind noch die im Riedisheimer Steinbruch vorkommenden Hornsteinconcretionen zu erwähnen, welche zuweilen verkieselte Limneen und andere Süsswasserconchylien einschliessen, also sich an Ort und Stelle gebildet haben. Ferner erwähnt DEsBos das Vorkommen einer dunkelbraunen bis schwarzen, sehr phosphorsäurereichen Erde, welche Bruchstücke von Melanienkalk und verwitterte Knochen enthält. Dieselbe findet sich nur auf dem BritzyBerg östlich von Illfurt.

Während die sandigen Schichten vorwiegend pflanzliche Reste enthalten, sind die dichten Kalke namentlich von thierischen Resten erfüllt und die plattgedrückten Schalen von Melanien bedecken oft zu Hunderten die Schichtflächen. Der einzige Steinbruch, welcher wohlerhaltene, bestimmbare Pflanzen geliefert hat, ist derjenige von

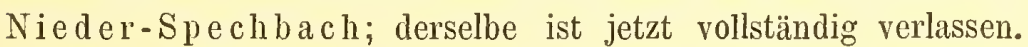
HeER hat folgende 31 Arten von dieser Lokalität beschrieben ${ }^{1}$.

1. Pteris Ruppensis HeER.

2. Carex tertiaria HeEn.

3. Salix varians GoEP.

4. Salix Lavateri HEER.

1. Diese Arten sind auch in DezBos und Köchlix-Schlumberger, Descript., pg. 17, aufgeführt. 
5. Myriea Graeffi HeER.

6. Myriea Studeri HeER.

+7. Betula mierophylla Heer.

8. Quereus lonchitis UNG.

+9. Quereus Sehimperi HeER.

+10. Quercus Koeehlini Heer.

11. Laurus primigenia UNG.

+12. Dryandra graeilis HeER.

13. Dryandra Schranekii SterNB.

14. Dryandroides lignitum UNG. sp.

15. Diospyros braehysepala Ad. Brong.

16. Eehitonium sophia WEB.

17. Myrtus Dianae? HeER.

+18. Callistemophyllum Mougcoti HeEr.

+19. Callistemophyllum Mühlenbeeki HeEr.

20. Eucalyptus oeeaniea UNG.

21. Celastrus Ettingshauseni HeER.

22. Celastrus pseudo-ilex ETtingsh.

+23. Ilex primiformis HeER.

24. Zizyphus tiliacfolius UNG. sp.?

25. Paliurus tenuifolius Hewr.

26. Rhus Pyrrhoe UNG.

+27. Crataegus alsatiea HeEs.

28. Caesalpinia Haidingeri Eтtingsh.

29. Acaeia Parsehlugiana HeER.

30. Mimosites Haeringiana Еттіngsh.

+31. Phyllites Buehingeri Hewr.

Ausserdem findet man in dem Melanienkalk selbst unbestimmbare Pflanzenstengel und Gräser, sowie:

Chara helieteres Brg. bei Klein-Kembs. Die Weiden (Salix varians) und Eichenblätter überwiegen in der Flora der Masse nach. 9 Arten, welche mit + bezeichnet, sind für den 
Fundort Spechbach eigenthümlich. Bemerkenswerth ist ferner, dass Cinnamomum, welches in den übrigen jüngeren Blättersandsteinen des Elsasses durchaus prävalirt, hier ganz fehlt. Ebenso hat Spechbach keine Palmen geliefert.

Die Fauna ist im ganzen ärmer als die Flora, jedoch ist ihre Verbreitung eine grössere. Es wurde bisher folgendes gefunden :

\section{Wirbelthiere.}

Palcueotherium medium Cuv., von H. v. Markr bestimmt. Ein Unterkiefer ${ }^{1}$ und vereinzelte Zähne aus dem Brunnstatter Steinbruch. Ferner ein isolirter Eckzahn von Rixheim. Ich möchte letzteren auch zu $P$. medium stellen und ihn als linken, oberen Caninen ansprechen, indem er nur an seiner vorderen Schmelzkante eine schwache Usur zeigt. Cuvier gibt folgende Beschreibung des Palaeotherium-Eckzahnes. Oss. foss., III, pag. 6. „La canine n'est point une défense ....., c'est un simple cône oblique, un peu arqué, dont la face interne est un peu plane, et l'externe plus qu'un demi-cône. Les faces sont distinguées par deux arêtes longitudinales et leur base est entourée de la même ceinture que l'on, voit aux molaires." Alles dies gilt für unseren Zahn, nur dass die Innenseite recht stark abgeflacht ist. Der Zahn ist auf Tf. III, Fig. $1^{17}$ wegen seiner auffallenden Form, abgebildet ${ }^{2}$.

Therialomys sp. Erwähnt GreppIN (p. 159) von Klein-

1. Dieser Unterkiefer wird im Museum der Soc. indust. zu Mülhausen aufbewahrt.

2. Aus dem Badischen ist das Vorkommen von Palaeotherium magnum Cuv. in dem Sandstein von Pfaffenweiler südlich von Freiburg bekannt. Vermuthlich gehören die Schichten zum Unt. Olig. Beitr. zur Statistik der inneren Verwaltung des Grossherzogthums Baden, XII, p. 20, 1862. 
Kembs. Diejenigen Reste, welche mir von dieser Lokalität vorliegen, erlauben nicht die Bestimmung der Species.

Schildkröten. Ueberreste einer Schildkröte (Emys sp.) gibt Sandberger (pg. 327) von Kle in-Kembs an. Delbos und KöchlıN-SchldMberger (pg. 16) erwähnen Schildkröten? Eier von Morvillars.

\section{Conchylien des Melanienkalkes.}

1. Neritina brevispira SANDBG., L. Sw. C., Tf. XVI, Fig. 17, pag. 322. Als Seltenheit bei Klein-Ke mbs, ferner bei Illfurt.

2. Melania Laurae MATHÉRon. Als Mel. Escheri Brong. v. Laurae Matri. in SandBg., L. Sw. C., pg. 323, Tf. XVII, Fig. 17. Diese häufigste Art im Brunnstatter-Kalk, welche oft ganze Schichtflächen bedeckt und Veranlassung zu dem Namen Melanienkalk gibt, gehört zu der Gruppe der $M$. Escheri. Brong. Von Merran und Delbos wurde sie geradezu als M. Escheri bezeichnet. Sandberger führt sie als Varietät Laurae der obengenannten Art auf, und Greppre als $M$. Laurae (= M. Koechlini Grepp.). Die verbreitete Gruppe der $M$. Escheri, zu welcher wir wohl auch die $M L$. alpina MAY. und die $M$. albigensis NouL. zählen müssen, reicht vom Eocän bis in das Miocän, woselbst sie ihr Maximum erlangt. Sandberger unterscheidet 5 Varietäten der ächten $M$. Escheri. Im Oligo-

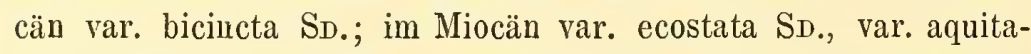
nica (Nous.), var. grossecostulata SD. und var. rotundata SD. Die letzte dieser Varietäten, bei welcher namentlich die Querleisten in grosser Zahl und sehr gleichmässig entwickelt sind, findet sich im Miocän von Vermes bei Delsberg. Sie liegt mir in grosser Zahl aus der Greppinschen Sammlung vor. Diese 
Varietät ist es, welche, wie schon SANDBERGER bemerkt hat, sich der $M$. Laurae am meisten nähert. Sie gleicht namentlich jugendlichen Exemplaren von Klein-Kembs, jedoch kommt bei v. rotundata niemals bie knotige Sculptur auf der letzten Windung zu Stande. Ferner gilt noch als Unterschied, abgesehen von der charakteristischen Sculptur, dass $M$. Laurae grösser, gedrungener ist und eine rundere Mündung besitzt als der Typus oder die Varietäten der $\boldsymbol{M} I$. Escheri.

Das im Alter decollirte Gehäuse der $M$. Laurae hat eine Länge von 50-60 mm, während die Breite gegen $20 \mathrm{~mm}$ (an nicht comprimirten Steinkernen) beträgt. Bei ausgewachsenen decollirten Stiicken zählt man meist 6-7 Umgänge, während etwas jüngere, die noch nicht so stark abgeworfen haben, 8 Umgänge zeigen; die totale Windungszahl würde, wenn alles erhalten bliebe, sich sogar auf etwa 17 Umgänge belaufen. Die Spitze, welche sich an den zahlreichen jugendlichen Exemplaren beobachten lässt, ist ungemein schlank. Die ersten 6 Windungen messen zusammen llur $2 \mathrm{~nm}$; auch sind dieselben glatt und erst auf der 5. oder 6. zeigen sich Querleisten. Die Zahl der Querleisten beträgt auf einem Umgang durchschnittlich 10 und wird auf den unteren, breiten Windungen, wo sie in der Regel ganz obliteriren, nicht vermehrt. Zwischen den Querrippen stehen feine, unregelmässige Anwachsstreifen, welche nach der Mündung zu gröber werden; in dem Maasse wie die Querrippen verschwinden. Ferner sind 4-6 Längskiele vorhanden, welche, auf den unteren Windungen namentlich, stark hervortreten und deren Zahl auf dem letzten Umgange meist 7 beträgt. An den Kreuzungspunkten der l」ängskiele mit den Querleisten bilden sich kleine Knoten; ihre Zahl ist auf der letzten Windung sehr vermehrt, indem auch die Anwachsstreifen sich an deren Bildung betheiligen. Es entsteht auf diese Weise die für $M$. Laurae so bezeichnende Gitterung. 
Bei der grossen Häufigkeit ist natürlich eine gewisse Variabilität nichts Auffallendes. Die Sculptur ist wechselnd stärker oder schwächer ausgebildet und die Knötchen erscheinen manchmal in der oberen Reihe etwas dornig.

Melania Laurae findet sich bei Klein-Kembs, Brunnstatt, in den Steinbrüchen bei Mülhausen (Tannenwald), bei Riedisheim, Nieder-Spechbach", Morvillars und wird ausserdem von Saxpberger aus den Mergeln von Apt erwähnt.

3. Melanopsis (Macrospira) Mansiana Noul. Var. Sandr., L. Sw. C., p. 324, Tf. XVIII, Fig. 2. Dieselbe unterscheidet sich von dem Typus, welcher im Palaeotherienkalk von Süd-Frankreich vorkommt, durch ihre nicht so stark verlängerte Spitze. Sie liegt mir von Klein-Kembs, Ilfurt und Nieder-Spechbach vor, wo sie überall ziemlich häufig ist.

4. Melanopsis cf. carinata Sow. var. Neben Melanopsis Mansiana findet sich bei Illfurt noch eine zweite Art, welche durch ilıre seicht ausgehöhlten Umgänge und ihren scharfen, an der Naht dachförmig überstehenden Kiel leicht zu unterscheiden ist. Das ganze Gehäuse hat durchaus einen an Pyrgula erimernden Habitus. Die ellglische $M$. carinata Sow. steht unserer Art nahe. Sie ist sehr verbreitet und reicht vom Obereocän (Rallingen) bis in das Mitteloligocän. Ich glaube, dass wir unsere Art als Varietät derselben ansehen müssen, indem sie sich folgendermassen unterscheidet: Sie ist schlanker und spitzer und zeigt noch schärfere Nahtkanten. Die Mündung konnte ich leider nicht untersuchen.

5. Nematuma? sp. Sandbg., L. Sw. C., pg. 326, Tf. XVIII, Fig. 9. Nur einmal bei Klein-Kembs gefunden.

1. Der für die Melanienkalk-Conchylien erwähnte Steinbruch, zwischen Vied erSpechbach und Illfurt, ist nicht mit dem nahe dabei gelegenen Sandsteinbruch zu rerwechseln, welcher früher die Pilanzenreste geliefert hat. 
6. Hydrobia indifferens SpBG., L. Sw. C., pg. 324, Tf. XVIII, Fig. 4. - Tf. III, Fig. 5. Die Steinkerue zeigen 5-6 Umgänge und messen $2,5 \mathrm{~mm}$. Die Nähte sind tief, die Schale ist fast glatt. Bei dem von Sandberger abgebildeten Exemplar dürfte der letzte Umgang verzeichnet sein; wenigstens begegnete mir kein Exemplar, welches mit seiner Abbildung übereinstimmt. Ziemlich selten bei Klein-Kembs und bei Brun utatt. Schlankere Exemplaie von Hydrobien mit 6--7 Umgängeu, welche sich vielleicht an diese Art anschliessen, fand ich im Abdruck bei Nieder-Spechbach.

7. Valvata circinate Mer. \$p., Sandbt., L. Sw. C., pg. 324, Tf. XVIII, Fig. 5. Da das voll SANDBERGER abgebildete Exemplar etwas zu flach erscheint, so wurde auf If. III, Fig. 6 von neuem die Abbildung eines Steinkernes dieser häufigen kleinen Art gegeben. Das Gehäuse hat keinen sehr weiten Nabel, zeigt 3-4 Umgänge und erreicht bis zu 1,5 mm Höhe. Für eine so kleine Valvata hätten wir es mit einer sehr hoch gewundenen Form zu thun, welche in der Gestalt an Amnicola erinnert. Brunnstatt, Klein-Kembs, Nieder-Spechbach und Rixheim.

? Pruludinu viviparoides Bronn. = P. Hammeri DEFr. wird von Greppix (pg. 160) von Klein-Kembs erwähnt. Weder ich, noch so viel ich weiss irgend jemand anders, hat je im Melanienkalk eine grosse Paludinen-Art beobachtet. Auch befindet sich in der Greppinschen Sammlung kein Fossil mit der obigen Bezeichnung. Vielleicht dürfte ein Irrthum vorliegen.

8. Nystia polita F. EDw. sp. Die beiden Stücke, welche zu dieser Art gehören, stammen von Brunustatt. Das kleine decollirte Gehäuse hat eine Länge von $6 \mathrm{~mm}$, eine Breite von $3,2 \mathrm{~mm}$ und zeigt 3-4. Umgänge. Die Nähte sind schmal und die Windungen sehr flach. An dem am besten erhaltenen Stück sind Spuren von einem Nabelritz zu erkennen. Die Mündung 
ist spitzig eiförmig, der Mundrand ist am oberen Theil verdickt und schwach, unten stärker umgeschlagen. Diese im Obereocän der Headon-Series verbreitete Art kenne ich aus dem Elsass nur von Bruninstatt.

9. Planorbis cf. goniobasis SandBg. Derselbe wird als Pl. rotundatus BraRd. bei Delbos (pg. 17) voll Brunnstatt und Morvillars und bei GrEPPIN (pg. 159) auch noch von Klein-Kembs erwähnt. Das thatsächliche Vorkommen eines wohl hierher gehörigen grossen Planorbis könnte ich ferner bei Kötzingen und Nieder-Spechbach beobachten. Die Art ist selten und der Erhaltungszustand ungenügend.

10. Planorbis patella SAnd, L. Sw. C., pg. 324, Tf. XVIII, Fig. 6. Nicht häufig bei Klein-Kembs, Brunnstatt, Mülhausen (Tannenwald) und Rixheim.

11. Planorbis sp. SAND., L. Sw. C., pg. 325 . Noch ein anderer kleiner segmentiner Planorbis aus dem Melanienkalk wird yon SANDBERger erwähnt, welcher zwischen $P l$. Chertieri (Ob. Eoc.) und $P l$. Lartetii (Mioc.) stehen soll. Ich habe mir kein gutes Exemplar davon verschaffen können.

12. Limner marginata SAND., L. Sw. C., pg. 325, Tf. XVIII, Fig. 7. Die häufigste Limnea im Melanienkalk, deren Mündung allerdings noch unbekannt ist. In ihrer Form ist diese Limnea, welche der L. strigosa Brong. von Pantin sehr nahe stehen soll, ziemlich variabel. Kleinere, spitze Exemplare mit flachen Nähten und glatter Schale gleichen oft der L. elongata M. DE Serres aus dem Bembridge-Kalk. Alle 3 soeben genannten Limneen gelı̈ren in die Gruppe des $L$. longiscata Brong., welche für das Obereocän bezeichnend ist. Ganz typische Exemplare sind häufig bei Klein-Kembs, abweichende Stücke finden sich bei Brunnstatt, Altkirch, etc.

13. Limnea fusiformis Sow. Dieselbe wird von Deubos (pg. 17) aus dem Kalk von Morvillars erwähnt. Steinkerne, 
die wahrscheinlich hierher gehören, besitze ich von Brunnstatt. Ferner liegt mir ein auffallend spitz aufgewundenes Steinkermfragment von Kötzingen vor, welches jedenfalls nichts mil L. marginata $\mathrm{zu}$ thun hat. (Tf. III, Fig. 8 neben L. marginata, Fig. 7, letztere Skizze nach SANDberger XVIII, 7 a.)

14. Limner polita Mer. ined. Tf. III, Fig. 10. Merian gibt folgende Beschreibung ohne Abbildung: „9 Windungen, $9^{3} / 4 \mathrm{~mm}$ lang, $3 \mathrm{~mm}$ breit, Naht kaum sichtbar. Seltell." SAndBerger vermuthet, dass diese Limnea eine Oleacina sei. Eine genau auf Merians Diagnose passende Form fand ich nicht im Melanienkalk, jedoch liegen mir verschiedene Exemplare einer sehr schlanken Limnea vom Habitus unserer recenten L. glabra MüLL. vor. Es mag sein, dass Merians L. polita einen extremen Fall unserer ziemlich variablen Formen darstellt.

Das kleine, ungemein schlanke Gehäuse ist spitzkegelförmig und besitzt sehr flache Nähte. Die Schale erscheint im Abdruck fast glatt, kaum merklich gestreift. Bei einer durchschnittlichen Grösse von $12 \mathrm{~mm}$ sind meist 6-7 Umgänge vorhanden. Ueber die Mündung lässt sich noch nichts aussagen. Selten bei Brunnstatt und Nieder-Spechbach.

15. Limnea subpolita n. sp. If. III, 9-9c. Steht der vorigen Form sehr nahe und gehört auch zur Gruppe der L. glabra. Sie unterscheidet sich durch ihre bedeutendere Grösse und ihre relativ geringere Windungszahl. Das Gehäuse ist spitz kegelförmig, am oberen Ende convex conisch. Die Nähte sind sehr flach aber deutlich. Die Windungen sind kaum gewölbt, mit Ausnahme des letzten, sehr niedrigen Umgangs, welcher etwas gerundet ist. Die Form zeigt, bei einer Länge von ungefähr $20 \mathrm{~mm}, 6$ Umgänge und $6-7 \mathrm{~mm}$ Breite. Die Grösse kann jedoch eine beträchtlichere werden, indem ein Bruchstück, welches nur die 2 letzten Umgänge zeigt, die gleiche Länge erreicht und etwa $8 \mathrm{~mm}$ Breite hat. Nach den Stein- 
kernen zu urtheilen, war die Spindelfalte kräftig entwickelt. . Die Mündung war spitz eiförmig und sehr kurz. Die Schale war glatt. $L$. subpolite findet sich bei Brunnstatt selten. In etwas unsicheren Resten kemne ich sie ferner von Rixheim und aus den Hornsteinknollen voll $R$ iedisheim.

16. Limnea cf. crossuln Desh. If. III, Fig. $11 a, b$. Eine kleine, bauchige Limnea mit tiefen Nähten liegt mir von Kötzingen vor. Dieselbe ist meist nur $7 \mathrm{~mm}$ lang, $5 \mathrm{~mm}$ breit und hat 4 Ungänge; dass dieselbe viel grössere Dimensionen erlangen kamn, ist aus einigen Steinkernenfragmenten des gleichen Fundortes zu ersehen. Eines derselben, welches nur 2 Umgänge hat, misst $13 \mathrm{~mm}$. Diese Limnea ist der L. olivula von Buchsweiler nicht unälnhlich, gleicht aber noch mehr der L. crassula Desn. aus dem Obereocän von Cherry-Chartreuve. Sehr kleine Steinkerne $(3-4 \mathrm{~mm})$ von $R$ ix heim, welche GrepPIN als $L$. ovum Brg. bestimmte, dürften auch hierher gehören. Eine sichere Bestimmung war deshalb unmöglich, weil die Mündung unbekannt ist.

17. Glandina cf. costellatı Sow. sp. Ein Bruchstück einer grossen Glandine sammelte ich bei Klein-Kembs. Die feine, gekörnelte Sculptur erinnert an diejenige der Gl. costellata Sow. sp. aus dem Bembridge-Kalk und von Villeneuve.

Heliceen kommen im Melanienkalk meltrere Arten vor, welche alle recht selten sind. Merian erwähnt deren drei ohne Benennung mit folgender Charakteristik:

$s p$. a. "Gross, gewöhnlich plattgedrückt, mit Spuren eines Bandes, $25 \mathrm{~mm}$ Durchmesser, 4-4\% Windungen."

$s p$. b. "Kleiner, $10 \mathrm{~mm}, 4-4 \frac{1}{2}$ Windungen, ziemlich flach."

sp. c. "Ganz klein, 4-5 Windungen, kegelförmig aufgerollt. Der Abdruck der Scliale ist gerippt oder fein gestreift."

18. Strobila pseudolabyrinthica SANDb. In die Nähe von dieser Art dürfte vielleicht die von Desbos erwähnte 
Helix labyrinthica Sar. gehören und diese würde damn der sp. c. von Merian entsprechen. Die in Nord-Amerika recente $S t$. labyrinthica $\mathrm{S}_{\triangle \mathrm{Y}}$. steht der obereocänen St. pseudolabyrinthica SAND. (Headon-Hill S.) nahe, und diese wiederum der noch wenig bekannten St. sublabyrinthica F. EDw. aus den Bembridge Series, mit welcher sie vielleicht sogar ident ist. Ich beobachtete nur einen kleinen Abdruck, welcher die erforder-

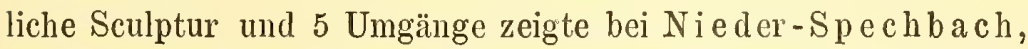
als weiterer Fundort wäre Brunnstatt zu nennen.

19. Helix sp. ined. If. III, Fig. $4 a, b$. Von Deubos und von Greppin wird Helix resp. Nanina occlusa F. EDw. sp. von Brunnstatt erwähnt. Ich habe dieselbe bisher niemals von dort gesehen. Hingegen liegt mir ein vereinzelter Steinkern von diesem Fundpunkte vor, welcher etwa die Grösse der $N$. occhusa hat und welcher, wenn er plattgedrückt wäre oder sich nicht aus der Gesteinsmasse herauslösen liesse, wohl mit dieser verwechselt werden könnte. Unsere Abbildung Tf, III, Fig. 4 zeigt jedoch, dass wir es mit einer anderen Species $\mathrm{zu}$ thun haben, indem schon allein der viel stärkere Kiel dieselbe leicht von $N$. occlusa unterscheidet. Da die Mündung mir unbekannt ist, muss ich auf die nähere Fixirung der Art verzichten und möchte nur darauf aufmerksam machen.

20. Nanina Köchlini n. sp. (Wahrscheinlich die Species $a$ von Merian) Tf. $1 I I$, Fig. 3-3d. Aus dem Kalk von Brunnstatt liegen mir 6 mehr oder weniger gute Steinkerne einer schönen, grossen Nanina vor. Der Durchmesser beträgt 20 bis $25 \mathrm{~mm}$, die Höhe gegen $12 \mathrm{~mm}$ und die Anzahl der Umgänge beläuft sich auf $4 \div 5$. Das Gehäuse ist ziemlich weitläufig aufgewunden, niedergedrückt, oben flach gewölbt und war auf der Unterseite jedenfalls verdeckt genabelt, wie dies der Eindruck am Steinkern (Fig. $3 b$, Tf. III) andeutet. Auf dem'Steinkerne erscheint der Nabel fein stichförmig. An der Peripherie war III. 
die Schale ohne jedwede Kielandeutung spitz zugerundet. Die Nähte sind sehr flach und die Umgänge sind mit sehr feinen, unregelmässigen Anwachslinien bedeckt. Die schräge Mündung besass, mit Ausnahme des umgeschlagenen Spindelsaumes, scharfe Ränder. Die nächst verwandte, fossile Art dürfte Nanina intricata Nous. sp. sein, dieselbe ist jedoch nicht so flach und überhaupt gedrungener als $N$. Koechlini und findet sich im Unteroligocän von Mas Saintes Puelles und Villeneuve.

21. Megalomastoma mumia LuK. sp. (= Cyclostoma Koechlinianum Merian, in SandB., L. Sw. C., pg. 326, Tf. XVIII, Fig. 10, als Megalom. Kocchlinianm Mer. sp.) Auf diese im Melanienkalk so häufig vorkommende Megalomastoma wurde von Merian zuerst hingewiesen; er nannte dieselbe Cycl. Koechlinianum und gibt folgende Beschreibung: "Ausgewachsen mit 7 Windungen, $18 \frac{1}{2} \mathrm{~mm}$ lang. Aehnlich dem C. Mumia Lмк. aus dem Pariser Süsswasserkalk". Spätere Autoren, wie Delibos und GREPPIN, vereinigen dieselbe mit $\boldsymbol{M I}$. mumia, während SANDBERGEr dieselbe noch als eigene Species festhält. Derselbe sagt in seinen Land- und Süssw.-Conch., pg. 326: "Schon von Merian wurde die Aehnlichkeit mit $M$. mumia hervorgehoben, sie ist in der That sehr gross, doch zeigt $M$. Koechlinianum 9 statt 8 flachere, an der Nalit kantige Umgänge, eine weit feinere Sculptur und auch die Ränder der Mündung sind viel weniger stark ausgebreitet als bei Mr. mumia." Beim Vergleich einiger Exemplare aus dem Grobkalk mit einer grossen Zahl von Stïcken aus dem Melanienkalk konnte ich keinen wesentlichen Unterschied finden, der mich veranlasste die beiden Arten zu trennen. 1. Was die Anzahl der Windungen betrifft, so ist der von SANDBERGER angegebene Unterschied nicht stichlialtig. SANDBERGER sagt selbst an anderer Stelle, bei Beschreibung der IM. mumia, die Schale „besteht aus 9 flach gewölbten an den Nähten gerandeten Umgängen". Bei den Groblalk-Exemplaren 
sind allerdings häufig die Spitzen abgebrochen, während sie bei den Stücken aus dem Melanienkalk in der Regel erhalten sind. 2. Dass die Umgänge bei $M$. Koechlinianum flacher sind als M. mumia, konnte ich bei gut erhaltenen Exemplaren nicht wahrnehmen, höchstens hat dies den Anschein bei den so häufig platt gedrückten Individuen. 3. Die eine Art hat an der Naht kantige, die andere gerandete Umgänge; auch hier war es mir nicht möglich, einen Unterschied zu constatiren. 4. Die Sculptur ist bei meinen Exemplaren durchaus gleich. 5. Schliesslich sind auch die Mündungsränder gleich weit ausgebreitet, wovon ich miclı namentlich durch Vergleichung von Wachsabdrücken der Mündung von $M$. mumia mit entsprechend grossen, nicht deformirten Steinkernen der $M$. Koechlinianum überzeugte. Meistens lässt allerdings die schlechter erhaltene $M$. Koechlinianum fast nichts von den Münlungscharakteren erkennen. Als einzigen Unterschied möchte ich geltend machen, dass die Exemplare aus dem Brunnstatter-Kalk, abgesehen von der Variabilität, durchschnittlich etwas kleiner und dünnschaliger? (vielleicht Erhaltungszustand z. Th.) sind, als die Pariser Stücke. Man könnte hierauf kaum eine Varietät begründen. Wir schliessen uns deshalb der Ansiclit von Detios und Greppin an und bezeichnen die Megalomastoma-Art aus dem Melanienkalk als M. mumia Limк sp.

Das Auftreten dieser Art im Melanienkalk ist durchaus nicht befremdend. M. mumia findet sich im oberen und mittleren Grobkalk in den Sables moyens und reicht hinauf bis in den Bembridge-Kalkstein. Aus dem Melanienkalk kenne ich sie von Klein-Kembs, Brunnstatt, Rixheim, Flaxlanden, Spechbach und Mülhausen (Tannenwald) überall häufig.

22. Auricula (Alexia) alsatica Mer., Tf. III, $12 a-c$. Von Sandberger als Mclampus alsaticus Mer. sp. beschrieben und abgebildet (pg. 325, Tf. XVIII, Fig. 8). Die Gattung Melam- 
pus $^{1}$ besitzt einen scharfen äusseren Mundsaum, was bei $\dot{A}$. alsatica nicht der Fall ist. Man erkennt deutlich die umgeschlagene Lippe, wenn die Steinkerne noch im Gestein festsitzen und noch nicht losgebrochen sind. Die oceanische Gattung Laimodonta, mit welcher SANDberger $A$. alsatica ganz speciell vergleichen möchte, ist ebenfalls recht verschieden und namentlich durch ihre äussere Spiralsculptur gekennzeichnet, von der bei A. alsatica jede Spur fehlt. Die schwierige Frage ist nun, in welche Gruppe soll $A$, alsatica eingereiht werden. Indem wir dieselbe zu Alexia stellen, kommen wir in gewissem Grade wieder auf die alte Mertansche Ansicht zurück, welcher A. alsatica mit A. myosotis vergleicht. Hierbei ist jedoch festzuhalten, dass manche fossilen Alexien, namentlich die älteren (im Oligocän), von den recenten und jüngeren Formen abweichen und sich der Gattung Pythiopsis nähern. Sie zeigen grosse Neigung zur Compression des Gehäuses. $\mathrm{Zu}$ diesen Formen, zu welchen z. B. auch die Alexia depressa Bötтg. aus dem Cyrenenmergel und die A. Böttgeri Mer. aus dem Meeressand gehören, möchte ich auch die $A$. alsatica rechnen.

Das von vorn nach hinten comprimirte Gehäuse wird meist gegen $12 \mathrm{~mm}$ lang, gegen $6 \mathrm{~mm}$ breit und gegen $4 \mathrm{~mm}$ dick. Es besitzt 7 flache Umgänge, welche durch gerandete Nähte getrennt sind, und hat eine dünne, fein gestreifte Schale. Auf dem letzten Umgange befindet sich, der Mündung gegenüber, ein schräger Wulst. Dieser Wulst, welcher eine periodische Mündung andeutet, erscheint auf der letzten Windung des Steinkernes als Furche. Er entspricht den längs der ganzen Peripherie der Schale ver-

1. Die Eintheilung der Auriculiden von ADAms in zwei grosse Abtheilungen nach der Beschaffenheit des äusseren Mundrandes in: 1) Melampidae mit scharfer, 2) Auriculidae s. s. mit verdickter oder umgeschlagener ausserer Lippe, ist unzu. lässig und wurde nicht beibehalten. Melampus ist also nur als Gattungsname gebraucht. 
laufenden Varices von Pythiopsis. Die Scheidewände der älteren Windungen werden im Innern, wie bei den anderen Alexien, beim Weiterwachsen vollständig resorbirt. Del rechte Mundsaum ist lippenartig verbreitert und verdickt; in der Mitte zeigt er einen sehr schwachen, schräg nach Innen laufenden Schmelzzahn. Eine Neigung zum Umschlagen des Perisoms ist auch bei anderen Alexien vorhanden. Auf der Mündungswand steht oben eine kleinere, darunter eine lräftige, mehr horinzontale Falte, hierauf folgt die Spindel mit einer dritten Falte. Die Art findet sich meist nur in Steinkernen, selten mit erhaltener Schale. Sie ist ziemlich luäufig bei $\mathrm{Br}$ unstatt, selten bei Klein-Kembs

23. Auricula (Alexia) sundgoviensis 11. sp. If. III, Fig. 13-15. Obwohl ich die Mrriansche A. protensa neben der A. alsatica nicht auffinden konnte, so überzeugte ich mich doch von dem Vorhandensein noch einer anderen Art im Melanienkalk. Diese Art, welche ich einstweilen auch zu Alexia stelle, ist kleiner, seltener und noch nicht vollständig gekannt. Das Gehäuse ist ähnlich demjenigen der $A$. alsatica, jedoch etwas schwächer comprimirt. Die Spitze bildet einen stumpferen Kegel als bei dieser Art. Exemplare von $3 \mathrm{~mm}$ zeigen bereits $5 \mathrm{Um}$ -

1. Von Meruan werden zwei Auricula-Arten aus der Gegend von Mülhausen angeführt.

1) A. alsatica "ausgewachsen 7 Windungen, $13-13,5 \mathrm{~mm}$ lang, $6 \mathrm{~mm}$ breit. Aehnlich der in der Provence und Italien lebenden A. myosotis. Häufig."

2) A. protensa HER. " 10,5 Windungen, 14,5 mm lang, $4 \mathrm{~mm}$ breit. Zeigt eine langc ausgebreitete Lippe und eine Rinne auf den Windungen der Steinkerne. Selten."

Greppin identifizirt die A. prolensa Men. mit der A. depressa Desr. und die A. alsatica mit der A. Dutemplei Desi. Nach dem mir vorliegenden Material, welches auch die von GrEPrıN gesammelten Stücke cnthält, scheinen alle grösseren Exemplare zu einer und derselben Art zu gehören, soweit es mich der zuweilen schlechte Erhaltungszustand beurtheilen lässt. Eine Identifizirung mit den sehr seltenen Arten des Pariser Beckens halte ich für unstatthaft. Abbildung und nahere Beschreibung del Meranschen Originale wäre sehr wünschenswerth. 
gänge (Fig. 13), welche eben so flach erscheinen wie bei der vorigen Art. Die Anzahl der Spindelfalten ist grösser. Es stehen auf der Mündungswand 2 kleinere Falten oberhalb. der Hauptfalte, und zwischen dieser und der Falten tragenden Spindel ist noch eine schwache Faltenandeutuug eingeschaltet (Fig. $14 \mathrm{a}$ ). Am wichtigsten ist jedoch der Unterschied, dass der äussere etwas umgeschlagene Mundrand im Inneren 3 Schmelzzähne trägt (Fig. 13, 14 6, 15). Die abgebildeten Exemplare wurden aus einem Kalkstïck von Brunnstatt herauspräparirt.

24. ? Cyclas sp. Von Merian folgendermassen angeführt: „Nur einmal gefunden, Wirbel nicht sehr excentrisch, ziemlich starke Falten auf dem Steinkern." Vielleicht eine Cyrena, welche sich in den Steinmergeln von Efringen und Istein in Baden gleich über dem Melanienkalk findet. 
Wir haben auf den vorstehenden Seiten gesehen, dass die geologischen Verhältnisse des Melanienkalkes durchaus keine ganz einfachen sind, und auch die organischen Reste, welche derselbe umschliesst, lassen in mancher Hinsicht zu wünschen übrig. Es kann uns aus diesem Grunde nicht auffallen, wenn namentlich in früherer Zeit eine grosse Unsicherheit über sein genaues geologisches Alter herrschte. Merian und Heer betrachteten den Melanienkalk als Miocän (resp. Ob. Oligoc.). Sie nahmen an, dass derselbe die an vielen anderen Punkten im Sundgau vorhandenen, den Melanienkalk umgebenden, marinen Thone und Sandsteine des Oligocäns (Tongrien) überlagere. Diese Ansicht, welche vom rein geologischen Standpunkte aus ganz plausibel erscheint, liess sich mit den palaeontologischen Befunden nicht in Einklang bringen, namentlich nicht nachdem der Steinbruch bei Brunnstatt Reste von Palaeotherium medium geliefert hatte. Deubos vertrat zuerst in seiner Beschreibung des Dép. du Haut-Rhin mit grosser Bestimmtheit die Ansicht, dass der Melanienkalk cine vortongrische Bildung sei. Er verwies denselben in das Obcreocän. Greppin schliesst sich der Ansicht von Deubos an, er stellt den Melanienkalk in das Obereocän und parallelisirt denselben mit der oberen Bohnerzformation (Fauna von Moutier, Mauremont, Ober-Gösgen etc.). In SANDberger's Ld. u. Sw. C. hingegen finden wir den Melanienkalk als jüngstes Unteroligocän abgehandelt, und es wird sogar die Möglichkeit offen gelassen, dass derselbe zum Mitteloligocän gehört.

Rufen wir uns in das Gedächtniss zurück, dass der Me- 
lanienkalk einerseits direkt auf dem oberen Jura (bei Morvillars), andererseits auf Bohnerzthonen (bei Klein-Kembs) oder auf unbestimmten Mergeln (Puits, Heidet etc.) aufruht, ferner dass derselbe im Elsass von Gyps bei Zimmersheim (Unt. Oligoc.), von Blättersandstein und Melettaschichten (Mit. Oligoc.), in Baden, nach den Untersuchungen von SandBerger und Schilu, von Sandstein mit Natica crassatina bedeckt wird, so bleibt uns schliesslich nur noch die Wahl zwischen Unteroligocän und Obereocän übrig. An ein höheres Alter können wir wegen der grossen Verschiedenheit der Buchsweiler und der Brunnstatter Fauna nicht denken; zumal, da in nicht allzuweiter Entfernung von Basel, bei Hobel, der Buchsweiler-Kalk mit Pl. pseudammonius ansteht. Die Entscheidung der Frage, ob wir den Melanienkalk als oberstes Eocän oder als tiefstes Oligocän ansprechen sollen, ist jedenfalls eine mehr oder weniger von individuellen Alsschauungen abhängige. Ich möchte mich zu der ersteren Ansicht bekennen, theils um die bisher im Lande übliche Bezeichnung als Eocän beizubehalten, theils weil es mir am zweckmässigsten erscheint, die Grenze zwischen Oligocän und Eocän im Elsass dahin zu verlegen, wo die Süsswasserbildungen vollständig den marinen oder stark brackischen Bildungen weichen müssen.

Bei dieser Discussion gewinnt der Gyps von Zimmersheim eine gewisse Bedeutung. Er überlagert im Elsass die Schichten des Melanienkalkes (cf. Fig. 2). Analoge Gypsvorkommnisse in Baden, bei Bamlach und Wasenweiler',

1. Auch das Gypsvorkommen von Hat ts tat $\mathrm{t}$ unweit Colmar dürfle hierher gehören. Der Gyps ist jetzt nicht mehr aufgesehlossen, doch fanden sich in den Aeckern noch Stücke von plattigem, hellem Mergelkalk, der den Gyps überlagern soll. Dieses Gypsvorkommen wäre das nördlichste und würde somit die ungefähre Nordgrenze der von Süden her eindringenden Meeresbueht andeuten, in welcher dic Gypsbildung zur Unteroligoeänzeit sieh vollzog. 
welche Sandberger und Prof. Benecke für gleichalterig ansehen, werden von mitteloligocänen Schichten überlagert'. Diese unteroligocänen Gypse würden damn, nebst den Gypsen des Terrain sidérolitique von Delsberg, wie Greppis und Hébert dies schon ausgesprochen haben, z. Th. den Montmartre-Gypsen entsprechen. Der Melanienkalk liegt aber unter diesen Gypsen oder könnte höchstens als Süsswassereinlagerung an deren Basis aufgefasst werden, falls ihn die schwarzen Gypsinergel im Bohrloch von Dornach unterteufen.

Sollte es sich ferner vielleicht herausstellen, dass die so fraglichen "marnes à cyrènes" mit ihren schlecht erhaltenen und daher noch nicht ganz sicheren Fossilresteu den nicht unähnlichen Mergelkalken von Istein mit Mytilus socialis A. Br. ${ }^{2}$ und der Rütireingrube bei Efringen mit Cyrena semistriata DesH. gleichalterig sind, so würden auch diese in das Bereich des Unteroligocän's fallen. Ihre nicht $\mathrm{zu}$ leugnenden Beziehungen zum Melanienkalk, welchen sie direkt überlagern, und ihr Fehlen über den jüngeren Tertiärgebilden der Mülhauser Gegend wären dann verständlicher.

Um noch nit wenigen Worten auf die Fauna zurückzukommen, so erscheint mir auch hiernach die Stellung im obersten Eocän zulässig. Pal. medium ist eine Form, welche

1. Sandb., L. Sw. G., pg. 283. "Die Ueberlagerung des Gypses von Wasenweiler dureh Sandstein mit Dicotyledonen-Blättern, welehe sich in gewissen Lagen des nitteloligocänen Sandstcins mit $N$. crassatina im Breisgau wiederlıolen, beweist jedenfalls, dass dieser jünger ist."

2. Die Exemplare von $\boldsymbol{M}$. socialis in den hellen, graugelben Steinmergeln von Istein, welche mir vorliegen, stimmen ganz mit denjenigen aus dem Gerithienkalk von Hochheim (Unt. mioc.) überein. Ein Stück des gleichen Steinmergels, das von Efringen stammt und Cyrenenabdrücke enthălt, besitze ich gleiehfalls. Von den elsässer Steinmergeln mit Cyrenen habe ich nur ein sehr ungenügendes Material in der Müllia user Sannlung gesehen. 
gerade für die Grenzschichten des Oligocän's und Eocän's bezeichnend ist. Die Conchylienfauna hat den gleichen Charakter. Die häufigsten Arten sind Melania Laurae und Mregalomastoma mımia. Erstere bietet uns keine weiteren Anhaltspunlite dar; sie gehört zu einer Gruppe, welche im Obereocän beginnt und bis in das Niocäln reicht. Die zweite Art hingegen ist grade für das Obereocän besonders wichtig; sie beginnt im Mitteleocän und reicht bis in das Unteroligocän hinauf. Die anderen Arten sind meist weniger häufig und charakteristiscl. Sie zeigen Anklänge, einerseits an das Obereocän, anderersits an das Unteroligocän und sind zum Theil auf den Melanienkalk beschränkt, wie z. B. die schlanken Limneen aus der Gruppe der L. glabra. Auf der Schlusstabelle sind die interessanten Bezieliungen der Faunen des Melanienkalkes und des Buchsweiler-Kalkes zur Anschauung gebracht. Bemerkenswerth ist, dass bei der verhältnissmässig geringen Altersdifferenz die meisten Genera und wohl alle Arten verschieden sind. Dieser Umstand spricht für einen Unterschied in der Facies. Buchsweiler hat 22 Genera, der Melanienkalk 13 (ausser der ? Nematura). Gemeinsam sind 7, Limnea, Planorbis, Hydrobia, Glandina, Nanina, Helix und Megalomastoma. Für den Melanienkalk sind bezeichnend Melania, Melanopsis, Valvata, Megalomastoma und Auricula; für den Kalk von Buchsweiler Planorbis, Paludina, Euchilus, Glandina etc. Wenn Nanina occlusa, wie ich vermuthe, im Melanienkalk fehlt, so hätten beide Faunen keine Art gemeinsam'. Buchsweiler ist etwas artenreicher wie $\mathrm{Br} u n n s t a t$, Klein-Kembs etc.;

1. Der etwas jüngere Kalk vom Bischenberg tritt gleichsam vermittelnd auf. Er enthält neben P. pseudammonius (hh.), Megalomastoma cf. mumia (ss.). Auch findet sich am Bischenberg vorwiegend $L$. olivula; die gleiche Art ist selten bei Buchsweiler und wird im Melanienkalk durch $L$, crassula vertreten. 
erstere Lokalität hat etwa 30 , die anderen etwa 24 Species. Die Fauna von Mülhausen ist, wie schon erwähnt wurde, nicht so rein limnisch wie die von Buchsweiler. Auch trägt sie einen allgemeineren Charakter und steht nicht so isolirt da, denn der Melanienkalk weist nur 8 sichere, ihm allein eigenthümliche Formen auf, während $\mathrm{Buchsweiler} \mathrm{(incl.} \mathrm{der} \mathrm{gleich-}$ alterigen rheinischen Vorkommnisse) fast die dreifache Zahl besitzt. 


\section{Vergleichende Uebersicht der Genera des Melanienkalkes und des Buchsweiler-Kalkes.}

Bei dem Vorkommen einer einzelnen Sp. ist der Name, sonst die Sp. Anzahl angegeben.

\begin{tabular}{|c|c|c|c|}
\hline & $\begin{array}{l}\text { Dem Melanienkalk } \\
\text { eigenthümliche Formen } \\
\text { sind mit } \times \text { bezeichnet. }\end{array}$ & $\begin{array}{l}\text { Melanienkalk i. Ob.-Els. } \\
\text { mit } \\
\text { Palaeotherium medium. }\end{array}$ & $\begin{array}{l}\text { Buchsweiler-Kalk i. Ut.-L. } \\
\text { mit } \\
\text { Lophiodon tapiroides otc. }\end{array}$ \\
\hline 1. & 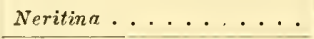 & brevispira X..... & \\
\hline 2. & 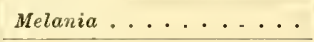 & Lurroue. ...... & \\
\hline 3. & Melanopsis. ........ & $2 \operatorname{sp} \ldots \ldots \ldots$ & \\
\hline 4. & 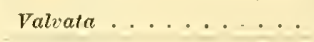 & circinata $\times \ldots \ldots$ & \\
\hline 5. & Paludina......... & $?$ & $2 \mathrm{sp}$ \\
\hline 6. & Enchilus. . . . . . . & - & Deschiensianmm. \\
\hline 7. & 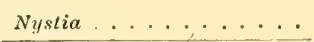 & 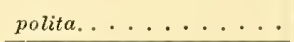 & \\
\hline 8. & Hydrobia. . . . . . . & indifferens $\times \ldots \ldots$ & $2 \mathrm{sp}$ \\
\hline 9. & Planorlis ......... & 2 sp. (1 sp.) . . . . . & pseudammoniess. \\
\hline 10. & Seamentinn. . . . . . & 1 sp. ined......... & Chertieri. \\
\hline 11 & Limnea. ......... & $5 \mathrm{sp},(2 \mathrm{sp} . \times) \ldots \ldots$ & $3 \mathrm{sp}$. \\
\hline 12. & Succinea (Brachyspira). . . & & polliolum. \\
\hline 13. & 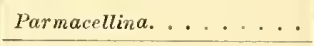 & & vitrinaeformis. \\
\hline 14. & Boltenia ........ & & teres. \\
\hline 15. & 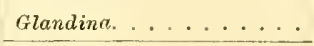 & 1 sp. ined. . . . . . & $3 \mathrm{sp}$. \\
\hline 16. & Cionella.......... & & formicina. \\
\hline 17. & 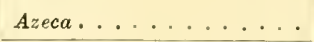 & & Büttgeri. \\
\hline 18 & 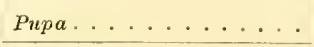 & $?$ & Buxavillana. \\
\hline 19. & Palaeostor........ & & Fontenayi. \\
\hline 20. & Clausilia (Canolicia).... & & densicostulata. \\
\hline 21 & 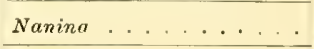 & Küchlini $\times \ldots \ldots$ & $2 \mathrm{sp}$ \\
\hline 22. & 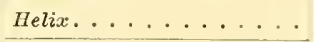 & $2 \mathrm{sp} . \ldots \ldots \ldots$ & laxecostulata. \\
\hline 23. & 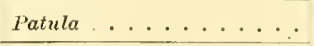 & & otigogyra. \\
\hline 24. & Megalomastoma...... & 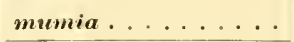 & turgidum. \\
\hline 25. & Strophostoma . . . . . & & striatum. \\
\hline 26. & Pomatias. . . . . . . . . & & Sandbergeri. \\
\hline 27. & Carychiopsis. . . . . . & & quadridens. \\
\hline 28. & 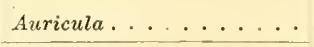 & $2-3 \mathrm{sp} \times \ldots \ldots$ & \\
\hline 29. & 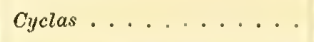 & 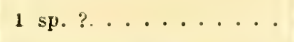 & Calyculina Castrense. \\
\hline
\end{tabular}




\section{LEBENSLA UF.}

Geboren wurde ich, Achilles Andreat, evangelischer Confession, Sohn des Banquiers Achilles Andreae und del Alimarda Andreae, geb. Freiin von der Borch, am 14. November 1859 zu Frankfurt a. M.

Ich besuchte 9 Jahre lang die Realschule I. Ordnung meiner Vaterstadt, und verliess dieselbe nach erlangtem Zeugniss der Reife im April 1879.

Mich dem Studium der Naturwissenschaften widmend, lielt ich mich der Reihe nach an folgenden Universitäten auf:

in Strassburg i./E. 3 Semester,

in Berlin 1 Semester,

in Boln 1 Semester, in Strassburg i./E. 3 Semester.

Den Hauptgegenstand meines Studiums bildete die Geologie und ihre verwandten Wissenschaften.

Während meiner vierjährigen Studienzeit waren meine Lehrer die Herren:

De Bary, Benecke, Cohen, Fitwig, Götte, Groth, Rose, Schmidt, Steinmand in Strassburg,

Bexrich, Dames, von Martens, Roth in Berlin, Kekulé, Kuinger, von Lasaulx, Schlüter in Bonn.

Allen diesen meinen hochverelirten Lehrern spreche ich hierdurch meinen besten Dank für die mir von ihnen zu Theil gewordene Belehrung und Anregung aus. 




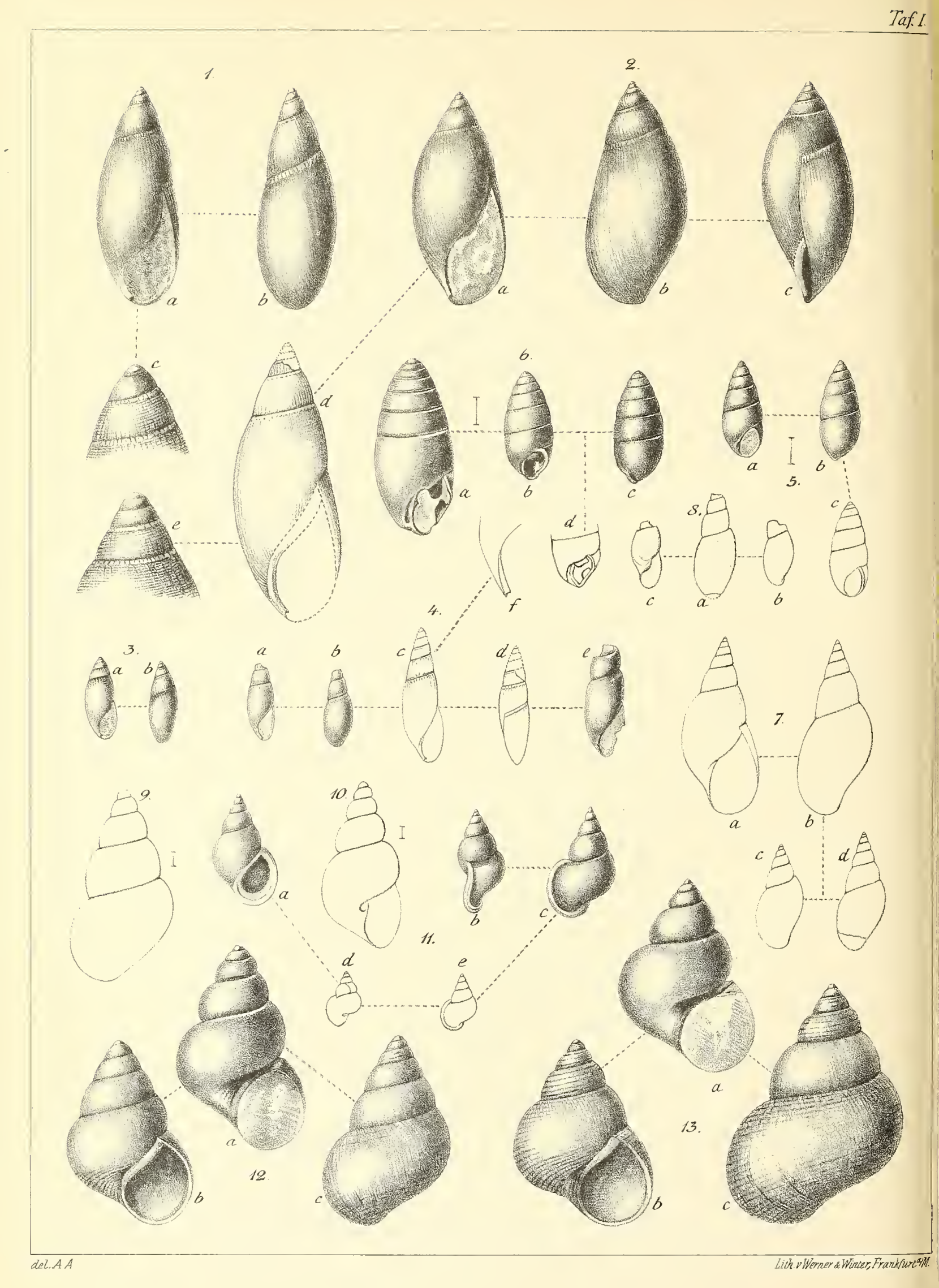




\section{Taf. I.}

1. Glandina rhencuna n. sp.

$a$ u. $b \frac{1}{1}$, nat. gr.; c Embryonalende vergr. Buchsweiler. Mittleres Eocän.

2. Glandina Cordieri DesH. sp.

$a$ von vorn $1 / 1 ; b$ u. $c$ anderes Exemplar von hinten $u$. von der Seite $1 / 1 ; e$ Embryonalende vergr. Buchsweiler. Mt. Eoc.

2d. Glandina Cordieri Desh. sp. var. elongatı n. v.

$1 / 1$ z. Th. ergänzt. Buchsweiler. Mit. Eoc.

3. Glandina Deeckei n. sp.

$a$ u. $b \frac{1}{1}$. Buchsweiler. Mt. Eoc.

4. Boltenia teres Rouss sp.

$a, b, e$ Steinkerne $1 / 1 ; c, d$ Exemplare mit Schale nach dem Abdruck ergänzt 1/1, Spitze noch unbekannt; $f$ Spindel verg. Buchsweiler. Mt. Eoc.

5. Cionella formicina Rouss sp.

$a, b$ Steinkern verg; $c$ Exemplar mit Schale verg. Buchsweiler. Mt. Eoc.

6. Azeca Böttgeri n. sp.

$a, c$ Steinlkerne verg; $b$ Exemplar mit Schale verg.; $d$ Mündung verg. Buchsweiler. Mt. Eoc.

\section{Limnea Michelini DESH.}

$c$, $d$ Steinkerne $1 / 1 ; b$ Exemplar mit Schale z. Th. ergänzt. Buchsweiler. Mt. Eoc.

8. Limnea sp. ined.

$a, b, c$ Steinkerne $1 / 1 ; a$ etwas deformirt. Buchsweiler. Mt. Eoc.

9. Hydrobia sp.

Steinkern vergr. Bischenberg. Mt. Eoc.

10. Hydrobia (?) sp.

Steinkern vergr. Buchsweiler. Mt. Eoc.

11. Euchilus Deschiensiunum DEsH. sp.

$a, b, c$ Exemplare mit Schale vergr.; $e$ desgleichen $1 / 1 ; d$ Steinkern 1/1. Buchsweilcr. Mt. Eoc.

12. Paludina (Vivipara) Orbignyana DesH.

$a$ Steinkern $1 / 1 ; b$ Exemplar mit Schale, Mündung ergänzt; $c$ Exemplar mit Schalc $1 / 1$. Buchsweiler. Mt. Eoc.

13. Paludina (Vivipaso) Hammeri DEFr.

$a$ Steinkern $1 / 1 ; b$ Exemplar mit Schale, Mündung ergänzt; c Exemplar mit Schale nach einem grossen Steinkern ergänzt. Buchsweiler. Mt. Eoc. 




\section{$g^{a}$}

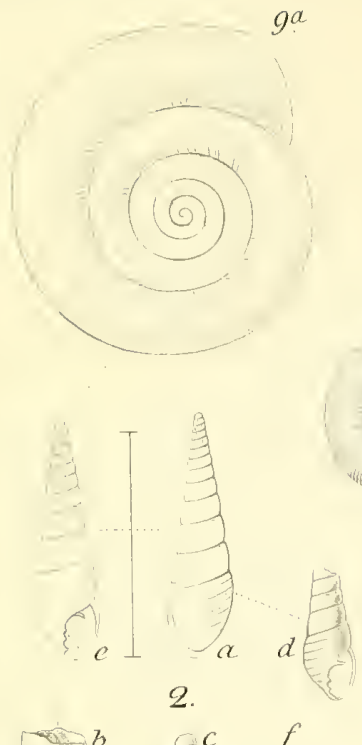

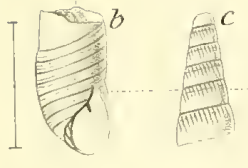
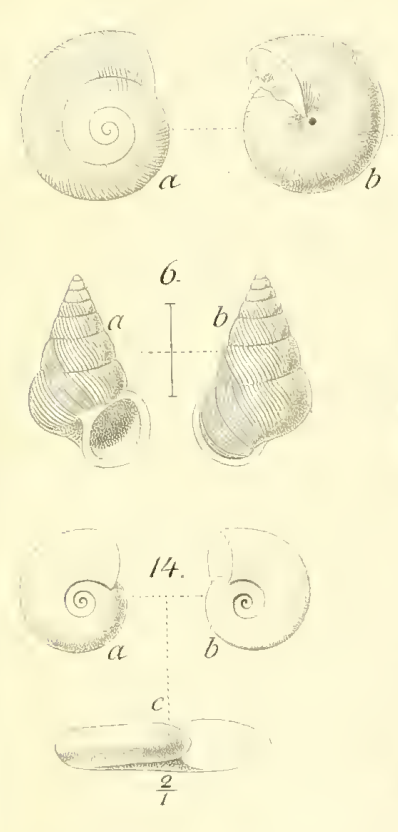

$1-a^{2} a$

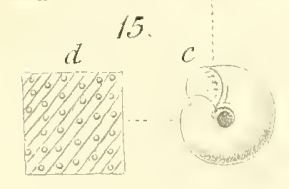

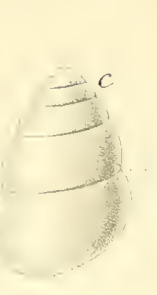
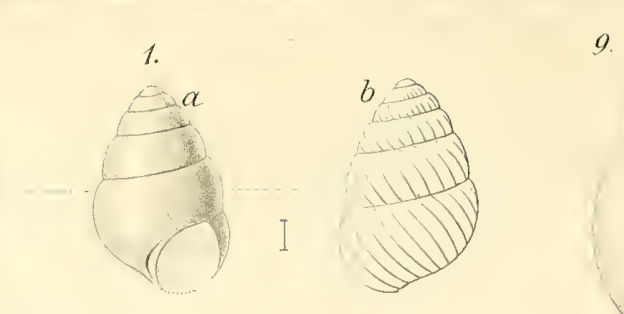

9
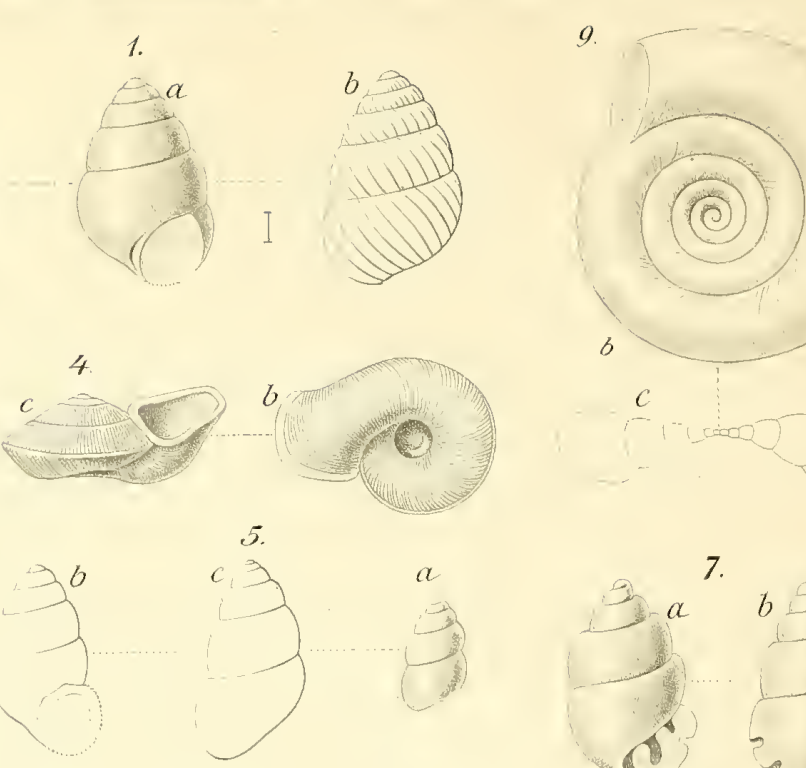

8
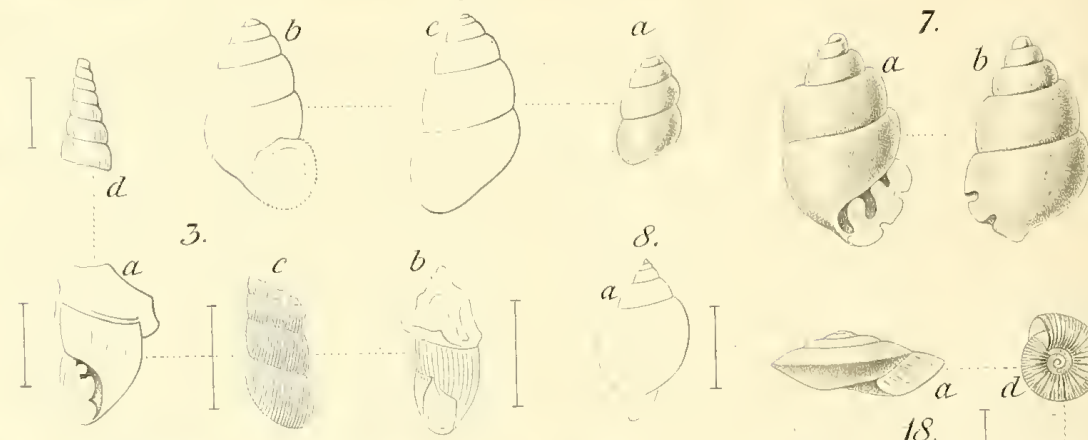

(i)
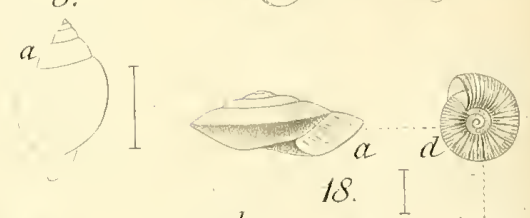

$6+5$

$$
b \begin{array}{cc}
8 \\
b & c
\end{array}
$$

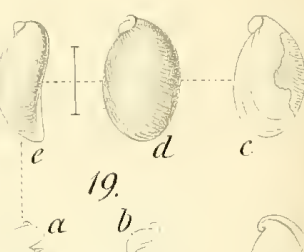

(c)

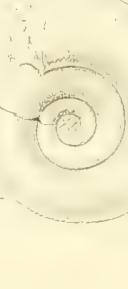

11. $a \quad b$

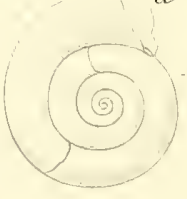

(6)

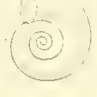

12.
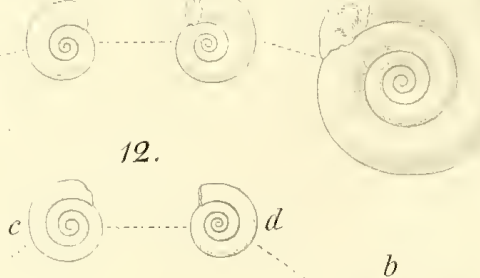
(a) $d$

$a$

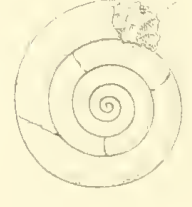

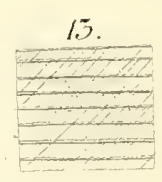

$b$

(อ)

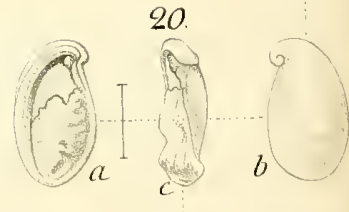

$\left(\frac{a}{a}\right)_{b}^{d}$

17

$e_{-\infty}^{c} d=$ 


\section{Taf. II.}

1. Pupa Buxovillana n. sp.

$a, b$ Steinkern verg.; $c$ Exemplar mit Schale nach dem Abdruck ergänzt verg. Buchsweiler. Mittleres Eocän.

2. Palcueoston Fontenayi Rouss sp.

$a$ Steinkern etwas verg.; $b$ normales Bruchstïck eines Steinkernes etwas verg.; c Spitze, Copie nach Sandberger - Land- u. Siissw. Conch. d. V. - Tf. 13, Fig. 19, als Clausilia crenata Sandbg.; d Exemplar mit Schale $1 / 1 ;$ e Exemplar mit Schale restaurirt u. vergr.; $f$ Spindel vergr. Buchsweiler. Mt. Eoc.

3. Clausilia (Canalicia) densicostulata SANDBG.

$a, b, d$ Steinkernfragmente vergr.; $c$ Fragment mit Schale vergr. (Copie aus Sandbg. L. Sw. C. d. V., Tf. 13, Fig. 20). Buchsweiler. II. Eoc.

4. Strophostoma striatum DESH.

$a, b, c{ }^{1 / 1}$ Die Sculptur ist nach dem am besten erhaltenen Exemplare gezeichnet, dieselbe ist meistens etwas schwächer. Buchsweiler. Mt. Eoc.

5. Megalomastoma turgidum Rours sp.

a Exemplar mit Schale $1 / 1 ; b, c$ Exemplar mit Schale z. Th. ergänzt u. vergr. Buchsweiler. Mt. Eoc.

6. Pomatias Sandbergeri Noul.

$a, b$ Exemplar mit Schale vergr., die Mündung nach dem Abdruck ergänzt. Buchs weiler. Mt. Eoc.

7. Carychiopsis quadridens n. sp.

$a, b$ Steinkern vergr. Buchsweiler. Mit. Eoc.

8. Limmer olivula Rous.

a Steinkern vergr. Buchsweiler. Mt. Eoc.

$8 b, c, d$. Limmen olivula Rous.

1/1 mit Schale ergänzt nach Steinkernen vom Bischenberg. Ut. Els. Mt. Eoc.

9. Planorbis pseudammonius v. SCHLTH. sp. $1 / 1 a$ von oben; $b$ von unten; $c$ Durchschnitt. Buchsweiler. Mt. Eoc.

10. Planorbis pseudammonius v. ScHLтH. sp. forma obtusa n. f. $a, b$ Exemplar mit Schale $1 / 1 ; c, d$ junge Exemplare $1 / 1$.

11. Planorbis pseudammonins v. ScHLтH. sp. typ.

$a, b$ ältere $1 / 1 ; c, d$ junge Exemplare $1 / 1$. Buchsweiler. IIt. Eoc.

12. Planorbis pseudammonius v. Schцтн. sp. var. angigyra $\mathrm{n}$. v. $a, b$ Steinkerne von alten $1 / 1 ; c, d$ von jungen Exemplaren $1 / 1$. Buchsweiler. Mt. Eoc.

13. Planorbis pseudammonius v. SchLth. sp. var. Leymeriei Desh. Sculptur vergrössert. Buchsweiler. Mt. Eoc.

14. Planorbis Chertieri Desh.

a, $b$ Steinkerne $1 / 1 ; c$ desgl. vergr. $2 / 1$ n. gr. Buchsweiler. Mt. Eoc.

15. Helix laxecostulata SANDBG. $a, b, c$ Steinkerne $1 / 1 ; d$ Sculptur vergr. Buchsweiler. Mt. Eoc.

16. Nanina occlusa F. EDw. sp. $a, b, c, d$ Typ. Steinkerne $1 / 1 ;$ e forma conica n. f. $1 / 1$. Buchsweiler. Mt. Eoc.

17. Nanina Voltai DesH. sp. $a, b, c, d$ Exemplare mit Schale $1 / 1$. Buchsweiler. Mt. Eoc.

18. Patula oligogyra n. sp.

b, c Steinkerne $2 / 1$ n. gr.; $d$, e Exemplar mit Schale nach dem Abdruck ergänzt $2 / 1$ n. gr.; a Steinkern von der Seite $4 / 1$ n. gr. Buchsweiler. MIt. Eoc.

19. Succinea palliolum Rovis. $a, b, c$ Steinkerne $1 / 1 ; d$, e Exemplar mit Schale vergr. Buchsweiler. Mt. Eoc.

20. Parmacellina vitrinaeformis SANDBG.

$e, d$ Steinkern vergr.; $a, b, c$ Exemplare mit Schale verg. Buchsweiler. Mt. Eoc. 



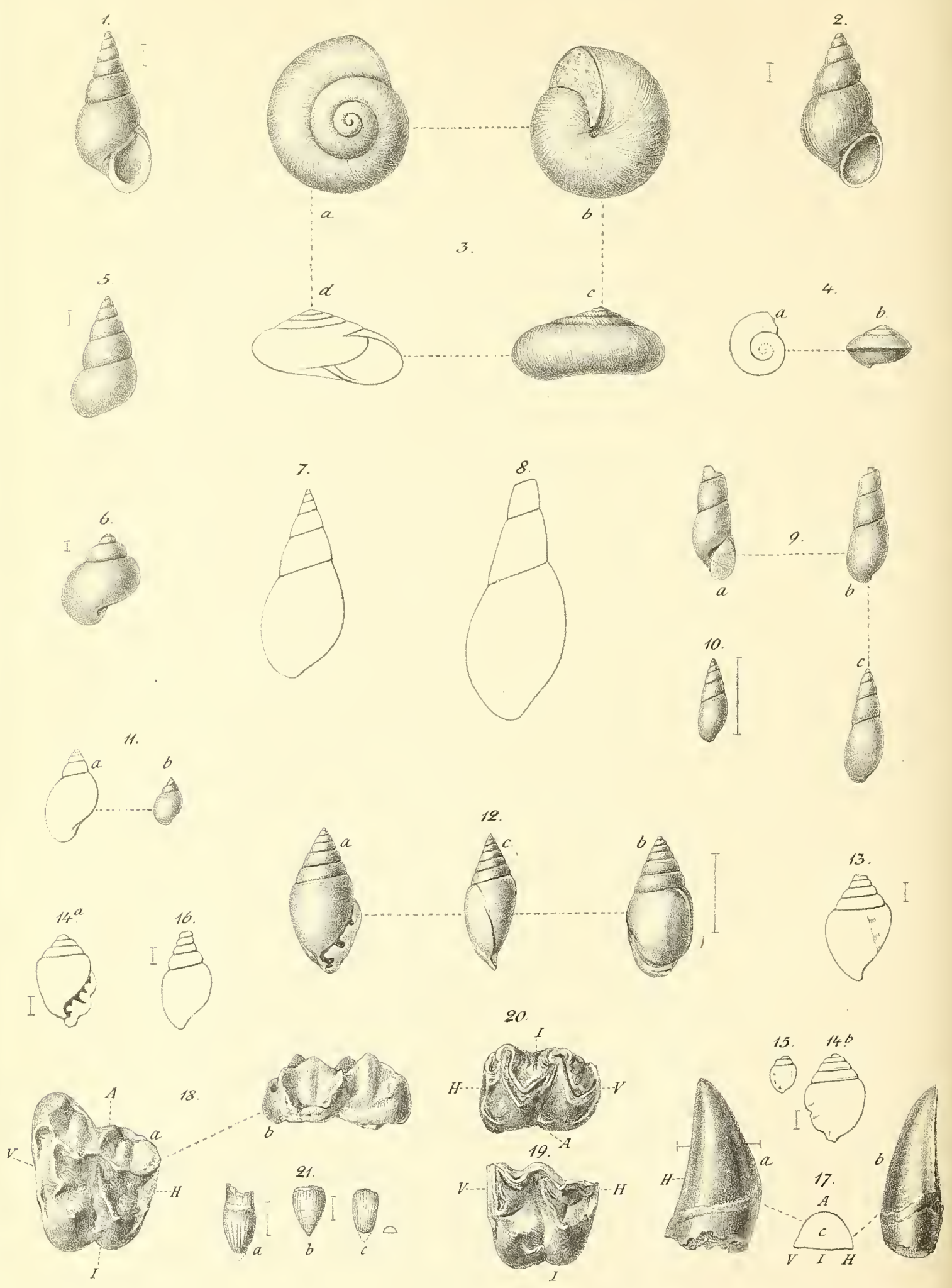
1. Hydrobia cf. Trebsteri MoRR.

3,2 mm. Dauendorf. Mittleres Eocän.

2. Hydrobia Danendorfensis n. sp.

$3 \mathrm{~mm}$. Dauendorf. Mt. Eoc.

3. Nanina Köchlini n. sp.

$1 / 1 a, b, c$ Steinkern nach mehreren Individuen ergänzt; $d$ Reconstruktion. Brunnstatt. Oberes Eocän.

4. Helix sp. ined.

$a, b^{1 / 1}$. Brunnstatt. Ob. Eoc.

5. Hydrobia indifferens SAND.

$2,5 \mathrm{~mm}$. Steinkern. Brunnstatt. Ob. Eoc.

6. Valvata (Amnicola?) circinata Mer. sp.

1,6 mm. Steinkern. Brunnstatt. Ob. Eoc.

7. Limmea marginata SAND.

1/1. Skizze nach Sandberger L. Sw. C. d. V., Taf. XVIII, Fg. 7. Klein-Kembs. Ob. Eoc.

8. Limnea cf. fusiformis Sow.

$1 / 1$ Steinkern. Kötzingen. Ob. Eoc.

9. Limnea subpolita n. sp.

$1 / 1 a, b$ Steinkern; $c$ anderer Steinkern z. Th. nach dem Abdruck ergänzt. Brunnstatt. Ob. Eoc.

10. Limnea polita Mer. ined.

Steinkern etwas ergänzt mit Zuhïlfenahme des Abdruckes. Brunnstatt. Ob. Eoc.

11. Limnea ef. crassula Desh.

$a$ u. $b^{1 / 1}$ Steinkerne. Kötzingen. Ob. Eoc.

12. Auricula (Alexia) alsatica MER.

$a, b, c$ Steinkern vergrössert und nach verschiedenen Exemplaren etwas ergänzt. Brunnstatt. Ob. Eoc.

13-15. Amricula (Alexia) sunalgoviensis n. sp.

13 Steinkern $=3 \mathrm{~mm} \cdot ; 14 a, b$ Steinkern $=2,5 \mathrm{~mm}$; 15 Steinkern ${ }^{1} /{ }_{1} \mathrm{n} . \mathrm{gr}$. Brunn. statt. Ob. Eoc.

16. Auricula sp. juv.

Steinkern $=2,3 \mathrm{~mm}$. Brunnstatt. Ob. Eoc.

17. Canin (sup. sin.) von Palaeotherium medium? Cur.

$1 / 1$ n. g. Rixheim. $a$ von aussen; $b$ von vorn; $c$ Durchschnitt. Ob. Eoc.

18. Letzter Molar. (sup. sin.) von Propalcueotherium Argentonicum Gerv.

$1 / 1$ n. g. von Buchsweiler. $\mathrm{A}=$ aussen; $\mathrm{I}=$ innen; $\mathrm{V}=$ vorn; $\mathrm{H}=$ hinten. 18 von oben gesehen; $18 b$ von aussen gesehen. Mt. Eoc.

19. Zweitletzter Molar. (sup) sin.) von Propalaeotherium Argentonicum Gerv.

$1 / 1$ n. g. mit abgebrochener Aussenwand. Buchsweiler. Mt. Eoc.

20. Zweitletzter Molar. (inf. dex.) von Prop. Argentonicum GErv.

$1 / 1$ n. gr. Buchsweiler. Mt. Eoc.

21. $a-c$ Reptilzähne von Buchsweiler. Mt. Eoc. 






AManohan M M

H

ค.

$$
\text { 12m-1 }
$$

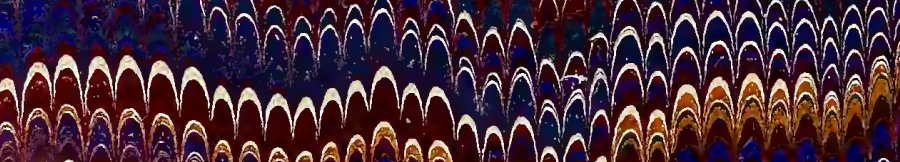

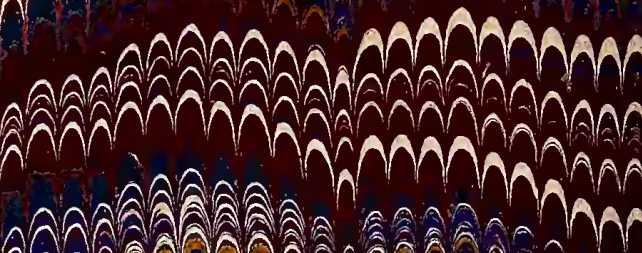
minm

等

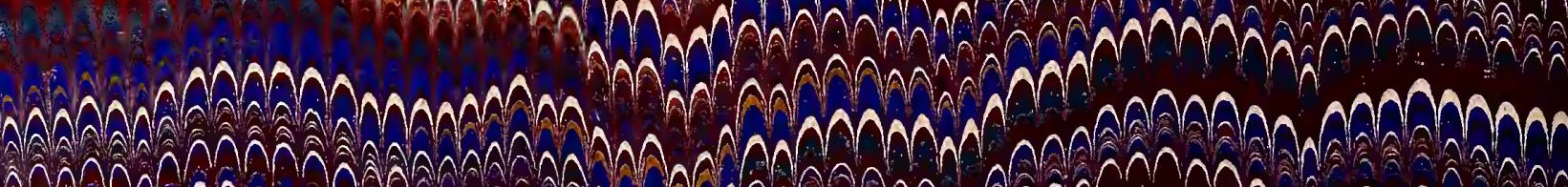

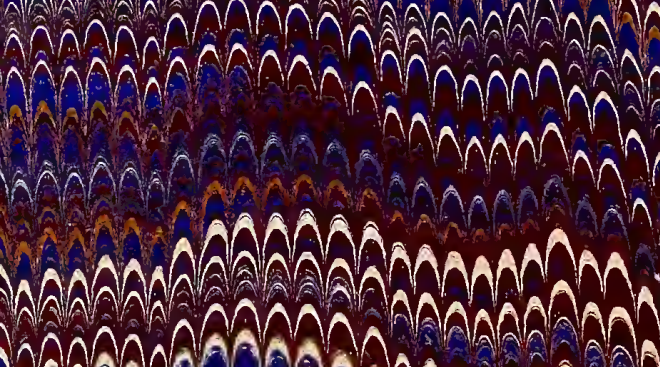

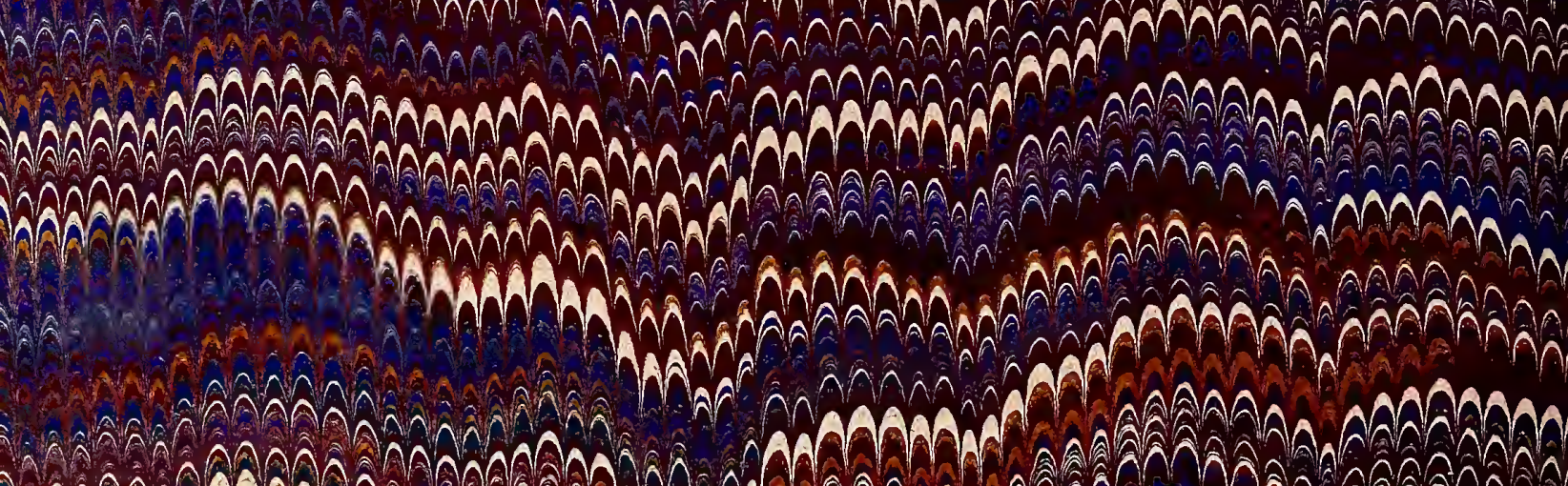
Minmin

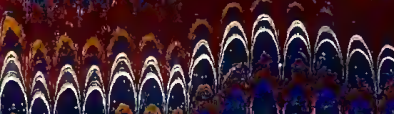

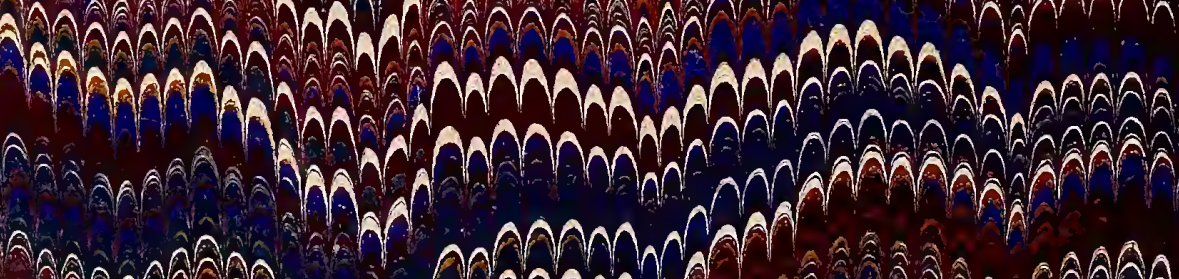


AAA A

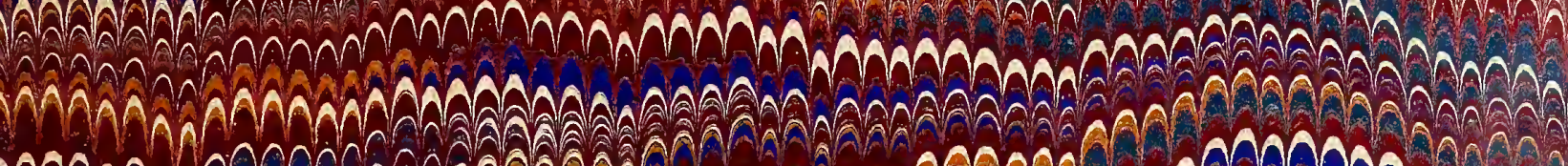

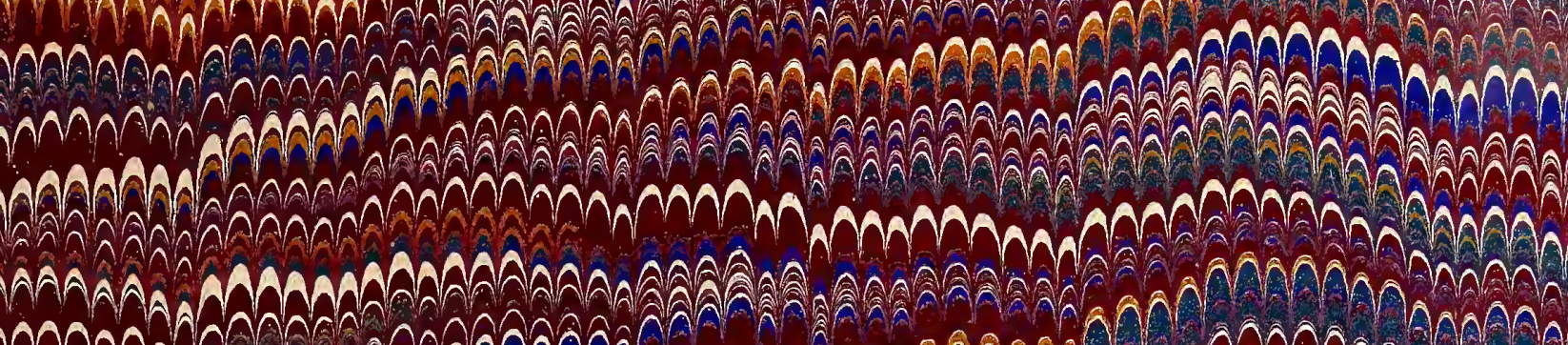
MAAAMA A AM M M

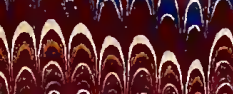
MAn

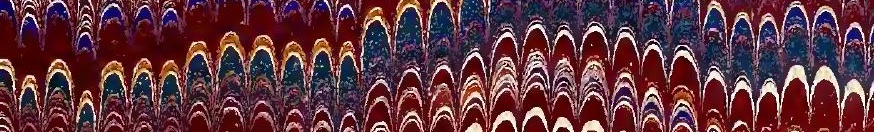

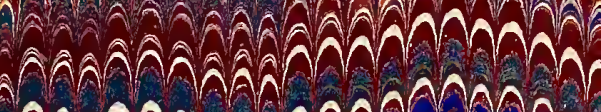
1 mompipmment

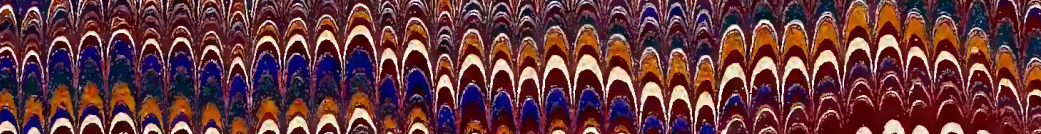

A

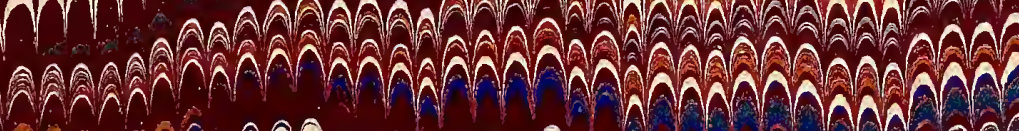

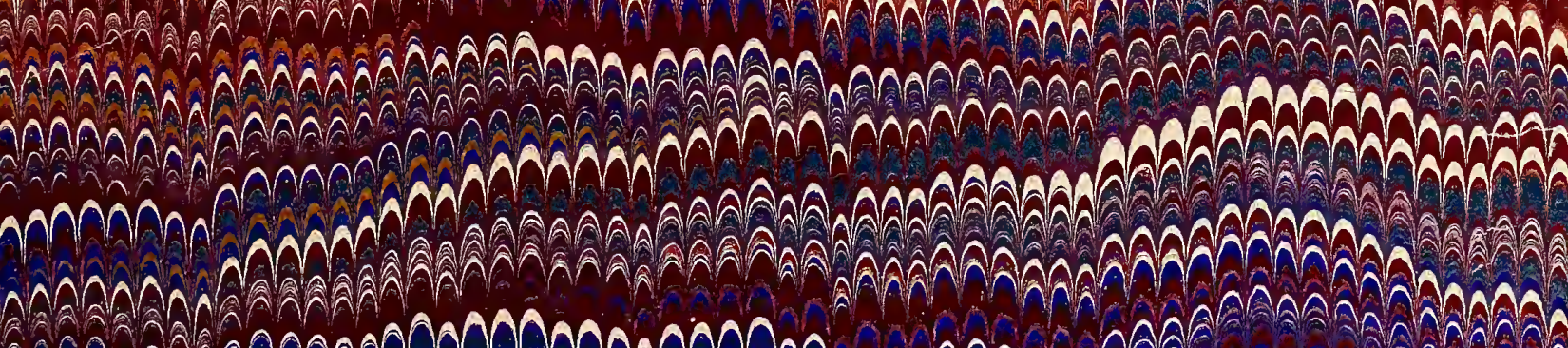
Mana

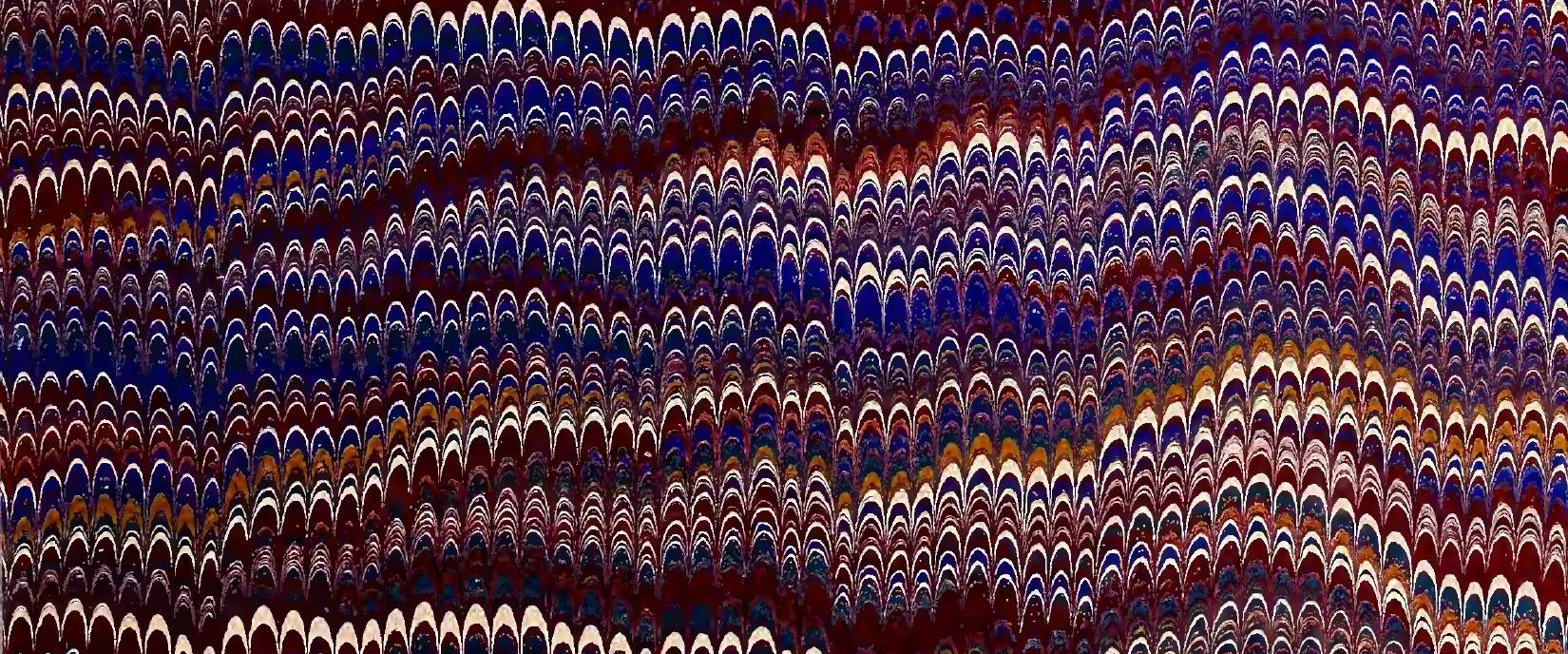

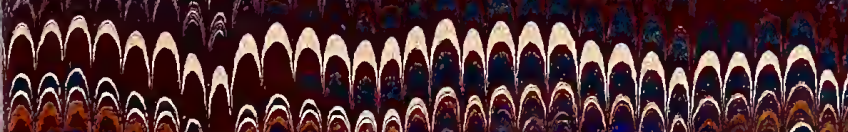
hama 
